UNIVERSIDADE DE BRASÍLIA

INSTITUTO DE CIÊNCIAS BIOLÓGICAS

PROGRAMA DE PÓS-GRADUAÇÃO EM BIOLOGIA ANIMAL

\author{
FLÁVIA MARIA MEDEIROS GOMES
}

Avaliação antiepiléptica do peptídeo Neuropolybina no modelo crônico de

Epilepsia do Lobo Temporal induzido por pilocarpina em camundongos

Brasília 


\title{
AVALIAÇÃO ANTIEPILÉPTICA DO PEPTÍDEO NEUROPOLYBINA NO MODELO CRÔNICO DE EPILEPSIA DO LOBO TEMPORAL INDUZIDO POR PILOCARPINA EM CAMUNDONGOS
}

\author{
Dissertação de Mestrado apresentada ao Programa \\ de Pós-Graduação em Biologia Animal da \\ Universidade de Brasília, como parte dos requisitos \\ para a obtenção do título de Mestre em Biologia \\ Animal.
}

Orientadora: Prof ${ }^{\mathrm{a}}$ Dr $^{\mathrm{a}}$ Márcia Renata Mortari

Brasília 


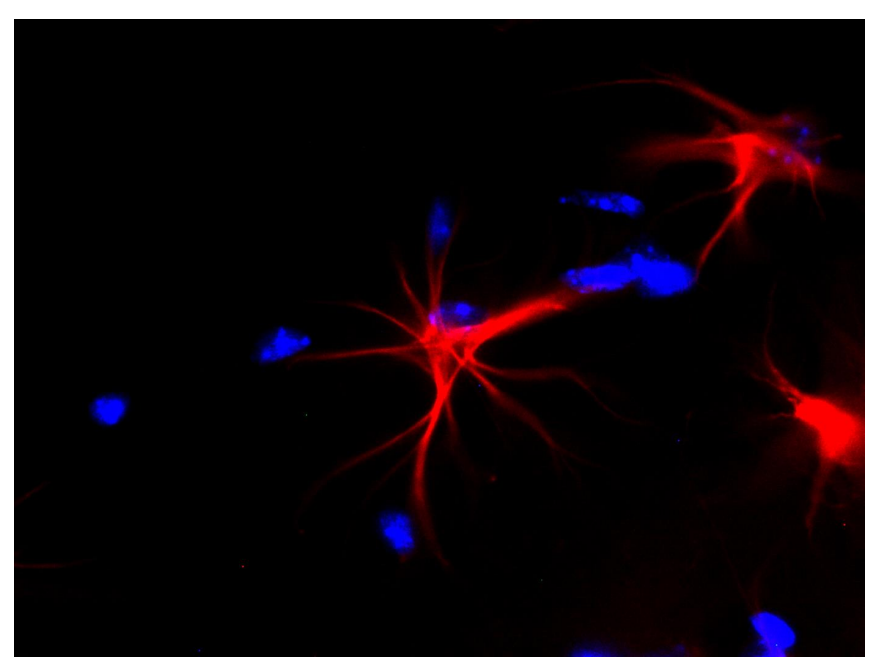

Capa: Marcação imunofluorescente de astrócitos por anti-GFAP (vermelho) na camada CA3 da formação hipocampal de camundongos submetidos ao Status Epilepticus. Núcleos celulares marcados com DAPI (azul). Imagem com aumento de 1000x. 


\section{DEDICATÓRIA}

Aos meus pais, Francisco e Marilene

A todas as pessoas com Epilepsia 


\section{AGRADECIMENTOS}

A Deus, pelo dom da vida. Agradeço por estar sempre me guiando e por colocar pessoas no meu caminho que me inspiram, ajudam e desafiam.

Aos meus pais, Francisco e Marilene, e meus irmãos, Arthur e Fernanda, pelo amor, segurança, motivação e por acreditarem no meu potencial.

Ao meu namorado, Pedro, que mesmo longe, apoiou meus sonhos, vibrou com minhas conquistas e sempre teve muita paciência e compreensão. Obrigada por me fazer tão feliz, por acreditar que eu posso superar tudo e nunca me deixar desistir.

A minha orientadora, Márcia, pelos ensinamentos, enorme paciência, confiança e amizade. Agradeço pelos valiosos momentos de discussão e dedicação em todos esses anos de convivência. Você é a minha fonte de inspiração, meu exemplo de profissional ética, competente e que ama o que faz. Foi uma grande honra poder ser orientada por você e por poder ter contribuído com o crescimento do Neuropharma Lab!

Ao Programa de Pós-Graduação em Biologia Animal, aos professores e a Universidade de Brasília, pela oportunidade e pelos auxílios financeiros para a participação em congressos científicos. Especialmente, agradeço a secretária Sílvia, pela ajuda e disposição.

A Coordenação de Aperfeiçoamento de Pessoal de Nível Superior - CAPES, pela concessão da bolsa de mestrado. A Fundação de Apoio à Pesquisa do Distrito Federal - FAPDF, ao Conselho Nacional de Desenvolvimento Científico e Tecnológico - CNPq e a Fundação de Empreendimentos Científicos e Tecnológicos - Finatec pelo suporte financeiro para a realização desta pesquisa. 
Ao Prof. Dr. Luis Eugênio Araújo de Moraes Mello e a Dr ${ }^{a}$. Alexandra Olímpio Siqueira Cunha pelas correções e sugestões no exame de qualificação deste trabalho.

A minha querida amiga, Ju, pela companhia, caronas e conselhos. Mesmo de tão longe, sempre esteve disposta a conversar e me mandar boas energias.

A todos os amigos do laboratório de Neurofarmacologia, aos que passaram por lá e aos que ainda continuam e compartilharam comigo o dia-a-dia, os sucessos e angústias nos experimentos e as comemorações nos churrascos as sexta-feiras: Gabriel, Henrique, Andreia, Vic, Leandro, Fernanda, Lilian, Pri, Jacq, Rafa, Lu, Carol, Sol, Claudia, Luana, Matheus, Danilo, Sebben, Carlos Schwartz, Beth, Rafael Maior, Washington e Angelita.

Ao Jivago e Adriana pelo cuidado com os animais do biotério.

Ao Adolfo, pelo desenho da estrutura química do peptídeo e pela ajuda com a espectrometria de massas, por conferir meus cálculos de diluições, por sanar minhas inúmeras dúvidas sobre tudo e pelos muitos litros de PBS preparados. Agradeço, especialmente, pelas fugidas para lanchar e pelas conversas tão enriquecedoras.

Ao Prof. Dr. Renato Malcher Lopes pela oportunidade de iniciação na vida acadêmica, permitindo que eu trilhasse meus caminhos na pesquisa de forma independente $e$ crítica.

Aos meus amigos, Flávio, Fred, Maísa, Fabiano, Taís, Nathália, Dariane, Amanda, João, Giuliano, Débora, Flavinha, Jéssica e Carol pelos anos de amizade e pelos momentos de distração aos fins de semana.

Aos camundongos, pelo sacrifício. 
"Percebi há muito tempo que as pessoas realizadas raramente relaxaram e esperaram que as coisas lhe acontecessem. Elas foram à procura e as coisas aconteceram.” Leonardo da Vinci 


\section{PREFÁCIO}

“[...] Quando descobri que tinha Epilepsia, eu tinha 7 anos de idade e estava com tanto medo, vergonha e me senti tão sozinha. Eu pensei que era a única criança com Epilepsia, que era a única com Epilepsia que se sentiu assim. Eu queria que ninguém soubesse que eu tinha Epilepsia e eu não deixei que meus pais ou qualquer um falasse sobre eu ter Epilepsia.

Quando eu tinha oito anos, minha mãe levou a Associação de Epilepsia da Nova Escócia à minha escola para fazerem uma apresentação para a minha classe para ajudá-los a aprender sobre Epilepsia. Eu vi como meus amigos estavam agindo e querendo aprender mais. Quando perguntaram à apresentadora se ela conhecia alguém com Epilepsia, ela disse que sim. Foi então que eu disse à minha mãe e professora que poderíamos dizer-lhes que eu tinha Epilepsia também. Eu estava com medo, mas vi o quão bom todos eles foram.

Então, no ano seguinte, eu estava sentada no sofá com a minha mãe e pergunteilhe porque não havia apenas um dia para a Epilepsia, como há para o câncer ou o dia de St. Patricks, um dia onde as pessoas possam aprender mais sobre a Epilepsia e para que as pessoas que têm Epilepsia saberem que elas não estão sozinhas. [...]Eu queria que todos, no mundo todo, vestissem algo roxo nesse dia. [...] Ela explicou-me que a cor da lavanda representava o sentimento de sentir-se sozinho, para algumas pessoas com Epilepsia em algumas partes do mundo. [...] A razão para ser dia 26 de março é que quando falamos com o diretor da minha escola, ele disse que o melhor dia para ele e a escola receberem a Associação de Epilepsia da Nova Escócia seria 26 de março. Eu queria fazer isso todos os anos, eu queria ter aquele dia, 26 de março como o dia da consciência sobre a Epilepsia. 
[...] Eu vejo o quanto 26 de março cresceu e ainda está crescendo para unir o mundo nesse dia. [...] Eu ouvi histórias de pessoas que dizem que isso os ajudou a falar, se sentirem corajosos e se sentirem parte de algo [...].”

Trechos da carta aos membros da International League Against Epilepsy e da International Bureau of Epilepsy, escrita pela canadense Cassidy Megan, hoje com 15 anos, extraídos e traduzidos da página: www.purpleday.org. Cassidy pede suporte a essas instituições para a criação do Purple Day, um dia em que todo o mundo se veste de roxo e faz ações de conscientização sobre a Epilepsia.
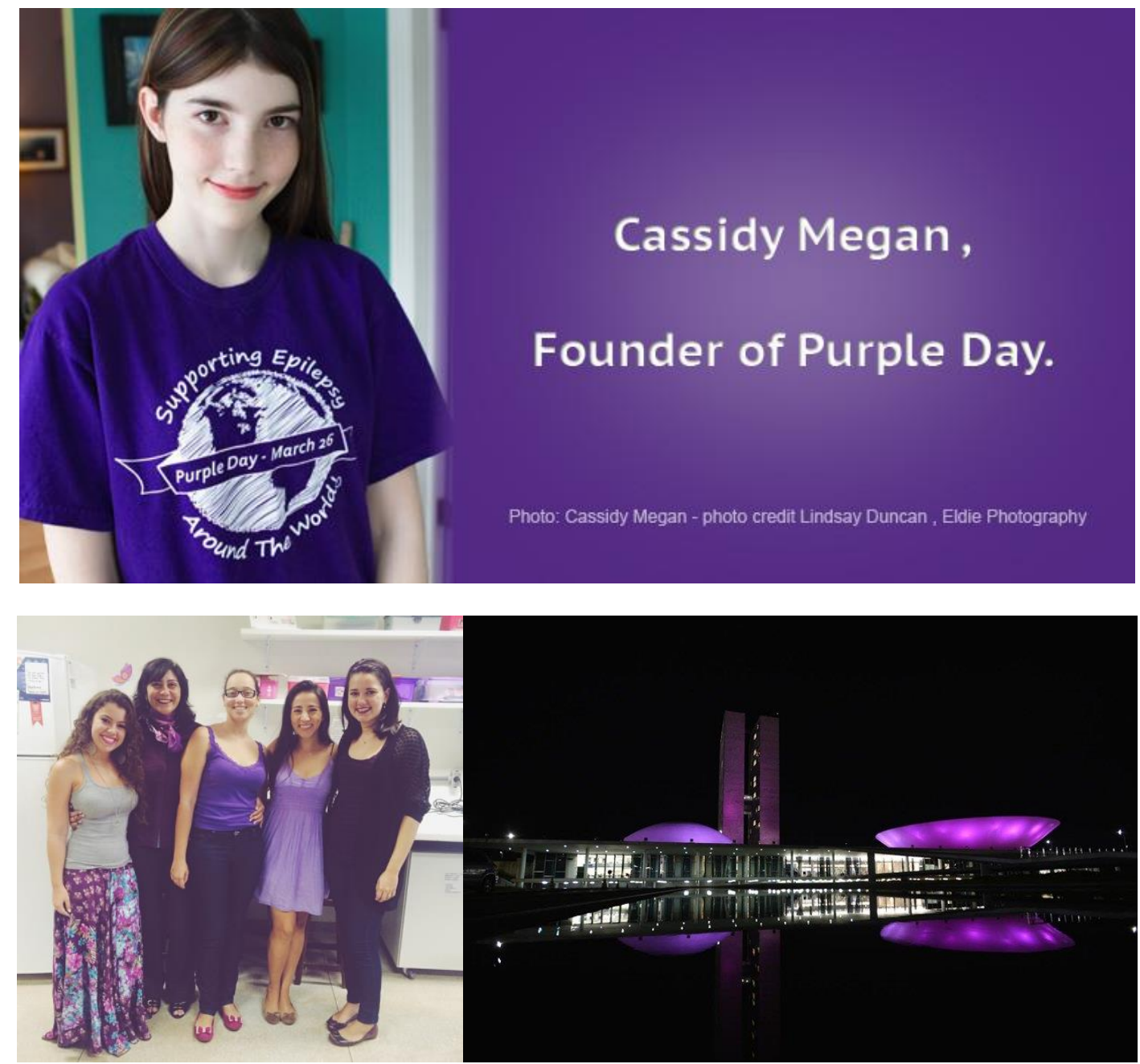

Alguns membros do Neuropharma Lab vestindo roxo no dia 26 de Março e Congresso Nacional em Brasília iluminado de roxo em suporte à causa do Purple Day em 2015. 


\section{LISTA DE FIGURAS}

Figura 1. Esquema resumido da definição prática de Epilepsia formulada pela ILAE em 2014. Modificada de Fisher et al., 2014. - 5 -

Figura 2. Esquema das vias responsáveis pelo fluxo de informação na formação hipocampal. Modificado de Neves et al., 2008. - 8 -

Figura 3. Causas e principais processos celulares envolvidos na epileptogênese da ELT. $-14-$

Figura 4. Fluxograma ilustrando as etapas realizadas em cada período do modelo crônico de ELT induzido nos sujeitos experimentais. - 26 -

Figura 5. Implantação da cânula-guia no ventrículo lateral de um camundongo. (A) Exposição do crânio e marcação do bregma (seta preta). (B) Implantação da cânula e do parafuso e cobertura da região exposta com resina acrílica. - 29-

Figura 6. (A) Cânula-guia de administração dos compostos diretamente no ventrículo lateral direito. (B) Parafuso de aço inoxidável para garantir a durabilidade do capacete de resina acrílica. (C) Fio de aço inoxidável colocado no interior da cânula para obstruíla até o momento de administração dos compostos. - $\mathbf{3 0}$ -

Figura 7. Camundongo recebendo o tratamento com o peptídeo Neuropolybina por via i.c.v. com o auxílio de uma microseringa acoplada a uma bomba de infusão. - 32 -

Figura 8. Etapas da implantação da cânula-guia e dos eletrodos para registro EEGs. (A) Superfície dorsal com os locais para as perfurações de cada eletrodo e a cânula marcados em preto. (B) Eletrodos e cânula implantados. (C) Conector acoplado aos eletrodos e selado com resina acrílica. - 34 -

Figura 9. (A) Eletrodo. (B) Conector de oito pinos em 90 ${ }^{\circ}$ (C) Conector com fios de prata soldados aos pinos para garantir melhor contato com os eletrodos. Esses componentes foram adquiridos da Pinnacle Technologies e utilizados na aquisição dos registros eletroencefalográficos. $\mathbf{- 3 5}$ -

Figura 10. Representação esquemática do posicionamento dos eletrodos, da cânula-guia e do conector para os registros EEGs nos camundongos. (A) Superfície dorsal do crânio de um camundongo com os locais de implante dos eletrodos e da cânula indicados. (B) Padrão de configuração do conector acoplado ao sistema de registros EEGs. (C) Indicação do local de implantação dos eletrodos intrahipocampais nas CA1, modificada do Atlas Estereotáxico de Paxinos \& Franklin (2001). - 36 -

Figura 11. Sistema de registros eletroencefalográficos para camundongos. (A) Software Sirenia $^{\circledR}$ recebendo os dados referentes à atividade elétrica do animal, recebida por quatro canais de aquisição (seta tracejada branca). O círculo verde evidencia a gaiola de Faraday que realiza a blindagem eletromagnética. (B) Camundongo acoplado ao 
conector (seta vermelha) que amplifica e filtra os sinais. (C) Animal sendo filmado com uma câmera digital (triângulo azul) e registrado pelo sistema de aquisição e condicionamento de dados que filtra e amplifica os sinais secundariamente (estrela amarela). - 38 -

Figura 12. Vibrátomo utilizado para a secção dos encéfalos (seta preta) dos animais experimentais. $\mathbf{- 4 1}-$

Figura 13. Prancha que evidencia o ventrículo lateral de camundongos marcado em preto com a cânula posicionada no ventrículo lateral direito, modificada do Atlas Estereotáxico de Paxinos \& Franklin (2001). - 42 -

Figura 14. Secção coronal representativa da formação hipocampal de camundongos, modificado do Atlas Estereotáxico de Paxinos \& Franklin (2001). A região azul correponde à camada de células piramidais de CA1, a região vermelha, de CA3 e a região verde corresponde à camada de células granulares do giro denteado. - 43 -

Figura 15. Microscópio de epifluorescência conectado a uma câmera digital (seta vermelha). As imagens foram produzidas com o auxílio do software LAS (Leica Microsystems, Alemanha). - 46 -

Figura 16. Representação esquemática das imagens obtidas para análise do dano neuronal, modificada do Atlas Estereotáxico de Paxinos \& Franklin (2001). O extrato piramidal de CA1 está delimitado pelos quadrados azuis, CA3 pelos vermelhos e a camada de células granulares do hilus do giro denteado está no quadrado verde. - 47 -

Figura 17. Fluxograma ilustrando toda a metodologia empregada para a realização desse trabalho. $\mathbf{- 5 0}-$

Figura 18. Representação da estrutura linear do peptídeo Neuropolybina, com cada um dos nove aminoácidos que o constitui indicados em azul. - 52 -

Figura 19. Perfil do espectro de massas MALDI-TOF/TOF do peptídeo Neuropolybina para confirmação da massa monoisotópica $[\mathrm{M}+\mathrm{H}]^{+}$, mostrando o alto grau de pureza do composto referente ao pico de m/z 1203,568 Da. - 53 -

Figura 20. Espectro do sequenciamento De Novo do peptídeo Neuropolybina obtido por espectrometria de massas MALDI-TOF/TOF. Em vermelho, os resíduos de aminoácidos após a fragmentação, que constituem a séries b e y-íons. - 54 -

Figura 21. Secção do tecido encefálico submetida à coloração de Nissl, demonstrando o correto posicionamento da cânula-guia de administração do veículo e do peptídeo em estudo no ventrículo lateral direito. Somente os sujeitos experimentais com a cânula posicionada corretamente foram considerados nas análises. - 55 -

Figura 22. Camundongo apresentando hipertonia intensa da cauda, um dos sinais de progressão para o Status Epilepticus após a administração sistêmica de pilocarpina. - 56 
Figura 23. Duração das CRE em cada fase ao longo dos cinco dias de tratamento, em segundos, nos grupos controles e experimentais $(n=4-8)$ após a administração independente de duas concentrações de Neuropolybina. A fase "pós" se refere às primeiras cinco horas logo após a administração do peptídeo e a fase "tardia", às cinco horas restantes de observação. Os dados passaram pelo teste de normalidade Kolmogorov-Smirnov e foram submetidos à ANOVA de uma via, seguido do pós-teste Tukey, sendo considerado p<0,05. (A) Dia 1 de tratamento subcrônico; (B) Dia 2; (C) Dia 3; (D) Dia 4 e (E) Dia 5. *: comparado ao controle sadio (pós), \#: comparado ao grupo doente (pós), ${ }^{\circ}$ : comparado aos tratados com 0,5 nmol de Neuropolybina (pós), @: comparado aos tratados com 2,5 nmol de Neuropolybina (pós), \%: comparado ao grupo sadio (tardia), §: comparado ao grupo doente (tardia), ?: comparado ao grupo Neuropolybina $0,5 \mathrm{nmol}$ (tardia), $£$ : comparado ao grupo Neuropolybina 2,5 $\mathrm{nmol}$ (tardia). - 58-

Figura 24. Número total de CRE em cada fase ao longo dos cinco dias de tratamento, nos grupos controles e experimentais $(n=4-8)$ após a administração independente de duas concentrações de Neuropolybina. A fase "pós" se refere às primeiras cinco horas logo após a administração do peptídeo e a fase "tardia", às cinco horas restantes de observação. Os testes estatísticos utilizados foram o teste de Kruskal-Wallis e o pósteste de Dunn, sendo considerado p<0,05. (A) Dia 1 de tratamento subcrônico; (B) Dia 2; (C) Dia 3; (D) Dia 4 e (E) Dia 5. *: comparado ao controle sadio (pós), \%: comparado ao grupo sadio (tardia), §: comparado ao grupo doente (tardia). - 60 -

Figura 25. Classe máxima das CRE em cada fase ao longo dos cinco dias de tratamento, nos grupos controles e experimentais $(n=4-8)$ após a administração independente de duas concentrações de Neuropolybina. A fase "pós" se refere às primeiras cinco horas logo após a administração do peptídeo e a fase "tardia", às cinco horas restantes de observação. Os testes estatísticos utilizados foram o teste de KruskalWallis e o pós-teste de Dunn, sendo considerado p<0,05. (A) Dia 1 de tratamento subcrônico; (B) Dia 2; (C) Dia 3; (D) Dia 4 e (E) Dia 5. *: comparado ao controle sadio (pós), \%: comparado ao grupo sadio (tardia). - 62

Figura 26. Latência para estabelecimento das crises eletroencefalográficas generalizadas nos cinco dias de tratamento, nos grupos controles e experimentais $(n=2)$ após a administração i.c.v. de Neuropolybina, na concentração de 3,75 nmol. Os testes estatísticos utilizados foram o teste de Kruskal-Wallis e o pós-teste de Dunn, sendo considerado $\mathrm{p}<0,05$. *: comparado ao controle sadio, \#: comparado ao grupo controle doente. $-63-$

Figura 27. Latência para estabelecimento das crises eletroencefalográficas focais nos cinco dias de tratamento, nos grupos controles e experimentais $(n=2)$ após a administração i.c.v. de Neuropolybina, na concentração de 3,75 nmol. Os testes estatísticos utilizados foram o teste de Kruskal-Wallis e o pós-teste de Dunn, sendo considerado $\mathrm{p}<0,05$. *: comparado ao controle sadio, \#: comparado ao grupo controle doente. $-64-$ 
Figura 28. Representação ilustrativa do perfil eletroencefalográfico de um animal sadio sem detecção de descargas epileptiformes sincronizadas. A montagem referencial dos eletrodos intrahipocampais bilaterais (EEG 1 e 2) e bipolar dos eletrodos corticais (EEG 3 e 4) gera as derivações observadas separadamente em cada um dos quatro canais de aquisição. $-65-$

Figura 29. Representação ilustrativa do perfil eletroencefalográfico ictal de um animal doente com presença de paroxismos epileptiformes caracterizados pela presença de espículas agudizadas, hipersincronizadas e de amplitude elevada nos quatro canais de registro, correspondendo a uma crise generalizada. A montagem referencial dos eletrodos intrahipocampais bilaterais (EEG 1 e 2) e bipolar dos eletrodos corticais (EEG 3 e 4) gera as derivações observadas separadamente em cada um dos quatro canais de aquisição. - 66 -

Figura 30. Representação ilustrativa do perfil eletroencefalográfico de um animal tratado com a presença de espículas de alta frequência no canal 2 (formação hipocampal do hemisfério direito) correspondendo a uma crise focal. A montagem referencial dos eletrodos intrahipocampais bilaterais (EEG 1 e 2) e bipolar dos eletrodos corticais (EEG 3 e 4) gera as derivações observadas separadamente em cada um dos quatro canais de aquisição. - 67 -

Figura 31. Diferença de densidade óptica entre as três regiões de interesse dos dois hemisférios da formação hipocampal $(\mathrm{n}=5-10)$. Os dados passaram pelo teste de normalidade Kolmogorov-Smirnov e foram submetidos à ANOVA de uma via, seguido do pós-teste Tukey, sendo considerado p $<0,05$. (A) Camada de células piramidais de CA1. (B) Camada de células piramidais de CA3. (C) Camada de células granulares do Hilus do Giro Denteado. *: comparado ao controle sadio (lado direito), \#: comparado ao grupo doente (lado direito), ${ }^{\circ}$ : comparado aos tratados com $0,5 \mathrm{nmol}$ de Neuropolybina (lado direito), \%: comparado ao grupo sadio (lado esquerdo), ?: comparado ao grupo Neuropolybina 0,5 nmol (lado esquerdo), ns: diferença não-significativa. - 69 -

Figura 32. Imagens representativas de secções coronais da camada CA1 da formação hipocampal de camundongos dos grupos experimentais (aumento de 200x) submetidas à técnica de coloração de Nissl. (A) Sadio. (B) Doente. (C) Tratado com 0,5 nmol de Neuropolybina. (D) Tratado com 2,5 nmol de Neuropolybina. - 70 -

Figura 33. Imagens representativas de secções coronais da camada CA3 da formação hipocampal de camundongos dos grupos experimentais (aumento de 200x) submetidas à técnica de coloração de Nissl. (A) Sadio. (B) Doente. (C) Tratado com 0,5 nmol de Neuropolybina. (D) Tratado com 2,5 nmol de Neuropolybina. - 70 -

Figura 34. Imagens representativas de secções coronais da camada de células granulares do Hilus do Giro Denteado da formação hipocampal de camundongos dos grupos experimentais (aumento de 400x) submetidas à técnica de coloração de Nissl. (A) Sadio. (B) Doente. (C) Tratado com 0,5 nmol de Neuropolybina. (D) Tratado com 2,5 nmol de Neuropolybina. - 71 - 
Figura 35. Número de astrócitos imunorreativos à proteína GFAP contabilizados nas três regiões de interesse dos dois hemisférios da formação hipocampal (n=5-10). Os dados passaram pelo teste de normalidade Kolmogorov-Smirnov e foram submetidos à ANOVA de uma via, seguido do pós-teste Tukey, sendo considerado $\mathrm{p}<0,05$. (A) Camada CA1. (B) Camada CA3. (C) Hilus do Giro Denteado. *: comparado ao controle sadio (lado direito), \#: comparado ao grupo doente (direito), \&: comparado ao grupo tratado com DZP (direito), ${ }^{\circ}$ : comparado aos tratados com 0,5 nmol de Neuropolybina (direito), \%: comparado ao grupo sadio (lado esquerdo), §: comparado ao grupo doente (esquerdo), !: comparado ao grupo tratado com DZP (esquerdo), ?: comparado ao grupo Neuropolybina 0,5 nmol (esquerdo).- 73 -

Figura 36. Imagens representativas de secções coronais da camada CA1 da formação hipocampal de camundongos dos grupos experimentais (aumento de 200x) submetidas à técnica de imunohistoquímica/imunofluorescência. Os núcleos celulares foram marcados com DAPI (azul) e os astrócitos com anti-GFAP (vermelho). - 74 -

Figura 37. Imagens representativas de secções coronais da camada CA3 da formação hipocampal de camundongos dos grupos experimentais (aumento de 200x) submetidas à técnica de imunohistoquímica/imunofluorescência. Os núcleos celulares foram marcados com DAPI (azul) e os astrócitos com anti-GFAP (vermelho). - 75 -

Figura 38. Imagens representativas de secções coronais da camada de células granulares do Hilus do Giro Denteado da formação hipocampal de camundongos dos grupos experimentais (aumento de 400x) submetidas à técnica de imunohistoquímica/imunofluorescência. Os núcleos celulares foram marcados com DAPI (azul) e os astrócitos com anti-GFAP (vermelho). - 76 - 


\section{LISTA DE TABELAS}

Tabela 1. Principais fármacos promissores para o tratamento de pacientes com ELT, modelo animal em que foram testados, seus efeitos adversos e mecanismo de ação. $\mathbf{- 1 7}$

Tabela 2. Classificação das crises límbicas induzidas por pilocarpina baseada no índice de Racine (1972), modificado por Shibley e Smith (2002). - 27 -

Tabela 3. Medidas de referência para o implante dos eletrodos corticais e intrahipocampais em camundongos segundo o Atlas Estereotáxico de Paxinos \& Franklin (2001). - 36 -

Tabela 4. Relação entre os eletrodos, os pinos conectores e os canais de registro do sistema de eletroencefalografia em camundongos. - 39- 


\section{LISTA DE ABREVIAÇÕES}

$\left[{ }^{3} \mathrm{H}\right]-\mathrm{GABA}$

$\left[{ }^{3} \mathrm{H}\right]-\mathrm{L}-$ Glutamato

AMPA

ANOVA

AVE

BSA

BRV

CA1-4

CE

CEUA

CLAE

CRE

DAPI

DO

DZP

EEG

$\mathrm{EH}$

ELT

ESL

GABA

$\mathrm{GABA}_{\mathrm{A}}$

GD

GFAP

HGD

HYP

IBE
GABA triciado

Glutamato triciado

Ácido amino 3-hidroxi-5-metil-isoxazol-4-propriônico

Análise de variância

Acidente vascular encefálico

Albumina de soro bovina

Brivaracetam

Áreas 1 a 4 do Corno de Ammon

Córtex entorrinal

Comissão de Ética no Uso Animal do IB/UnB

Cromatografia líquida de alta eficiência

Crises recorrentes e espontâneas

4,6-diamidino-2-fenilindole (Marcador de núcleo celular)

Densidade óptica

Diazepam

Eletroencefalografia

Esclerose Hipocampal

Epilepsia do Lobo Temporal

Acetato de Eslicarbazepina

Ácido $\gamma$-aminobutírico

Receptor de GABA do tipo A

Giro denteado

Proteína glial fibrilar ácida

Hilus do Giro denteado

Hypersyncronous Onset Pattern

International Bureau of Epilepsy 
I.C.V.

ILAE

I.P.

IHQ/IF

LCM

$L V F$

MALDI-TOF/TOF

PBS

PBST

PCE

PER

PILO

Ppnp7

PTZ

RTG

S.C.

SE

SNC

SV2A

VL

WHO
Administração intracerebroventricular

International League Against Epilepsy

Administração intraperitoneal

Imunohistoquímica/Imunofluorescência

Lacosamida

Low-Voltage Fast Onset Pattern

Matrix Assisted Laser Desorption Ionization - Time Of Flight/Time Of Flight

Solução tampão fosfato de sódio

Solução tampão fosfato de sódio com Triton ${ }^{\circledR}$ X-100

Pessoas com Epilepsia

Perampanel

Pilocarpina

Neuropeptídeo 7 da Polybia paulista

Pentilenotetrazol

Retigabina

Administração subcutânea

Status Epilepticus

Sistema nervoso central

Proteína vesicular sináptica $2 \mathrm{~A}$

Ventrículo lateral

World Health Organization 


\section{RESUMO}

Gomes, FMMG. Avaliação antiepiléptica do peptídeo Neuropolybina no modelo crônico de Epilepsia do Lobo Temporal induzido por pilocarpina em camundongos. Dissertação de mestrado - Programa de Pós-Graduação em Biologia Animal, Instituto de Ciências Biológicas, Universidade de Brasília, 2016.

A Epilepsia do Lobo Temporal (ELT) é o subtipo mais prevalente de Epilepsia em adultos e sua relevância clínica deve-se à sua gravidade e alta porcentagem de pacientes resistentes aos fármacos antiepilépticos disponíveis atualmente. Há, portanto, uma necessidade pela busca de novas terapias farmacológicas capazes de controlar essa condição patológica de forma eficiente, assim como de compreender melhor as alterações causadas pelo funcionamento anormal das estruturas neuronais durante a Epilepsia. Nesse aspecto, os artrópodes peçonhentos representam uma fonte alternativa de compostos neuroativos selecionados pela evolução dessas espécies. A potencialidade farmacológica dessas moléculas reforça o interesse em compreender sua ação no sistema nervoso central, foco desse trabalho. O Laboratório de Neurofarmacologia isolou o peptídeo Neuropolybina a partir da peçonha da vespa Polybia paulista, e ele apresentou uma interessante atividade antiepiléptica em modelos agudos de crises epilépticas. Além disso, não apresentou efeitos adversos na exploração espontânea e na coordenação motora dos animais testados. Portanto, o objetivo foi avaliar a efetividade antiepiléptica da Neuropolybina em camundongos submetidos ao modelo crônico de Status Epilepticus (SE) induzido por pilocarpina. Esse modelo é amplamente utilizado na literatura e apresenta similaridades com achados histopatológicos e comportamentais observados em pacientes epilépticos em apenas algumas semanas, enquanto as mesmas alterações levam anos para se manifestar nos pacientes. A Comissão de Ética no Uso Animal (CEUA/UnB) aprovou todos os experimentos. Camundongos Swiss receberam a administração i.p. de pilocarpina e após 10 minutos, manifestaram sinais do SE, que durou três horas (período agudo do modelo). No período de 15 dias após o SE (período latente), foi realizado um procedimento estereotáxico para implantar uma cânula-guia no ventrículo lateral e oito eletrodos profundos e corticais. Após os 15 dias, durante o período das crises recorrentes e espontâneas (CRE), os camundongos foram tratados por cinco dias consecutivos com administração i.c.v. de veículo, Neuropolybina $(0,5$ e 2,5 nmol) e Diazepam (4 mg. $\left.\mathrm{kg}^{-1}\right)$. Durante esse período, o comportamento, as CRE e a atividade epileptiforme foram monitoradas por filmagem e eletroencefalografia. Após o período de tratamento, os camundongos foram eutanasiados $\mathrm{e}$ as alterações morfológicas foram avaliadas por técnicas histológicas (Coloração de Nissl para neurônios) e Imunohistoquímica/imunofluorescência (GFAP para astrócitos e DAPI para núcleos celulares). Foi observada uma redução da duração das CRE após o tratamento com Neuropolybina. O número de neurônios viáveis nas regiões CA1 e CA3 da formação hipocampal dos tratados foi significativamente diferente dos doentes, e a presença de astrócitos não foi diferente quando comparada aos sadios, sugerindo que o peptídeo evitou a perda neuronal induzida pelo SE. O peptídeo produziu um efeito antiepiléptico e possui um potencial terapêutico no modelo de ELT. Ademais, ele pode ser usado como uma ferramenta na pesquisa em neurociência e no desenvolvimento de novos fármacos para o tratamento da Epilepsia.

Palavras-chave: Epilepsia do Lobo Temporal, peptídeo antiepiléptico, Neuropolybina, pilocarpina, eletroencefalografia, imunohistoquímica. 


\begin{abstract}
Gomes, FMMG. Antiepileptic evaluation of the peptide Neuropolybin in the chronic model of Temporal Lobe Epilepsy induced by pilocarpine in mice. Master dissertation - Programa de Pós-Graduação em Biologia Animal, Instituto de Ciências Biológicas, Universidade de Brasília, 2016.
\end{abstract}

Temporal Lobe Epilepsy (TLE) is the most prevalent subtype of Epilepsy in adults and its clinical relevance is due to the gravity and the high percentage of patients resistant to antiepileptic drugs currently available. Thus, there is a need to seek new pharmacological therapies able to efficiently control this disease, as well as a better understanding of the changes caused by the abnormal functioning of neuronal structures during Epilepsy. In this aspect, venomous arthropods represent an alternative source of evolutionary selected neuroactive compounds. The pharmacological potentiality of these molecules reinforce the interest on its action on the central nervous system, focused by this work. The Neuropharmacology Laboratory previous isolated Neuropolybin from the Polybia paulista wasp venom and this peptide has demonstrated an interesting antiepileptic activity on acute models of seizures. Furthermore, Neuropolybin has not presented side effects on spontaneous exploration and motor coordination of the animals tested. Therefore, the aim was to evaluate the antiepileptic effectiveness of the peptide Neuropolybin in mice submitted to a chronic model of status epilepticus (SE) induced by pilocarpine. This model has been used frequently and presents similarities with histopathological and behavioral findings in epileptic patients in just a few weeks, while the same changes take years to manifest in patients. The Ethical Committee on Use of Animals (CEUA/UnB) approved all procedures. Swiss mice received an i.p. injection of pilocarpine and after 10 minutes, they manifested signs of SE for three hours (acute period of the model). Fifteen days after SE (latent period), a stereotaxic procedure was perfomed to implant a guide cannula in the lateral ventricle and eight deep and cortical electrodes. After 15 days, already during the spontaneous recurrent seizures (SRS), treatment was carried out during five consecutive days by i.c.v. injections with vehicle solution, Neuropolybin (0.5 and $2.5 \mathrm{nmol})$ or Diazepam (4 mg. $\left.\mathrm{kg}^{-1}\right)$. During this period, behavioral, SRS and epileptiform activity were monitored by video recording and electroencephalography. After the period of treatment, the animals were euthanized and morphological changes were evaluated by histological (Nissl stain for neurons) and immunohistochemistry and immunofluorescence (GFAP stain for astrocytes and DAPI stain for cells nuclei) techniques. There was a reduction in SRS duration with Neuropolybin treatment. The number of viable neurons in CA1 and CA 3 regions of the hippocampus formation of treated mice was significantly different from that of epileptic mice after the treatment. The presence of astrocytes did not increase when compared to healthy animals, suggesting that the peptide minimized neuronal loss induced by SE. Neuropolybin thus exerts a promising antiepileptic effect and provides a therapeutic potential on this model of TLE. Nevertheless, the peptide may also be used as a tool in neuroscience research and as a framework in the design of novel drug agents for epilepsy treatment.

Keywords: Temporal Lobe Epilepsy, antiepileptic peptide, Neuropolybin, pilocarpine, electroencephalography, immunohistochemistry. 


\section{SUMÁRIO}

1 INTRODUÇÃ 0 ..............................................................................................................

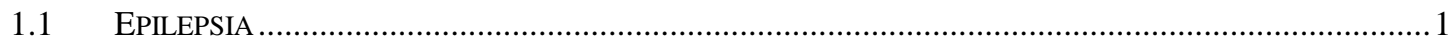

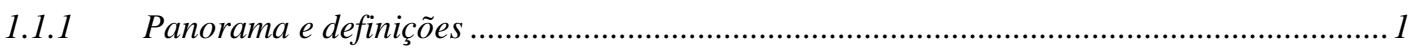

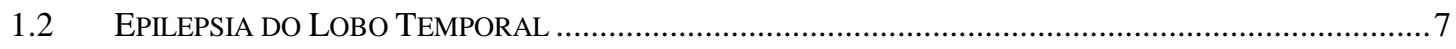

1.3 O MODELO ANIMAL DE ELT INDUZIDO POR PILOCARPINA …………...................................... 10

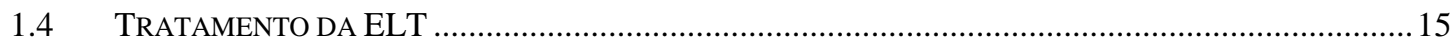

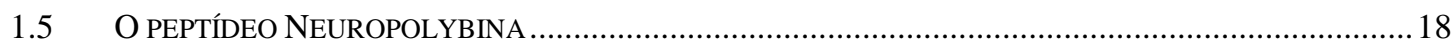

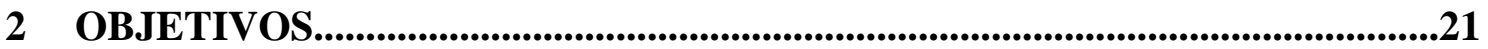

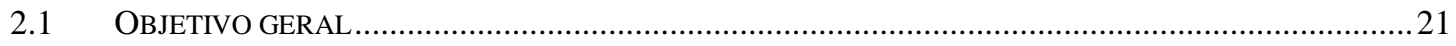

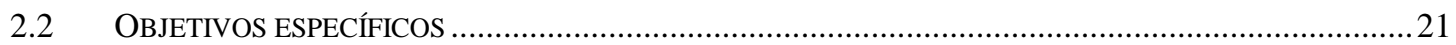

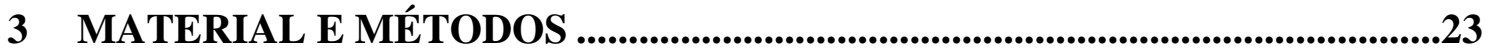

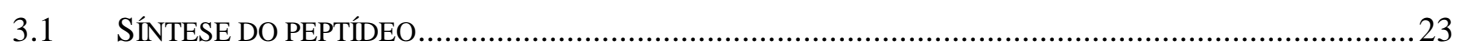

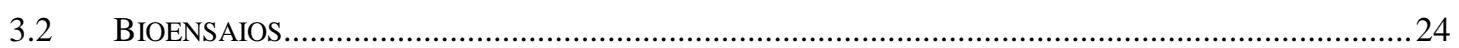

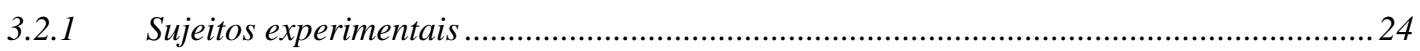

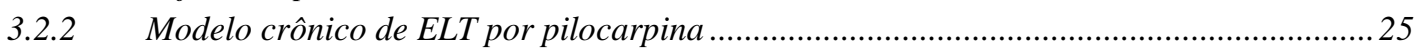

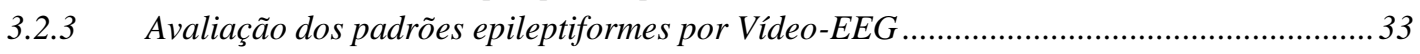

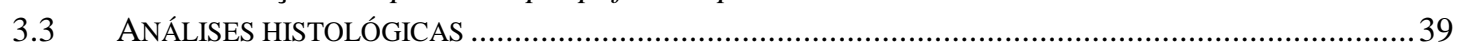

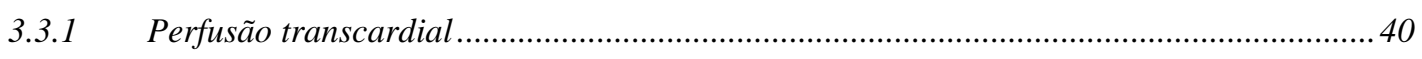

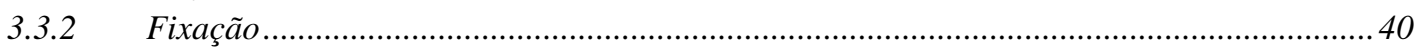

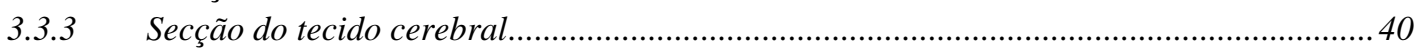

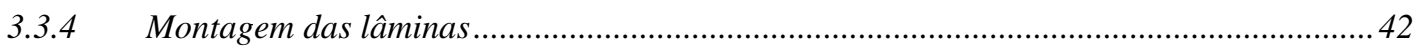

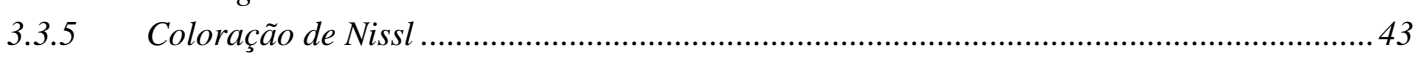

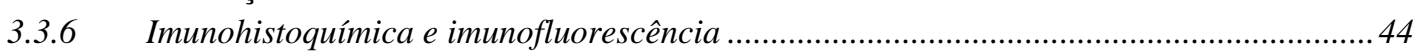

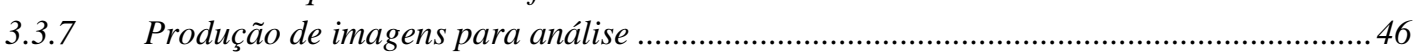

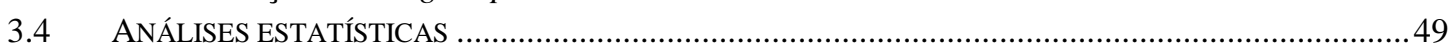

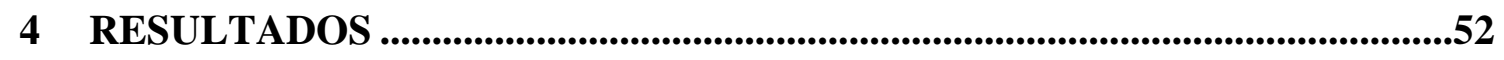

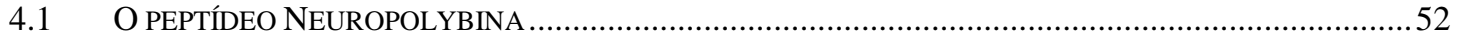

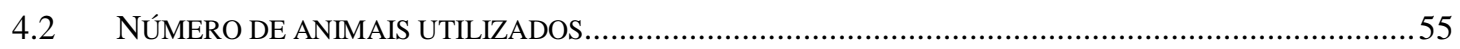

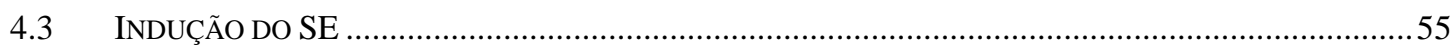

4.4 AVALIAÇão DA ATIVIDADE ANTIEPILÉPTICA DO PEPTÍDEO ……………………......................57

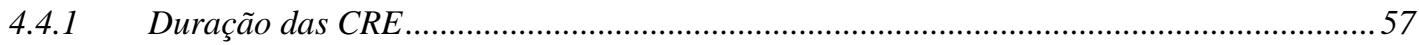

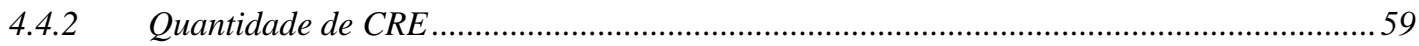

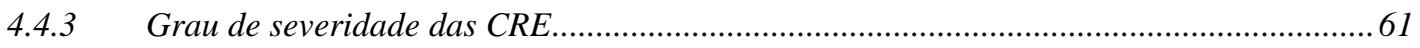

4.5 AVALIAÇÃO DOS PADRÕES EPILEPTIFORMES POR VÍDEO-EEG ………........................................6

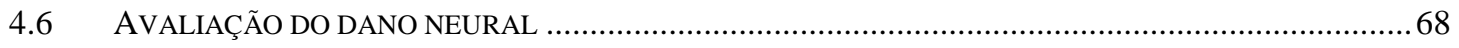

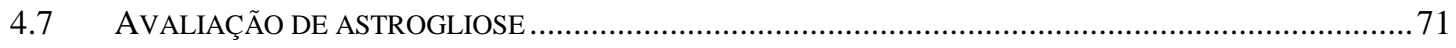

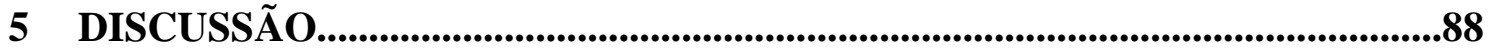

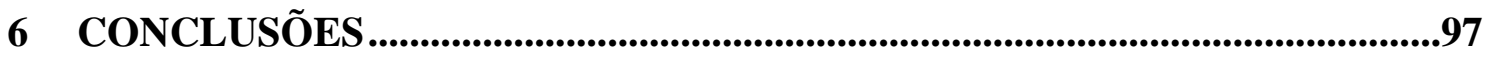

7 REFERÊNCIAS BIBLIOGRAFICAS................................................................99

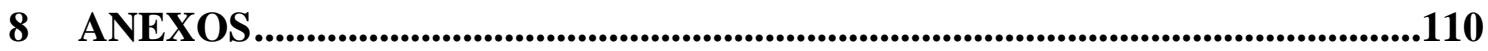


8.1 ANEXo A - ESPECTRO DE MASSAS FORNECIDOS PELA EMPRESA AMINOTECH PESQUISA E

DESENVOLVIMENTO LTDA E RELATÓRIO DE QUALIDADE FORNECIDO PELA EMPRESA FASTBIO LTDA.. 110

8.2 ANEXO B - DECLARAÇÃO DA CEUA.

8.3 ANEXo C - AutorizaÇÃo DE ACESSO E DE REMESSA DE COMPONENTE DO PATRIMÔNIO GENÉTICO

8.4 APÊNDICE A - PREPARAÇÃO DA SOLUÇÃo PBS.

8.5 APÊNDICE B - PREPARAÇÃO DO CORANTE DE NISSL 


\section{INTRODUÇÃO}




\section{INTRODUÇÃO}

\subsection{Epilepsia}

\subsubsection{Panorama e definições}

A Epilepsia tem sido citada na história da humanidade desde muitos anos antes de Cristo, sendo que os primeiros relatos foram em escritos médicos babilônicos (Sakkiku) da antiga Mesopotâmia (hoje, Iraque). Primeiramente, era citada como a “doença da queda", na qual o indivíduo acometido apresentava os seguintes sintomas descritos na época e que eram atribuídos à possessão de maus espíritos: auras subjetivas, apertamento dos dentes, boca espumante, crises em série com quedas, perda de consciência, desvio da cabeça e dos olhos (Wilson \& Reynolds, 1990; Todman, 2008; Brodie et al., 2012). O termo "Epilepsia", que deriva do verbo epilambaneim e significa "ataque", só começou a ser usado na Grécia antiga. O médico grego Hipócrates foi o primeiro a investigá-la como uma doença do cérebro, assim como escreveu em seu livro "A doença sagrada" (The Sacred Disease, 400 a.C.), após inúmeras observações de pacientes (Todman, 2008). No entanto, a ideia hipocrática de que uma crise epiléptica poderia ser causada por uma desordem da atividade elétrica cerebral e não por uma maldição sobrenatural foi somente aceita por volta do século XVIII (Masia \& Devinsky, 2000).

Os vestígios do misticismo de que forças sobrenaturais controlariam os comportamentos de um paciente acometido pela Epilepsia estiveram presentes na sociedade por muito tempo, mesmo após os avanços no tratamento e no entendimento sobre sua fisiopatologia. Ademais, pessoas com Epilepsia (PCE) continuam sendo estigmatizadas porque possuem um atributo não desejado, incontrolável e não premeditado que as deixa impotente. Um dos fatores que contribui para esse fenômeno, é estereotipar um indivíduo devido à sua condição, nesse caso, chamá-lo de epiléptico. 
Distingui-lo transmite a ideia de que ele é diferente das demais pessoas, o que colabora com a estigmatização das PCE (Jacoby et al., 2005).

As PCE ainda são vistas como incapazes de exercerem ocupações cotidianas e também não recebem informações suficientes sobre sua própria condição, contribuindo para que apresentem sinais de ansiedade, além de depressão e se sintam socialmente excluídas e com baixa auto-estima (Kerr, 2012; Ekenze \& Ndukuba, 2013, Mameniskiene et al., 2015). Isso gera, portanto, uma necessidade de intervenções e medidas educativas e maiores investimentos econômicos em opções de tratamento que garanta às PCE o controle das crises epilépticas, permitindo melhor qualidade de vida e minimizando tais impactos negativos em seu cotidiano (Gao et al., 2015; Mathern \& Nehlig, 2015).

Retardos cognitivos, comprometimentos na fala, na linguagem e no aprendizado, consequentes em alguns casos, do próprio uso de fármacos antiepilépticos (Mula \& Trimble, 2009) também são fatores comprometedores no dia-a-dia das PCE (De Boer et al., 2008; Kerr et al., 2009). A Epilepsia é, portanto, fortemente associada a consequências psicológicas, sociais, econômicas e cognitivas (De Boer et al., 2008) e tais fatores motivam a comunidade científica a se empenhar no entendimento a cerca dessa doença e na construção de novas estratégias para o avanço do seu tratamento.

Por muito tempo, a Epilepsia foi interpretada como uma condição ou conjunto de desordens associadas a uma disfunção da atividade elétrica do cérebro. No entanto, o uso do termo "desordem" foi recentemente discutido pela Liga Internacional Contra a Epilepsia (International League Against Epilepsy - ILAE) e pela International Bureau of Epilepsy - IBE, que sugeriram que a Epilepsia seja definida como uma doença. Segundo Fischer e colaboradores (2014), uma desordem implica em um desequilíbrio fisiológico não necessariamente duradouro, enquanto o termo "doença" pode transmitir 
a ideia de um desarranjo mais duradouro da função normal. Além disso, o termo “desordem" é fracamente compreendido pela população, gerando um entendimento errôneo a respeito da Epilepsia, que pode minimizar a sua real natureza. Espera-se que o novo uso do termo possa contribuir para que a sociedade a entenda como uma condição médica séria, na qual a perturbação da função normal do cérebro do paciente pode ser duradoura ou permanente (Fisher et al., 2014).

O documento consolidado após ampla discussão entre especialistas da área trouxe uma nova descrição mais prática e específica, definindo que uma crise epiléptica é "uma ocorrência transitória de sinais e/ou sintomas devido à atividade neuronal anormal, excessiva ou síncrona do cérebro" e a Epilepsia é, portanto, "uma predisposição persistente do cérebro em gerar crises epilépticas e todas as consequências neurobiológicas, cognitivas, psicológicas e sociais que essa condição acarreta" (Fisher et al., 2005). No entanto, essa definição ainda precisa explorar alguns aspectos controversos e um exemplo disso é que ela preconiza a ocorrência de pelo menos uma crise epiléptica para o devido diagnóstico da doença, mas não fornece as orientações sobre como a "predisposição persistente" deve ser conceituada. Sugeriu-se, então, que se houver o aparecimento de duas ou mais crises não provocadas (ausência de fator provocativo, fator temporário ou reversível que reduz o limiar, produzindo uma crise naquele instante), em um intervalo de 24 horas, o diagnóstico de Epilepsia pode ser considerado (Fisher et al., 2014).

As principais causas para o aparecimento da Epilepsia que têm sido destacadas pela Organização Mundial de Saúde - OMS (World Health Organization - WHO) compreendem os incidentes de danos cerebrais provenientes de injúrias pré e perinatais (falta de oxigênio ou trauma durante o nascimento, baixo peso ao nascer), anormalidades congênitas ou condições genéticas associadas à malformações cerebrais, 
fortes golpes na cabeça, acidentes vasculares encefálicos que privam o cérebro de oxigenação, síndromes genéticas, infecções cerebrais como meningite, encefalite ou neurocisticercose e tumores cerebrais (WHO, 2012).

Ainda sobre a determinação de fatores para o diagnóstico dessa doença, destacam-se casos de pessoas que apresentam crises reflexas (evocadas por um estímulo aferente ou por uma atividade específica realizada pelo paciente) ou indivíduos portadores de síndromes epilépticas, como por exemplo, a Síndrome de LandauKleffner, que também podem ser considerados portadores da doença (Sinclair \& Snyder, 2005; Wolf \& Koepp, 2012).

Por último, a recomendação da ILAE é que o termo "Epilepsia resolvida" seja utilizado somente para pacientes que tiveram alguma síndrome epiléptica idadedependente e passaram da idade aplicável, ou em casos cujo paciente esteja livre das crises por mais de 10 anos e esteja há pelo menos cinco anos sem ser tratado com fármacos antiepilépticos (Fisher et al., 2014). Ressalta-se que o termo "resolvido" implica que mesmo que o paciente não apresente mais as crises, não há uma garantia de que essas não irão retornar. As circunstâncias para o uso do termo "curado" não foram delimitadas e por esse motivo não se recomenda sua utilização nesse quesito. A figura 1 resume as recomendações recentes da ILAE para a definição da Epilepsia. 


\section{Epilepsia}

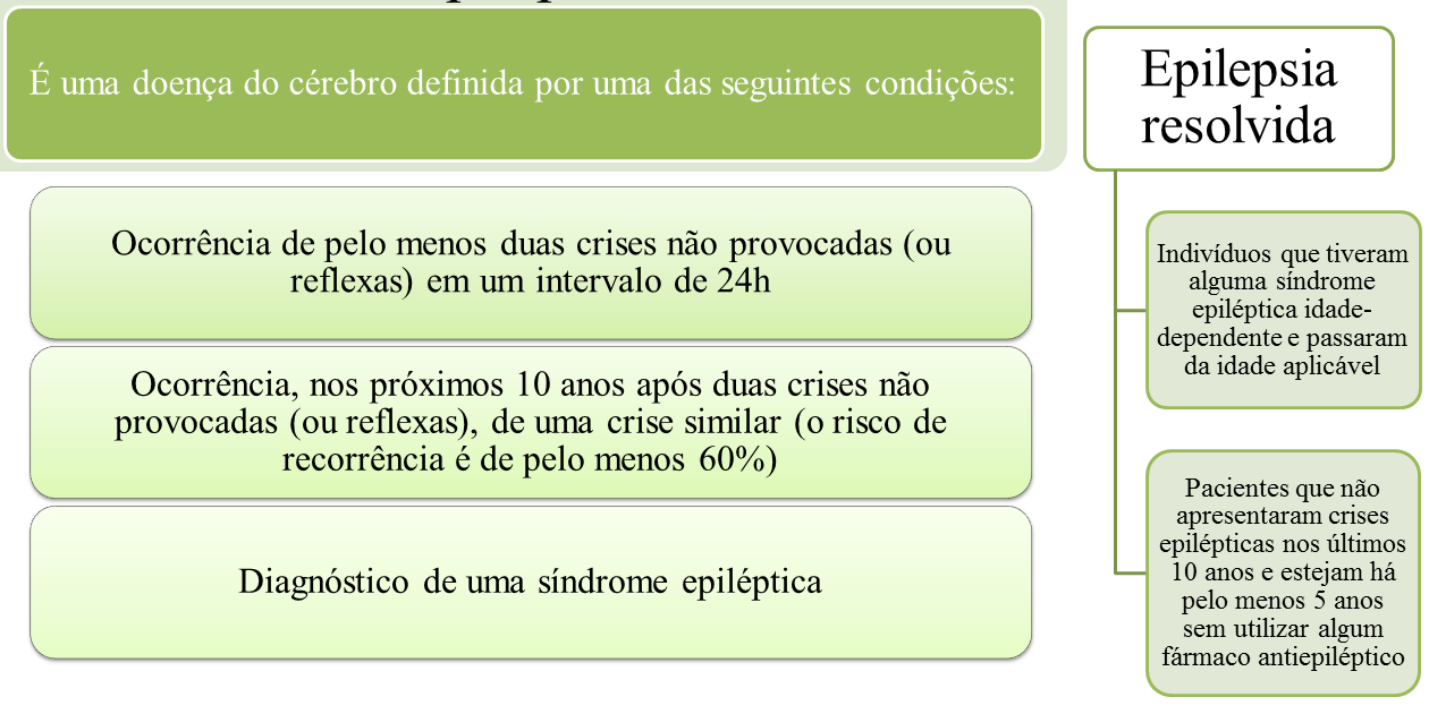

Figura 1. Esquema resumido da definição prática de Epilepsia formulada pela ILAE em 2014. Modificada de Fisher et al., 2014.

Segundo a OMS (WHO, 2012), a Epilepsia é a uma das doenças neurológicas mais prevalentes no mundo, juntamente com acidente vascular encefálico (AVE), a Doença de Alzheimer e a Doença de Parkinson. Estima-se que cerca de 65 milhões de pessoas, de todas as idades, sejam afetadas mundialmente pela Epilepsia (Ngugi et al., 2010; England et al., 2012), e a maior parte delas enfrenta problemas no tratamento, apresentando resistência aos fármacos seletivamente escolhidos para cada caso de Epilepsia (Kwan et al., 2010; Kwan et al., 2011; Kerr, 2012). Além disso, a Epilepsia possui implicações significativas no que diz respeito aos cuidados de saúde requisitados pelos pacientes, morte prematura e perda de produtividade no trabalho, conforme citado anteriormente (WHO, 2012). Ela permanece pouco reconhecida dentre as demais condições neurológicas e por isso, continua a receber poucos financiamentos em relação aos cuidados clínicos e à pesquisa. Tais fatores reforçam a preocupação em reconhecer que a Epilepsia é uma questão de saúde pública e merece mais atenção por parte das autoridades brasileiras e mundiais. 
Como intuito de facilitar o diagnóstico, as classificações da epilepsia também foram recentemente revistas pela Comissão sobre Classificação e Terminologia da ILAE (Berg et al., 2010). No que diz respeito às crises epilépticas, estas podem ser classificadas em focais, quando há uma região de atividade excessiva em determinada rede cerebral restrita a um dos hemisférios, ou generalizadas, quando se originam em algum ponto específico, mas rapidamente se espalham para redes em ambos os hemisférios (Berg \& Scheffer, 2011). Essas redes bilaterais podem compreender estruturas corticais e subcorticais, no entanto, não significa que incluam necessariamente a ativação do córtex em sua totalidade (Berg et al., 2010).

Em relação à etiologia das Epilepsias, a classificação se baseia nos recentes avanços de estudos de neuroimagem, tecnologia genômica e conceitos de biologia molecular, dividindo-as entre "genética", "estrutural/metabólica" e de "causa não conhecida" em substituição aos antigos termos "idiopática", "sintomática” e “criptogênica". Sendo assim, a Epilepsia de origem genética pode ser compreendida como resultado direto de um defeito genético conhecido ou presumido, onde as crises são o principal sintoma da doença. Por sua vez, as condições estruturais ou metabólicas, ou outra doença que definem o segundo tipo de Epilepsia citado, estão associadas a um aumento substancial do risco de desenvolvê-la. Um exemplo são as lesões estruturais que incluem distúrbios adquiridos como o AVE, trauma e infecção. Por fim, Epilepsias de causas não conhecidas podem ser consequências de um distúrbio ainda não identificado (Berg et al., 2010). É válido ressaltar que essa classificação proposta ainda segue em discussão (para revisão ver Shorvon, 2011) e apesar do debate acerca das várias definições a respeito da Epilepsia, alguns tipos se sobressaem devido à sua alta incidência e dificuldade no tratamento. 


\subsection{Epilepsia do Lobo Temporal}

Entre as Epilepsias de maior incidência em adultos, a Epilepsia do Lobo Temporal (ELT) é a de maior relevância clínica, principalmente devido à sua gravidade e pela alta porcentagem de pacientes resistentes aos fármacos antiepilépticos disponíveis (50 a 70\% dos pacientes são refratários) (Engel et al., 2012; White \& Löscher, 2014). Seu nome se deve ao fato de as crises se originarem em estruturas do lobo temporal, em especial a formação hipocampal, estrutura primeiramente descrita pelo "pai da neurociência moderna", Santiago Ramón y Cajal (1852-1934) (Andersen et al., 2006 Walker et al., 2006).

A formação hipocampal é uma estrutura composta pelo córtex entorrinal (CE), o giro denteado (GD), o hipocampo propriamente dito (CA1-3, em roedores e CA1-4, em humanos) e o complexo subicular (parasubículo, pré-subículo e subículo) (para revisão ver Kiernan, 2012). O critério para essa divisão consiste em considerar que os componentes se conectam predominantemente por projeções unidirecionais. Dessa forma, grande parte da informação que circula no interior da estrutura realiza um circuito trissináptico. A maior via de entrada de informação é a perfurante, formada por projeções axonais de neurônios presentes na camada II do CE (região de convergência de fibras vindas dos demais córtices) e que são emitidas para a camada molecular do GD, estabelecendo conexões excitatórias com os dendritos das células granulares do GD. Na sequência, as fibras musgosas (axônios das células granulares do GD) projetam para a camada piramidal da CA3 e parte das células piramidais desse extrato podem se projetar ipsilateralmente para a camada CA1, pelas colaterais de Schaffer, e de CA1 a informação se encaminha para o subículo (região transitória entre o CE e o hipocampo) e para a camada V do CE. Outra parte da informação é encaminhada contralateralmente, para a outra formação hipocampal e outras estruturas do encéfalo. Adicionalmente, há 
ainda outra importante via de entrada de informação, na qual neurônios presentes na camada III do córtex entorrinal medial e lateral emitem projeções para a camada piramidal de CA1, constituindo a via temporoamônica (Figura 2).

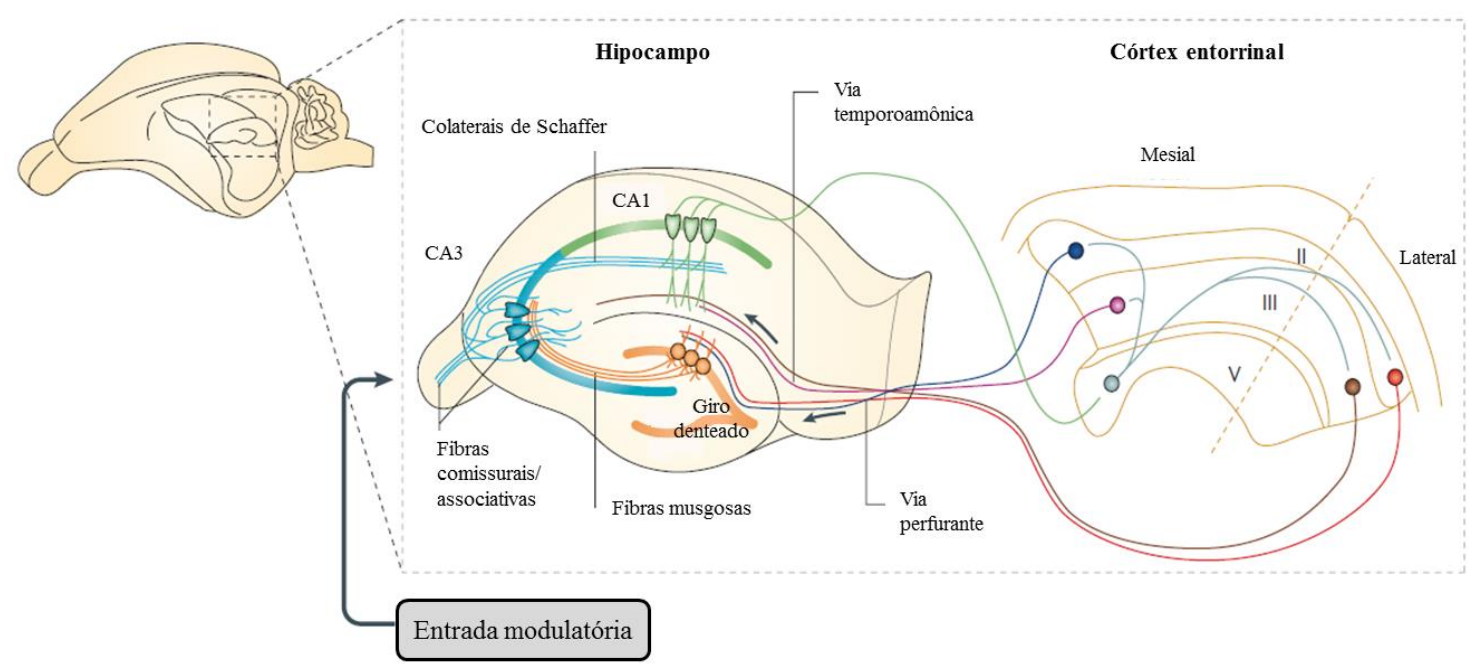

Figura 2. Esquema das vias responsáveis pelo fluxo de informação na formação hipocampal. Modificado de Neves et al., 2008.

Todo esse circuito excitatório é modulado por interneurônios GABAérgicos, que compreendem cerca de $10 \%$ das sinapses hipocampais e estão presentes, principalmente, nas camadas granulares do GD. Dessa forma, o controle do fluxo de informação é altamente monitorado, evitando uma potencialização da excitação de maneira desnecessária, fenômeno presente em algumas situações patológicas, como a ELT (Spruston \& McBain, 2006).

O desenvolvimento da ELT ocorre por um processo dinâmico denominado epileptogênese. Esse fenômeno pode ser definido como o período entre o insulto e o aparecimento das primeiras crises espontâneas e abrange todos os tipos de injúrias (crises febris prolongadas, AVE, infecções) ao encéfalo capazes de gerar eventos que transformam a rede neuronal normal em um circuito cronicamente hiperexcitável, que 
eventualmente começa a apresentar crises epilépticas espontâneas (Acharya et al., 2008).

Além disso, a ELT é frequentemente associada à esclerose hipocampal (EH), caracterizada por uma grande perda das células piramidais das camadas da formação hipocampal, associada a um severo quadro de astrogliose, fenômeno marcado pelo aumento anormal do número de astrócitos (Thom et al., 2009). As células gliais passam a se proliferar após a morte de neurônios próximos à região cerebral que sofreu trauma, infecção, isquemia, ou como consequência de alterações morfológicas e bioquímicas ocasionadas por algumas doenças neurodegenerativas e respostas autoimunes (hiperexcitabilidade e inflamação). Além disso, os corpos celulares dos astrócitos reativos sofrem uma intensa hipertrofia e a síntese de proteínas gliais fibrilares ácidas (Glial fibrillary acidic protein - GFAP) ocorre muito rapidamente em filamentos intermediários do citoesqueleto dessas células (Wetherington et al., 2008; Sofroniew, 2009).

Um sistema de classificação dos tipos de EH foi recentemente proposto pela ILAE após uma análise histopatológica criteriosa de tecido nervoso removido cirurgicamente de alguns pacientes com ELT (Blümcke et al., 2013). O tipo mais comum de EH é o Tipo 1, presente em aproximadamente $60-80 \%$ dos casos reportados de ELT-EH e é caracterizado por uma grande perda neuronal em CA1 (>80\%), seguida de dano em CA2 (30-50\%), CA3 (30-90\%), CA4 (40-90\%) e no GD (50-60\%) e presença de gliose. Além disso, há sinais de reorganização dos axônios excitatórios e inibitórios. O tipo 2 é mais incomum e foi somente observado em 5-10\% dos casos cirúrgicos e também compreende perda predominante de $80 \%$ das células piramidais de CA1, seguida de CA2 $(<20 \%)$, CA3 $(<20 \%)$ e CA4 $(<25 \%)$. A última classificação de EH é a de tipo 3 e também é incomum, com predominância de perda celular em CA4 
(aproximadamente 50\%) e no GD (35\%) enquanto que as camadas CA3 (<30\%), CA2 $(<25 \%)$ e CA1 $(<20 \%)$ são moderadamente afetadas (Blümcke et al., 2013; Thom, 2014).

De forma geral, a EH elimina algumas células musgosas do GD, responsáveis por fornecer retroalimentação excitatória aos interneurônios GABAérgicos, removendo funcionalmente a inibição adjacente no GD. Esse fenômeno é denominado inibição dormente e também é responsável por gerar a hiperexcitabilidade (Sloviter, 1991).

A ELT também é capaz de aumentar a neurogênese (Parent et al., 1997), no entanto, esse fenômeno parece contribuir negativamente, pois as novas células migram de forma aberrante e as células imaturas sofrem alterações morfológicas. Além disso, a densidade de espinhos dendríticos diminui (Kurz et al., 2008; Yuste, 2011).

\subsection{O modelo animal de ELT induzido por pilocarpina}

Grande parte do conhecimento que possuímos acerca da Epilepsia foi adquirida a partir do uso de modelos animais. Apesar de não haver nenhum modelo capaz de representar integralmente a Epilepsia, os modelos experimentais são uma rica ferramenta de pesquisa, pois são capazes de reproduzir ou modelar características da doença foco do estudo (Grone \& Baraban, 2015). Nesse campo de pesquisa, os modelos permitem investigar mecanismos envolvidos na patofisiologia da Epilepsia, avaliar e desenvolver novos tratamentos antiepilépticos e estudar as consequências de condições que podem ocorrer concomitantemente à Epilepsia, como por exemplo, consequências cognitivas e/ou comorbidades (Mula, 2012; Simonato et al., 2012; Auvin \& Dupuis, 2014).

Um dos modelos mais utilizados para simular a ELT é o induzido pelo convulsivante pilocarpina, que foi primeiramente descrito em ratos, por Turski e colaboradores $(1983 \mathrm{a}, \mathrm{b})$ e, posteriormente, reproduzido por Cavalheiro em ratos (1995) 
e camundongos (1996). A administração intraperitoneal sistêmica de pilocarpina foi capaz de produzir uma sequência de automatismos faciais, seguida de crises motoras límbicas nos roedores utilizados nesses estudos. A pilocarpina se liga a receptores muscarínicos do tipo M1 e atua ativando essas vias colinérgicas cujos circuitos eferentes ativam vias glutamatérgicas. A iniciação das crises epilépticas é induzida, portanto, por agonistas colinérgicos, enquanto que agonistas glutamatérgicos são responsáveis pela manutenção das crises. Esse mecanismo pôde ser sugerido após a demonstração de que um pré-tratamento com antagonistas colinérgicos é capaz de bloquear as crises epilépticas, enquanto que se o tratamento ocorrer após a manutenção do SE, não há reversão das crises (Turski et al., 1984).

As vantagens do uso da pilocarpina são as semelhanças com achados histopatológicos e comportamentais de pacientes com ELT que podem ser obtidos em poucas semanas pós-administração, enquanto no paciente, tais alterações demoram anos para se estabelecerem (Curia et al., 2008; Kuruba et al., 2009). Além disso, a utilização de camundongos necessita o uso de menores volumes de substâncias nos testes, o que implica em menores custos econômicos e maior rendimento para as pesquisas (Mazzuferi et al., 2012). Apesar de algumas linhagens de camundongos serem resistentes aos efeitos excitotóxicos e epileptogênicos induzidos pelo cainato (Schauwecker \& Steward, 1997), isso não ocorre no modelo de indução por pilocarpina (Shibley \& Smith, 2002; Schauwecker, 2012), outro importante fator que favorece o uso desse modelo.

A pilocarpina é um alcaloide extraído das folhas da planta Pilocarpus jaborandi e ao ser administrada sistemicamente em altas doses em camundongos $\left(\sim 300 \mathrm{mg} \cdot \mathrm{kg}^{-1}\right)$, produz diversas alterações comportamentais com manifestações de crises motoras límbicas, mioclonia dos membros anteriores e automatismos faciais 15-30 minutos 
posteriores à administração (insulto), que persiste por horas e caracteriza o quadro de status epilepticus (SE), no qual o animal não é capaz de recuperar-se espontaneamente desse estado (Turski et al., 1984; Cavalheiro et al., 1996). O status epilepticus em humanos é definido como o período de ocorrência de uma crise ou um conjunto de crises, durante pelo menos 30 minutos, no qual o indivíduo permanece em uma condição de perda total de consciência e não é capaz de recuperar-se desse estado espontaneamente (Scott, 2014). Em sujeitos experimentais, as falhas respiratórias apresentadas nesse período são a principal causa da alta mortalidade, caracterizando a fase aguda do modelo (Buckmaster \& Haney, 2012).

Os camundongos que sobrevivem ao quadro agudo passam por um período latente, com uma normalização progressiva do perfil eletroencefalográfico e comportamental. Durante esse período não há sinais clínicos de atividade epiléptica, no entanto, presume-se que alterações nas estruturas e funções neuronais e gliais das células estejam ocorrendo, caracterizando a epileptogênese. Brotamentos axonais, mudanças estruturais nos receptores pré- e pós-sinápticos e nos canais iônicos voltagem-dependentes, alterações em mecanismo de homeostase e degeneração neuronal são alguns fenômenos associados à transformação do cérebro normal em um cérebro capaz de gerar crises recorrentes espontâneas (CRE; Pitkänen \& Lukasiuk, 2009).

As primeiras CRE começam a aparecer por volta de 15 dias após o SE e perduram por toda a vida do animal e é esse fenômeno que se assemelha à ocorrência de inúmeras crises por dia e por vários dias consecutivos que os pacientes apresentam, caracterizando uma condição crônica (Cavalheiro, 1995; Haut, 2006; Curia et al. 2008). As crises apresentadas no período crônico do modelo, após a indução sistêmica de pilocarpina, reproduzem dois padrões eletroencefalográficos de geração de crises 
observados em pacientes com ELT. O primeiro tipo é o padrão de início rápido de baixa voltagem ( $L V F$ - low-voltage fast onset pattern), caracterizado por uma espícula de ponta única seguida por atividade de alta frequência, maior que $25 \mathrm{~Hz}$. O segundo tipo consiste do início de crises com espículas de periodicidade variadas que ocorrem em uma frequência de aproximadamente $2 \mathrm{~Hz}$ e é chamado de padrão de início hipersincronizado (HYP - hypersyncronous onset pattern) (Velasco et al., 2000). Enquanto a maioria dos pacientes apresenta padrões estereotipados de início de crises, podendo ser o tipo LVF ou o HYP (Velasco et al., 2000), os sujeitos experimentais são capazes de reproduzir ambos os tipos (Lévesque et al., 2012), o que permitiu inferir hipóteses que justifiquem a geração das crises durante o período crônico por mecanismos distintos e sua localização mais prevalente em regiões específicas do Lobo Temporal (Bragin et al., 2011).

Em relação às mudanças histopatológicas observadas após a administração sistêmica de pilocarpina, esse modelo experimental é capaz de reproduzir a perda neuronal nas CAs e o brotamento de fibras musgosas no GD que também são observados em pacientes de ELT (Sharma et al., 2007). O dano celular inicialmente produzido após o insulto avança rapidamente das células granulares do GD e do hilus para CA3 e CA1, causando uma degeneração massiva (Covolan \& Mello, 2000). Além disso, a geração das crises recorrentes tem sido associada ao brotamento das fibras musgosas no GD (Mello et al., 1993; Cho et al., 2015). Um resumo dos processos envolvidos na geração da ELT em humanos e sujeitos experimentais está representado na figura 3 . 


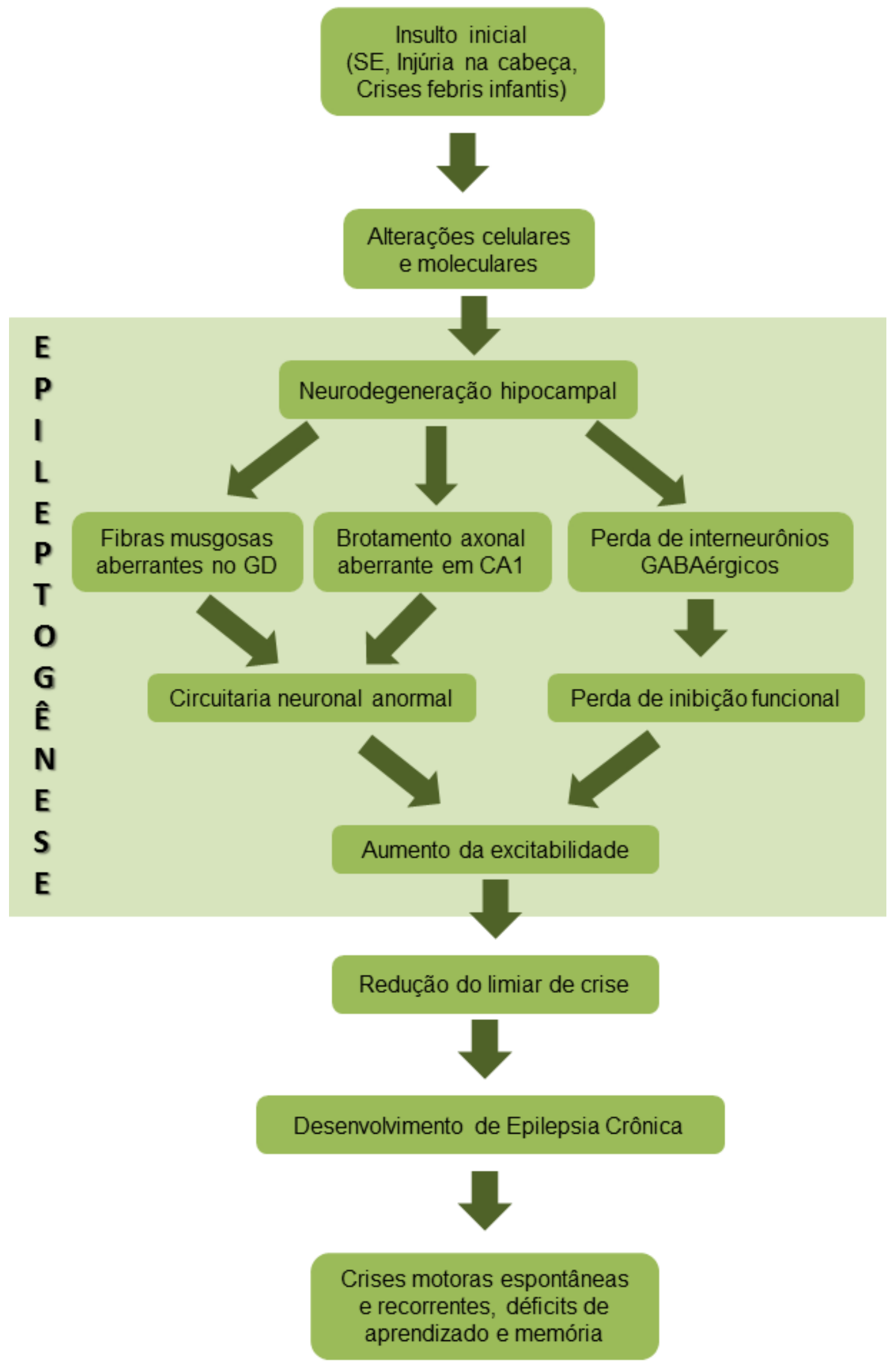

Figura 3. Causas e principais processos celulares envolvidos na epileptogênese da ELT. 
O primeiro estudo que demonstrou a capacidade de alguns fármacos antiepilépticos convencionais em reduzir a frequência de crises espontâneas originadas em ratos foi realizado por Leite \& Cavalheiro em 1995. Estudos posteriores tentaram mostrar a eficácia de alguns outros fármacos no tratamento de sujeitos experimentais submetidos a modelos de ELT. No entanto, a dificuldade enfrentada pelos pacientes resistentes ao tratamento também é reproduzida no modelo experimental, pois sempre existem animais que apresentam crises farmacoresistentes. Além disso, alguns fármacos possuem propriedades anti-ictogênicas (contra as crises epilépticas), mas se o tratamento for interrompido, as crises podem voltar a ocorrer (Glien et al., 2002; Grabenstatter et al., 2005; Chakir et al., 2006; Grabenstatter et al., 2007; Ali et al., 2012; Doeser et al., 2015).

\subsection{Tratamento da ELT}

Como descrito anteriormente, a ELT é altamente refratária, sendo considerada, segundo a ILAE, como Epilepsia Fármaco-Resistente. A ILAE preconiza que Epilepsias Fármaco-Resistentes são aquelas em que o esquema de tratamento com dois fármacos antiepilépticos, bem tolerados e apropriadamente escolhidos, apresenta falhas (TéllezZenteno et al., 2014). Devido a isso, a lobectomia temporal é um tratamento mais indicado em candidatos selecionados, pois pode aumentar em 60 a $80 \%$ as chances do paciente de se tornar livre de crises. Mesmo assim, existem pacientes que apresentam epilepsias resistentes à cirurgia de remoção do lobo temporal (Cendes et al., 2014).

Na prática clínica, por outro lado, o tratamento farmacológico da ELT se inicia com carbamazepina, fenitoína ou oxcarbazepina em monoterapia, preferencialmente. No caso de insucesso no controle das crises ou impossibilidade de uso desses fármacos a segunda opção de tratamento indica o uso de lamotrigina, topiramato, ácido valpróico 
ou derivados benzodiazepinicos, como o clobazam. No entanto, além da refratariedade, os efeitos adversos e os altos custos da terapia impõem sérias restrições ao uso desses fármacos (Schmidt \& Schachter, 2014; Vadja \& Eadie, 2014).

Nesse sentido, o desenvolvimento de fármacos antiepilépticos que sejam capazes de diminuir a excitação e aumentar a inibição neuronal, por variados mecanismos farmacológicos, incluindo a potenciação da atividade GABAérgica, a modulação de canais iônicos, a inibição de processos glutamatérgicos e a modificação da liberação de neurotransmissores, ainda são estratégias altamente almejadas (Remy \& Beck, 2006; Radzik et al., 2015). Alguns fármacos, como o brivaracetam (BRV), o acetato de eslicarbazepina (ESL), a lacosamida (LCM), o perampanel (PER) e a retigabina (RTG), apresentaram uma eficácia comprovada em modelos animais e, recentemente, vem sendo testados para o controle de diversos tipos de Epilepsias, mostrando-se como potenciais candidatos a tratarem principalmente a ELT.

A seguir, é apresentada uma tabela que indica os principais modelos em que cada um desses fármacos foram testados e produziram efeitos terapêuticos de redução da duração e da severidade das crises induzidas. Alguns efeitos adversos têm sido observados em humanos e também estão indicados, assim como o mecanismo de ação sugerido para cada um deles (para revisão, ver Palleria et al., 2015). 
Tabela 2. Principais fármacos promissores para o tratamento de pacientes com ELT, modelo animal em que foram testados, seus efeitos adversos e mecanismo de ação.

\begin{tabular}{|c|c|c|c|c|}
\hline Fármaco & Modelo animal & Efeitos adversos & Mecanismo de ação & Referências \\
\hline BRV & $\begin{array}{l}\text { Abrasamento hipocampal e do } \\
\text { complexo amigdaloide }\end{array}$ & $\begin{array}{l}\text { Agressividade, ansiedade, } \\
\text { amnésia, insônia, depressão }\end{array}$ & $\begin{array}{l}\text { Ligante de alta afinidade de } \\
\text { SV2A e inibidor de canais de } \\
\text { sódio voltagem-dependentes }\end{array}$ & $\begin{array}{l}\text { Kenda et al., 2004; } \\
\text { Dupuis et al., } 2015\end{array}$ \\
\hline ESL & Abrasamento hipocampal & $\begin{array}{l}\text { Ataxia, náuseas, disfunção } \\
\text { sexual, desordens do sono }\end{array}$ & $\begin{array}{l}\text { Interage com o sítio } 2 \text { do } \\
\text { estado inativo do canal de } \\
\text { sódio voltagem-dependente }\end{array}$ & $\begin{array}{l}\text { Almeida \& Soares-da- } \\
\text { Silva, 2007; Potschka et } \\
\text { al., } 2014\end{array}$ \\
\hline LCM & $\begin{array}{l}\text { Abrasamento hipocampal e do } \\
\text { complexo amigdaloide }\end{array}$ & $\begin{array}{l}\text { Ataxia, depressão, distúrbios } \\
\text { gastrointestinais, alucinações, } \\
\text { sedação, perda de peso }\end{array}$ & $\begin{array}{l}\text { Aumenta a inativação lenta } \\
\text { do canal de sódio voltagem- } \\
\text { dependente }\end{array}$ & $\begin{array}{l}\text { Errington et al., 2006; } \\
\text { Brandt et al., } 2006\end{array}$ \\
\hline PER & $\begin{array}{l}\text { Abrasamento do complexo amigdaloide, } \\
\text { Lítio-pilocarpina (SE agudo) e Cainato } \\
\text { hipocampal (crises espontâneas pós-SE) }\end{array}$ & $\begin{array}{l}\text { Diarreia, irritabilidade, } \\
\text { náuseas, rinite, sonolência }\end{array}$ & $\begin{array}{l}\text { Antagonista não-competitivo } \\
\text { do receptor de AMPA }\end{array}$ & $\begin{array}{l}\text { Hanada et al., 2011; } \\
\text { Hanada et al., } 2014\end{array}$ \\
\hline RTG & $\begin{array}{l}\text { Abrasamento hipocampal e do } \\
\text { complexo amigdaloide }\end{array}$ & $\begin{array}{l}\text { Prejuízos na memória, } \\
\text { tremores, desordens renais e } \\
\text { urinárias, visão turva. }\end{array}$ & $\begin{array}{l}\text { Agonista do canal de } \\
\text { potássio voltagem- } \\
\text { dependente }\end{array}$ & $\begin{array}{l}\text { Backburn-Munro et al., } \\
\text { 2005; Tober et al., 1996; } \\
\text { Mazarati et al., } 2008\end{array}$ \\
\hline
\end{tabular}




\subsection{O peptídeo Neuropolybina}

Desde 2008, pesquisadores do Laboratório de Neurofarmacologia da Universidade de Brasília (UnB) têm investigado a ação de moléculas isoladas a partir da peçonha de vespas sociais no SNC de roedores. Tais pesquisas levaram ao isolamento de alguns compostos promissores, como é o caso do peptídeo em estudo.

Couto e colaboradores (2012a,b) o isolaram e caracterizaram a partir de técnicas de ultrafiltração, cromatografia líquida de alta eficiência (CLAE) e espectrometria de massas. Após o indício de um perfil antiepiléptico nos compostos de baixa massa molecular (<3000 Da) extraídos da peçonha da vespa social Polybia paulista, testados no modelo agudo de indução de crises epilépticas por Pentilenotetrazol (PTZ) em ratos Wistar, foi possível obter a fração cromatográfica que continha a molécula responsável por tal efeito, a fração 7. Sendo assim, a molécula inédita descoberta recebeu o nome de Ppnp7, ou seja, Neuropeptídeo 7 da Polybia paulista (Couto et al., 2012b).

Ainda nesse trabalho, o peptídeo foi testado no mesmo modelo e em três diferentes concentrações (4,5; 3 e 1,5 $\mu \mathrm{g}$ /animal) após administração direta no SNC (via intracerebroventricular - i.c.v.) e apresentou notável proteção contra as crises induzidas, em um efeito dose-dependente. Possíveis alterações motoras e comportamentais induzidas pela administração do composto também foram avaliadas e os resultados não mostraram o aparecimento de efeitos adversos nos testes de avaliação da exploração geral espontânea (campo aberto) e de coordenação motora (rotarod), sugerindo que esse peptídeo pode ser uma ferramenta farmacológica interessante.

Posteriormente, Silva e colaboradores (2014) prosseguiram as pesquisas com o peptídeo sintetizado com base na sequência de aminoácidos do Ppnp7 (Pyr-Gln-TrpGln-Pro-Gln-Leu-His-Arg-OH), que passou a ser denominado Neuropolybina. Nesse trabalho, foi realizado o monitoramento das crises epilépticas em ratos Wistar por 
vídeo-eletroencefalografia e foi demonstrado que a latência para o estabelecimento das crises EEG coincidiu com a latência das crises comportamentais induzidas por PTZ. O peptídeo também foi capaz de reduzir a severidade das crises e protegeu $80 \%$ dos ratos contra as crises induzidas após a administração do peptídeo.

Além disso, foram realizados os primeiros testes do peptídeo em camundongos Swiss e ele também se mostrou eficaz em protegê-los contra crises induzidas por PTZ e não induziu alterações na atividade geral espontânea dos camundongos nas doses de proteção testadas e também não foi hemolítico em eritrócitos de camundongos. Tais resultados guiaram os testes neuroquímicos com o peptídeo, pois sugeriu-se ter uma ação modulatória na neurotransmissão GABAérgica, uma vez que havia sido capaz de controlar crises induzidas por um antagonista de $\mathrm{GABA}_{\mathrm{A}}$. No entanto, a Neuropolybina nas concentrações testadas não apresentou atividade sobre a captação de $\left[{ }^{3} \mathrm{H}\right]-\mathrm{L}-$ Glutamato e sobre a ligação a receptores de $\left[{ }^{3} \mathrm{H}\right]-\mathrm{GABA}$ e $\left[{ }^{3} \mathrm{H}\right]-\mathrm{L}-$ Glutamato, em sinaptossomas corticais de ratos, o que permite inferir que outros mecanismos de ação podem ser sugeridos para o peptídeo em questão.

Todos os dados adquiridos até o momento sobre a potencialidade farmacológica do peptídeo Neuropolybina reforçam o interesse depositado no estudo desse imenso arsenal de compostos neuroativos selecionados pelos processos evolutivos que conduziram a adaptação dessas espécies de artrópodes peçonhentos. Neste sentido, essas novas moléculas isoladas podem contribuir enormemente para as neurociências, seja na elucidação de aspectos envolvidos no funcionamento de estruturas neuronais ou em seu papel no estudo da fisiopatologia de algumas desordens neurológicas, como a Epilepsia. Além disso, também podem ser úteis no desenvolvimento de fármacos mais potentes e com menos efeitos adversos, capazes de tratar as crises epilépticas apresentadas pelos pacientes (Mortari et al., 2007; Monge-Fuentes et al., 2015; Silva et al., 2015). 
OBJETIVOS 


\section{OBJETIVOS}

\subsection{Objetivo geral}

Diante do grande potencial dos compostos obtidos das peçonhas de vespas sociais na descoberta de moléculas com atividade no Sistema Nervoso Central de mamíferos, bem como da grande necessidade de buscar novas alternativas farmacoterapêuticas para o tratamento da ELT, o objetivo do presente trabalho é aprofundar o conhecimento acerca do efeito antiepiléptico do peptídeo Neuropolybina em camundongos submetidos ao modelo crônico de indução de SE por pilocarpina.

\subsection{Objetivos específicos}

- Verificar o efeito antiepiléptico do peptídeo Neuropolybina pelo monitoramento por vídeo-EEG e comportamental dos animais no período crônico, utilizando o modelo de ELT induzido por pilocarpina em camundongos;

- Verificar se a administração do peptídeo altera a densidade de neurônios do extrato de células piramidais de CA1 e CA3 e da camada granular do GD contra morte celular induzida após 20 dias de SE induzido por pilocarpina, utilizando a estimativa de densidade óptica de células coradas pela técnica de Nissl;

- Verificar se a administração do peptídeo também é capaz de alterar o número de astrócitos imunorreagentes ao anticorpo anti-GFAP nas mesmas regiões já citadas, utilizando a análise quantitativa de astrócitos submetidos às técnicas de imunohistoquímica e imunofluorescência. 
MATERIAL E MÉTODOS 


\section{MATERIAL E MÉTODOS}

\subsection{Síntese do peptídeo}

O peptídeo Neuropolybina foi sintetizado pelas empresas AminoTech Pesquisa \& Desenvolvimento Ltda (Brasil) e FastBio Ltda (Brasil), utilizando a técnica de síntese em fase sólida - Fmoc. Esse processo foi realizado com base na sequência do composto Ppnp7 isolado a partir da peçonha da vespa social neotropical Polybia paulista por Couto e colaboradores (2012a).

Após o recebimento do material, que conta com um relatório de qualidade (Anexo A), foram realizadas análises para inspeção da massa monoisotópica e o grau de pureza do peptídeo por Espectrometria de Massas. Sua sequência de aminoácidos também foi confirmada por sequenciamento De Novo. Para essas devidas identificações, foi utilizado o método MALDI-TOF/TOF no espectro de massas Autoflex speed (Bruker Daltonics, Alemanha) no modo positivo $[\mathrm{M}+\mathrm{H}]^{+}$. Uma alíquota do peptídeo foi ressuspendida em água deionizada e misturada a uma matriz pronta de ácido $\alpha$-cyano-4hidroxi-cinâmico em acetonitrila/água deionizada/3\% de ácido trifluoracético, 5/4/1, v/v/v e, posteriormente, essa mistura foi aplicada em triplicata em uma placa Bruker MTP Massive 384. As aplicações secaram em temperatura ambiente e então foram analisadas.

O espectro de massas estava equipado com laser SmartBeam e foram utilizados em dois modos de operação, o refletido positivo, para a obtenção de espectros de MS, e o LIFT, para a obtenção de espectros de MS/MS. A faixa de detecção da razão massa/carga $(\mathrm{m} / \mathrm{z})$ foi de 600 a 3000. A calibração foi realizada com a mistura Peptide Calibration Standard I (Bruker Daltonics, Alemanha). O software utilizado nessas análises foi o FlexControl 3.0. Alíquotas do peptídeo foram submetidas às análises 
citadas a cada seis meses a fim de monitorar e garantir a estabilidade do composto em estudo.

A etapa de verificação do grau de pureza e sequenciamento do peptídeo Neuropolybina foi realizada no Laboratório de Neurofarmacologia (Departamento de Ciências Fisiológicas, UnB) pelo técnico químico MSc. Adolfo Carlos Barros de Souza.

\subsection{Bioensaios}

Para analisar a atividade antiepiléptica potencial do peptídeo Neuropolybina no modelo crônico de Epilepsia do Lobo Temporal (ELT), foi utilizado o modelo de indução por pilocarpina em camundongos (Mus musculus) Swiss machos, após aquisição das autorizações e licenças pertinentes. A manipulação dos animais experimentais seguiu os princípios éticos do Conselho Nacional de Controle de Experimentação Animal (CONCEA) e a Lei Arouca (Lei 11.794/2008). O projeto foi submetido à Comissão de Ética no Uso Animal do Instituto de Ciências Biológicas (CEUA/IB) da Universidade de Brasília - UnB e deferido (UnBDOC nº 139668/2014, Anexo B). Além disso, a permissão para utilizar componentes presentes na peçonha de animais da biodiversidade brasileira com a finalidade de pesquisa científica foi aprovada pelo CNPq (Autorização de Acesso e de Remessa de Componente do Patrimônio Genético, Processo nº 010476/2013-0, Anexo C).

\subsubsection{Sujeitos experimentais}

Os camundongos pesando de 18 a 22 g (início dos experimentos) e com 5 a 6 semanas de idade foram adquiridos do Biotério do Instituto de Ciências Biológicas da UnB, acondicionados em caixas de polipropileno (41 x 34 × $16 \mathrm{~cm}$ - comprimento $\mathrm{x}$ largura $\mathrm{x}$ altura), dez camundongos/caixa, mantidos em biotério com ciclo claro/escuro de $12 / 12$ horas, temperatura $\left(25^{\circ} \mathrm{C}\right)$ e umidade $(55 \%)$ controladas. Durante todo o 
período experimental, foram oferecidas água e alimentação (ração específica para camundongos - Labina) ad libitum. Os sujeitos experimentais foram identificados individualmente por marcações na cauda e no dorso com caneta permanente.

\subsubsection{Modelo crônico de ELT por pilocarpina}

O modelo crônico de ELT utilizado neste estudo foi dividido em três períodos. O primeiro deles, chamado de período agudo, é caracterizado pela administração sistêmica de um antagonista colinérgico 20 minutos antes da administração sistêmica do agonista colinérgico pilocarpina (pilo). Em alguns minutos, os sujeitos experimentais passam a apresentar sinais de estimulação colinérgica e respostas comportamentais estereotipadas que progridem para o quadro de Status Epilepticus (SE). A partir desse momento, eles são mantidos em SE por 180 minutos até receberem a administração sistêmica de um barbitúrico, para serem resgatados do quadro de crises ininterruptas do SE.

Os camundongos que sobrevivem após o insulto realizado com pilo no período agudo, passam para o período latente, que corresponde aos 15 dias subsequentes ao SE em que não apresentam nenhuma crise epiléptica. $O$ procedimento cirúrgico de implantação da cânula-guia e dos eletrodos para registro da atividade elétrica cerebral foi realizado nesse período, no $10^{\circ}$ dia após o SE.

A partir do $15^{\circ}$ dia, os camundongos passam a apresentar crises recorrentes e espontâneas (CRE), caracterizando o terceiro período do modelo utilizado neste trabalho, o período crônico. Nos cinco primeiros dias desse período foi realizado o tratamento subcrônico das CRE com o veículo, o peptídeo ou com o benzodiazepínico Diazepam (DZP). Além disso, também foi realizado o monitoramento da atividade epileptiforme por vídeo-eletroencefalografia nesse período. Um resumo do modelo está 
ilustrado na figura 4 e a descrição de cada procedimento realizado durante os períodos brevemente explicados neste tópico estão detalhados a seguir.

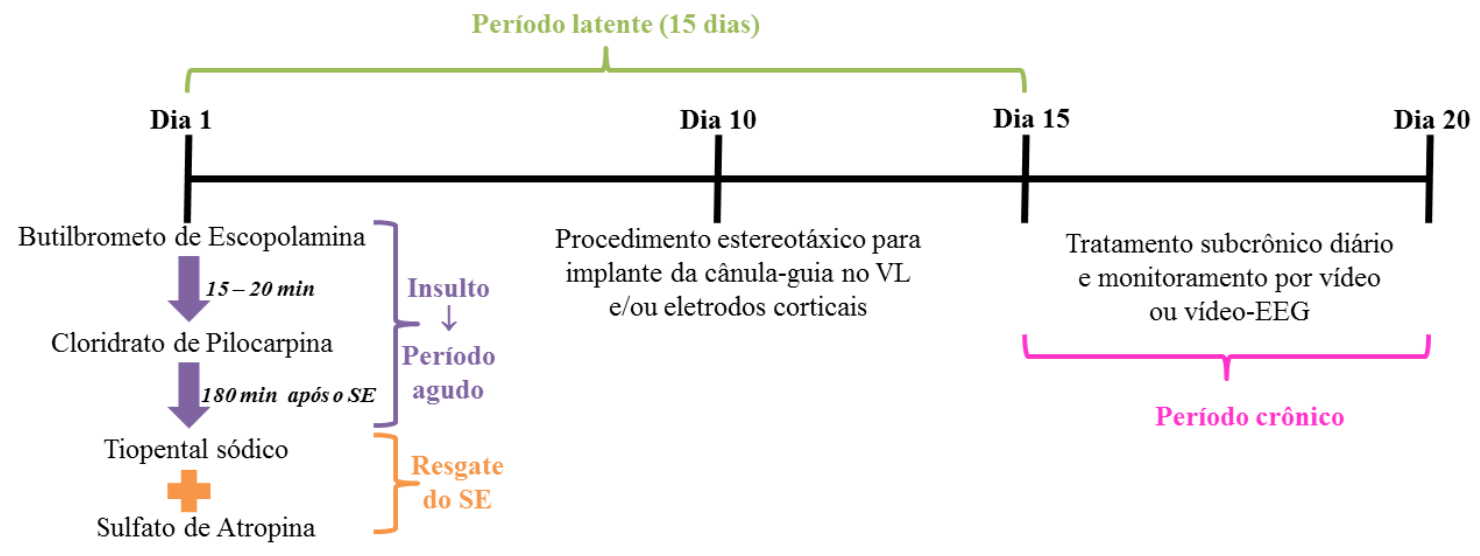

Figura 4. Fluxograma ilustrando as etapas realizadas em cada período do modelo crônico de ELT induzido nos sujeitos experimentais.

\section{a. Indução de Status Epilepticus}

Para que os camundongos entrassem em SE, foi realizada a indução química com o agonista colinérgico. Primeiramente, os sujeitos experimentais receberam uma injeção intraperitoneal (i.p.) do antagonista colinérgico butilbrometo de escopolamina (4 mg.kg ${ }^{-1}$; Boehringer Ingelheim, Brasil) que não atravessa a barreira hematoencefálica, afim de prevenir os efeitos periféricos da pilo e reduzir a mortalidade e morbidez dos animais. O insulto foi realizado de 15 a 20 minutos após essa administração, quando receberam uma injeção por via i.p. de cloridrato de pilocarpina $\left(210 \mathrm{mg} \cdot \mathrm{kg}^{-1}\right.$; SigmaAldrich $^{\circledR}$, EUA), solubilizado em solução fisiológica $150 \mathrm{mM}$ e a seguir, os camundongos permaneceram em observação, tendo seus comportamentos monitorados. A dose de pilo foi estabelecida em ensaios prévios que revelaram a dose ideal para induzir crises epilépticas ininterruptas com alta taxa de sobrevivência. 
O SE foi interrompido 180 minutos após sua manutenção, pela injeção por via i.p. de tiopental sódico (50 mg. $\mathrm{kg}^{-1}$; Cristália, Brasil), solubilizado em solução fisiológica $150 \mathrm{mM}$ e imediata administração de sulfato de atropina (0,1 mg/animal, i.p.; Hypofarma, Brasil). Mesmo após a interrupção do SE, alguns sujeitos experimentais continuaram a receber $20 \%$ da dose de tiopental administrada inicialmente, sempre que necessário, até cessarem totalmente as crises epilépticas.

A avaliação comportamental para estabelecer o início do SE foi baseada na classificação de crises límbicas de Racine (1972) modificada por Shibley \& Smith (2002) (Tabela 2). Essa classificação também foi modificada para se adequar aos comportamentos observados nos sujeitos submetidos ao protocolo experimental neste trabalho. O critério de definição correspondeu ao momento em que o camundongo começou a apresentar crises límbicas de classe $\geq 3$, sem se recuperar espontaneamente.

Tabela 2. Classificação das crises límbicas induzidas por pilocarpina baseada no índice de Racine (1972), modificado por Shibley e Smith (2002).

\section{Classe Comportamento do camundongo}

1 e 2 Enrijecimento da cauda e tremores generalizados, de duração de 1 a 5 segundos

3 Crises tônico-clônicas pouco intensas marcadas por mioclonias unilaterais dos membros anteriores e os demais comportamentos das classes 1 e 2

4 Crises mioclônicas bilaterais dos membros anteriores com elevações e manifestações da classe 3

5 Crises mioclônicas bilaterais dos membros anteriores e posteriores com perda transitória do controle postural (Crise generalizada) 
Os camundongos foram monitorados durante as 24 horas seguintes à indução do SE, mantidos hidratados com $100 \mu \mathrm{L}$ de soro glicosado $5 \%$ e foram alimentados com uma sonda a fim de garantir a sobrevivência dos mais debilitados. Permaneceram no biotério nas condições citadas anteriormente, em suas caixas de origem, durante os dez dias subsequentes ao SE, fase correspondente ao período latente do modelo.

b. Procedimento cirúrgico de implantação da cânula-guia para a administração do peptídeo

As doses do peptídeo, foco desse estudo, foram administradas por via intracerebroventricular (i.c.v.), uma vez que Silva (2014) demonstrou que a Neuropolybina não é capaz de produzir efeitos terapêuticos quando sua administração é sistêmica. Em vista disso, foi realizado um procedimento para a implantação de uma cânula-guia no ventrículo lateral cerebral direito (VL) dez dias após o estabelecimento do SE, durante o período latente do modelo, para a administração do peptídeo diretamente no SNC dos camundongos durante a fase crônica.

Os sujeitos experimentais foram anestesiados via i.p. com solução de cloridrato de quetamina (75 mg.kg ${ }^{-1}$; Ceva, Brasil) e cloridrato de xilazina (15 mg.kg ${ }^{-1}$; Ceva, Brasil) diluídas em solução fisiológica $150 \mathrm{mM}$. Sob o efeito da anestesia, foram fixados em um estereotáxico (Insight Equipamentos ${ }^{\circledR}$, Brasil) por meio das barras auriculares e após a devida assepsia com iodopolividona 10\% (Vic Pharma ${ }^{\circledR}$, Brasil), foi realizada a tricotomia da cabeça e a injeção local s.c. de cloridrato de lidocaína com hemitartarato de norepinefrina (30 mg. $\mathrm{ml}^{-1}$ com 0,04 mg.ml ${ }^{-1}$; Dentsply Pharmaceutical, Brasil). Em seguida, o crânio foi exposto para a realização das medições estereotáxicas para o posicionamento da cânula no VL, tendo como base o ponto do bregma (Anteroposterior: - 0,2 mm; Mesolateral: - 1,0 mm; Dorsoventral: - 2,3 mm), de acordo com o Atlas Estereotáxico de Paxinos \& Franklin (2001). Foi realizada outra perfuração 
oposta à da cânula, no lado esquerdo à sutura sagital para a fixação de um parafuso que auxilia na aderência do acrílico, aumentando a durabilidade do implante e garantindo um equilíbrio com a cânula implantada (Figura 5).

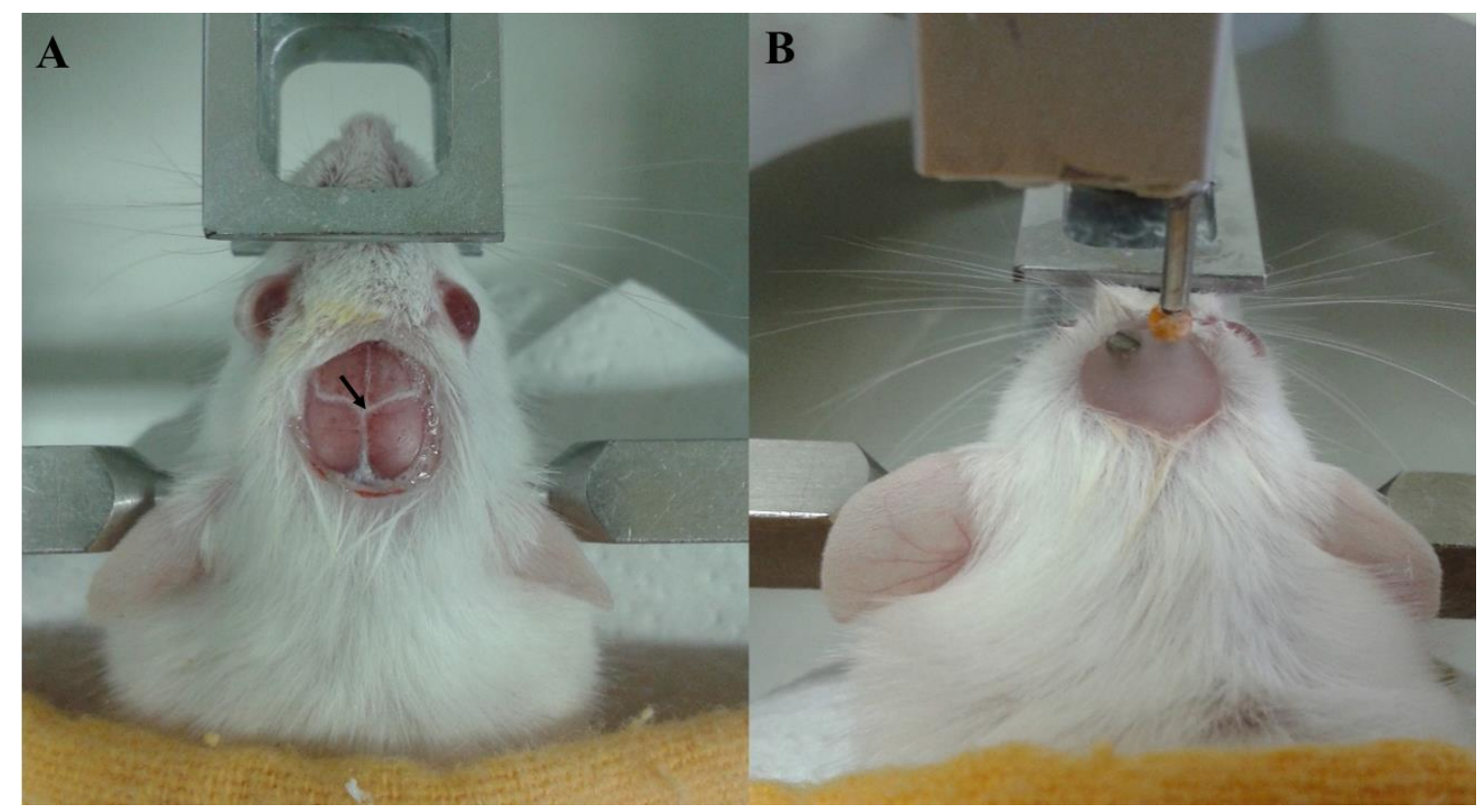

Figura 5. Implantação da cânula-guia no ventrículo lateral de um camundongo. (A) Exposição do crânio e marcação do bregma (seta preta). (B) Implantação da cânula e do parafuso e cobertura da região exposta com resina acrílica.

A cânula e os parafusos foram fixados com resina acrílica (Dentbras ${ }^{\circledR}$, Brasil) polimerizada com líquido acrílico (Dentbras ${ }^{\circledR}$, Brasil) e a cânula foi selada com um fio de aço inoxidável para evitar obstrução. A cânula de administração foi produzida a partir de um fragmento de $10 \mathrm{~mm}$ de uma agulha hipodérmica BD 0,70 × $2522 \mathrm{G}$ (Figura 6). Por fim, foi administrada uma pomada tópica de sulfato de neomicina e bacitracina (5 mg.g ${ }^{-1}$ e $250 \mathrm{Ul.g}^{-1}$; Medley, Brasil) ao redor do capacete de resina, que auxilia a cicatrização e impede infecções locais. Cinco dias após esse procedimento, os camundongos foram submetidos aos tratamentos subcrônicos. 


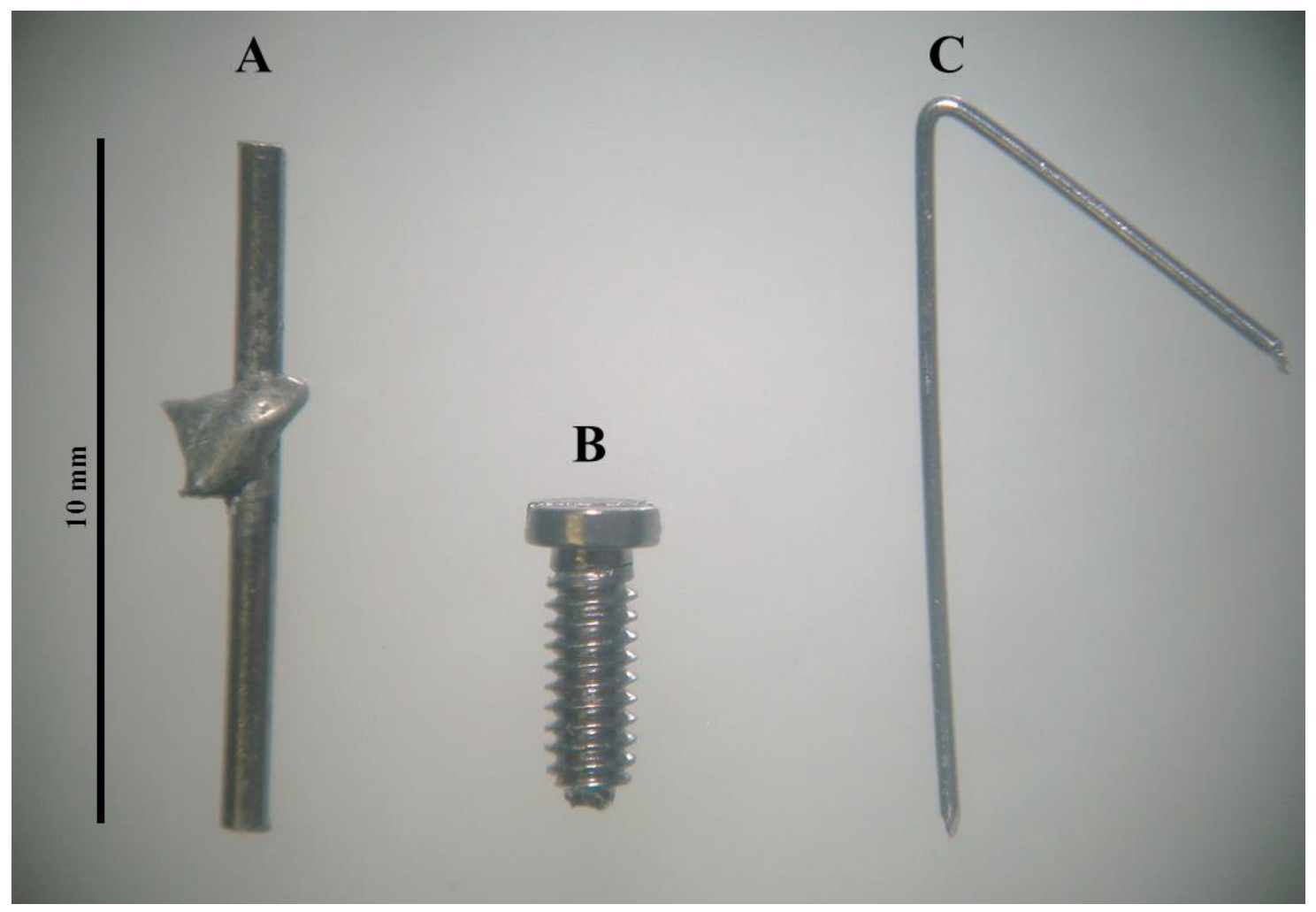

Figura 6. (A) Cânula-guia de administração dos compostos diretamente no ventrículo lateral direito. (B) Parafuso de aço inoxidável para garantir a durabilidade do capacete de resina acrílica. (C) Fio de aço inoxidável colocado no interior da cânula para obstruí-la até o momento de administração dos compostos.

\section{c. Grupos experimentais}

Os animais submetidos aos protocolos experimentais foram divididos em quatro grupos independentes:

- $\quad$ Grupo Sadio $(\mathrm{n}=8)$ : animais tratados com água deionizada (veículo) por via i.c.v. no VL. Tendo em vista que o presente trabalho contribui com dados que possam ser usados em comparação aos resultados já obtidos por trabalhos anteriores, optamos por utilizar o mesmo veículo que utilizados por esses trabalhos. Esse grupo não apresenta CRE, correspondendo ao grupo controle sadio.

- $\quad$ Grupo Doente $(\mathrm{n}=8)$ : animais que desenvolveram o SE e foram tratados com água deionizada por via i.c.v. Esse grupo representa os animais que apresentam as CRE, ou seja, grupo controle negativo/epiléptico. 
- $\quad$ Grupo Neuropolybina $(n=14)$ : animais que desenvolveram o SE e foram tratados com duas concentrações independentes do peptídeo Neuropolybina (2,5 e 0,5 nmol), administradas por via i.c.v. em $1 \mu \mathrm{L}$ e solubilizados em água deionizada.

- $\quad$ Grupo Diazepam (DZP) $(n=8)$ : animais que desenvolveram o SE e foram tratados com diazepam (Compaz ${ }^{\circledR} ; 4$ mg/kg, i.p; Cristália, Brasil). Esse grupo representa o controle positivo.

\section{d. Tratamento subcrônico}

O tratamento dos sujeitos experimentais iniciou-se 15 dias após o insulto inicial, ou seja, o estabelecimento do SE e diariamente durante os cinco primeiros dias do período crônico do modelo. O peptídeo ou veículo foram administrados por via i.c.v. nos grupos experimentais independentes a uma taxa de infusão de $1 \mu \mathrm{L} / \mathrm{min}$, com auxílio de uma bomba de infusão (BI-2008, AVS Projetos, Brasil) acoplada à uma microseringa (Gastight $10 \mu \mathrm{L}$, Modelo 1701 N SYR, Hamilton ${ }^{\circledR}$, EUA). Ao término da infusão, aguardou-se 1 minuto antes de retirar a agulha de microinjeção para garantir a difusão total do volume administrado no VL (Figura 7). O fármaco DZP foi administrado por via i.p. nos animais do grupo controle positivo. 


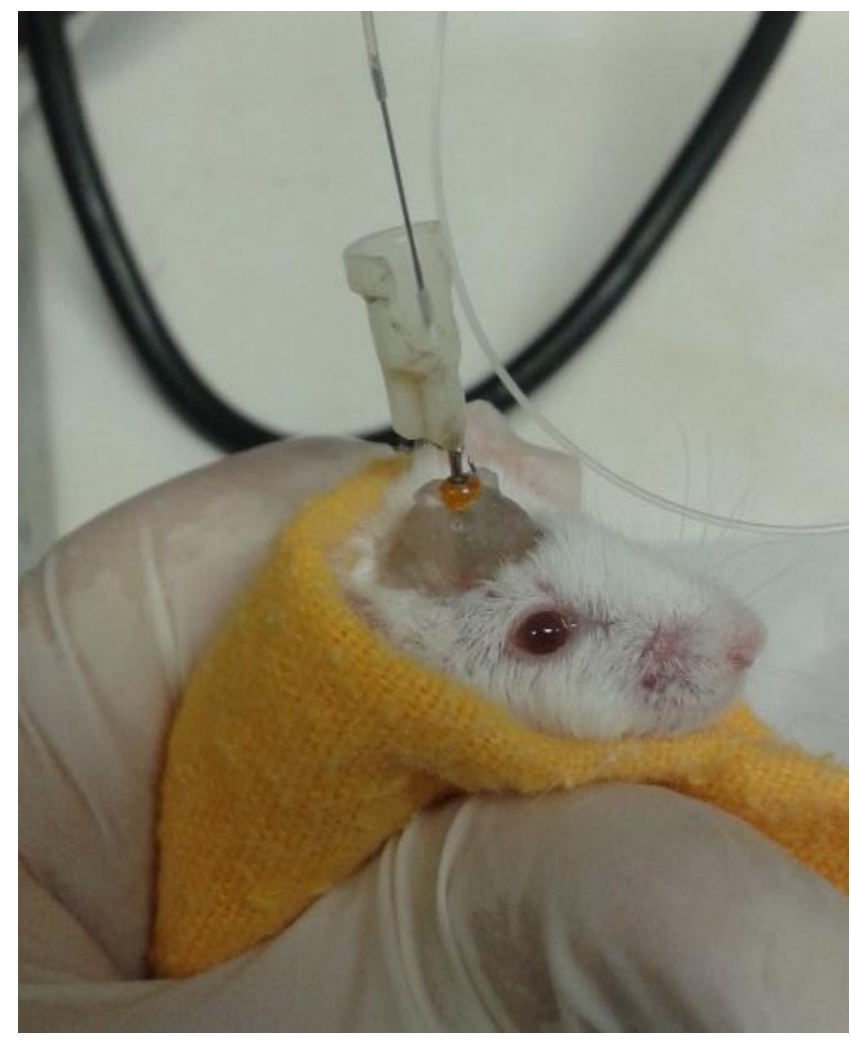

Figura 7. Camundongo recebendo o tratamento com o peptídeo Neuropolybina por via i.c.v. com o auxílio de uma microseringa acoplada a uma bomba de infusão.

\section{e. $\quad$ Monitoramento das crises recorrentes espontâneas}

O monitoramento das CRE dos sujeitos experimentais iniciou-se após o tratamento com o peptídeo, sempre às $8 \mathrm{~h}$, no biotério. Uma câmera gravadora de vídeo digital (Sony DCR-SR47, Brasil) foi instalada acima da caixa dos camundongos, a uma distância de aproximadamente $50 \mathrm{~cm}$, para registrar seus comportamentos durante $10 \mathrm{~h}$, gravando das 8:00 às 18:00 horas, diariamente. Sabe-se que o limiar de crises epilépticas em roedores é reduzido durante a fase de sono sendo, portanto, mais prováveis de ocorrer nesse período, ou seja, no período claro do dia (Arida et al., 1999; Buckmaster \& Haney, 2012). Os primeiros trinta minutos de filmagem foram descartados da análise, pois os camundongos estavam bastante ativos após o manuseio pelo experimentador e as horas seguintes foram monitoradas e os comportamentos de 
crise analisados (seguindo a escala de Racine, 1972, modificada por Shibley \& Smith, 2002), durante os cinco dias de tratamento subcrônico.

A quantificação total das CRE em cada grupo experimental foi realizada, sendo contabilizado o tempo total em que os sujeitos experimentais estiveram em crise (em segundos), o número de crises apresentadas e a categorização segundo a tabela 2 (classe 1 a 5) da crise máxima apresentada durante o período de monitoramento. Além disso, a quantificação também foi dividida temporalmente ao longo dos cinco dias de tratamento para julgar de forma mais precisa o efeito antiepiléptico do peptídeo Neuropolybina no período crônico do modelo. Para detectar um possível efeito da eliminação do peptídeo pelo organismo antes do fim do período de filmagem, a análise temporal também foi dividida em duas fases: pós, que correspondem às cinco primeiras horas de monitoramento após a administração do veículo ou tratamento e tardia, período correspondente das cinco às dez horas posteriores à administração do veículo ou tratamento nos animais.

\subsubsection{Avaliação dos padrões epileptiformes por Vídeo-EEG}

\section{a. Procedimento cirúrgico para a implantação dos eletrodos}

Com o objetivo de realizar registros amostrais da atividade epileptiforme, foi realizado um procedimento de implantação de eletrodos em duas montagens: referencial e bipolar. Os camundongos foram submetidos ao mesmo procedimento inicial de implantação da cânula, seguido da implantação dos eletrodos. Pares de três eletrodos foram implantados nos córtices cerebrais e um par com dois eletrodos foi implantado profundamente ao tecido encefálico (Figura 8). 


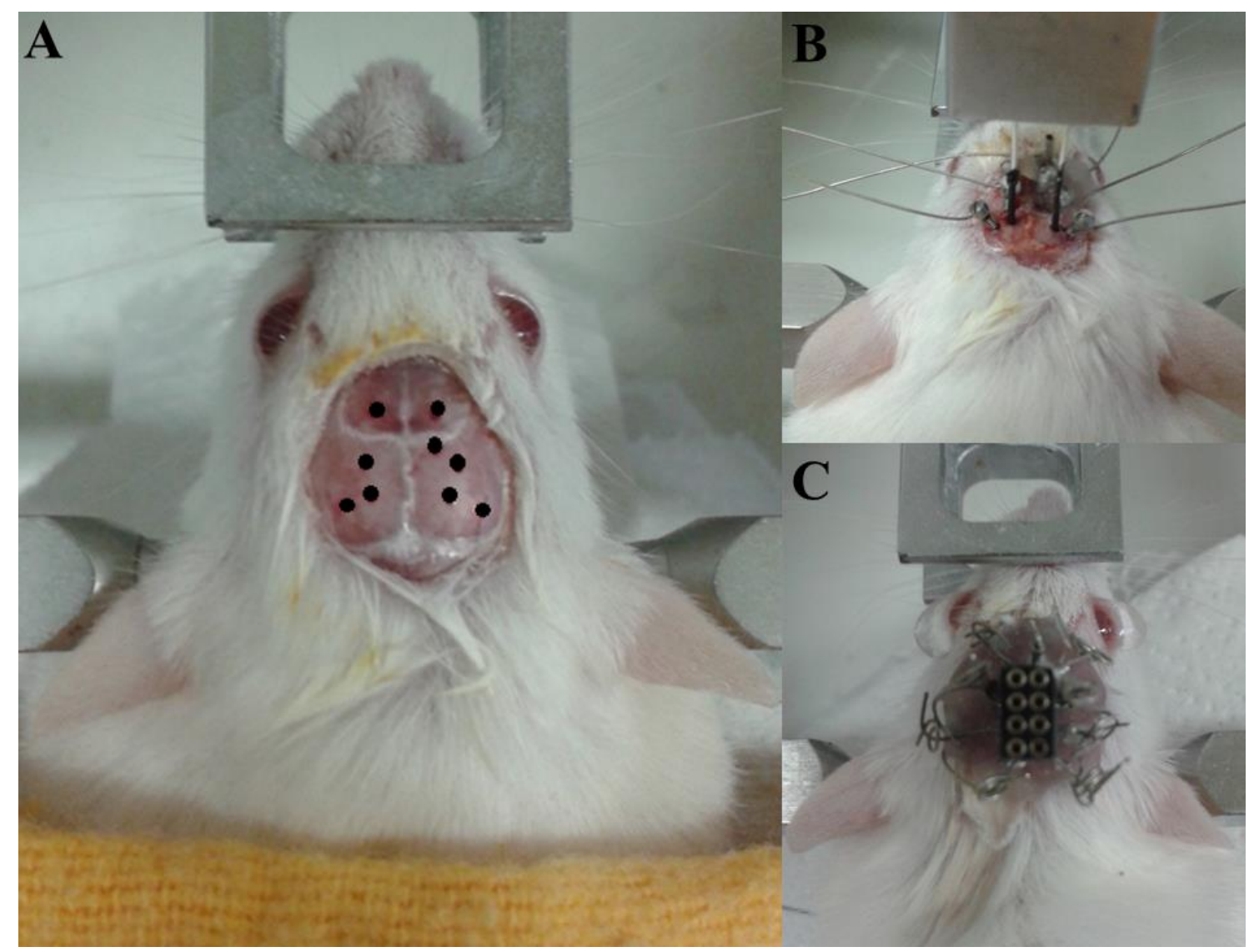

Figura 8. Etapas da implantação da cânula-guia e dos eletrodos para registro EEGs. (A) Superfície dorsal com os locais para as perfurações de cada eletrodo e a cânula marcados em preto. (B) Eletrodos e cânula implantados. (C) Conector acoplado aos eletrodos e selado com resina acrílica.

Os eletrodos corticais são formados por parafusos estéreis com fios condutores de $5 \mathrm{~cm}$ de comprimento (8403, Pinnacle Technologies, EUA) (Figura 9) e os eletrodos intrahipocampais são constituídos por fios de prata revestidos com material isolante (AGW1510, WPI - World Precision Instruments, EUA). Todos os fios dos parafusos e dos eletrodos intrahipocampais, ao fim do procedimento cirúrgico, foram acoplados aos oito pinos de um conector (8415-SM, Pinnacle Technologies, EUA) fixado acima do crânio do camundongo com resina acrílica. 


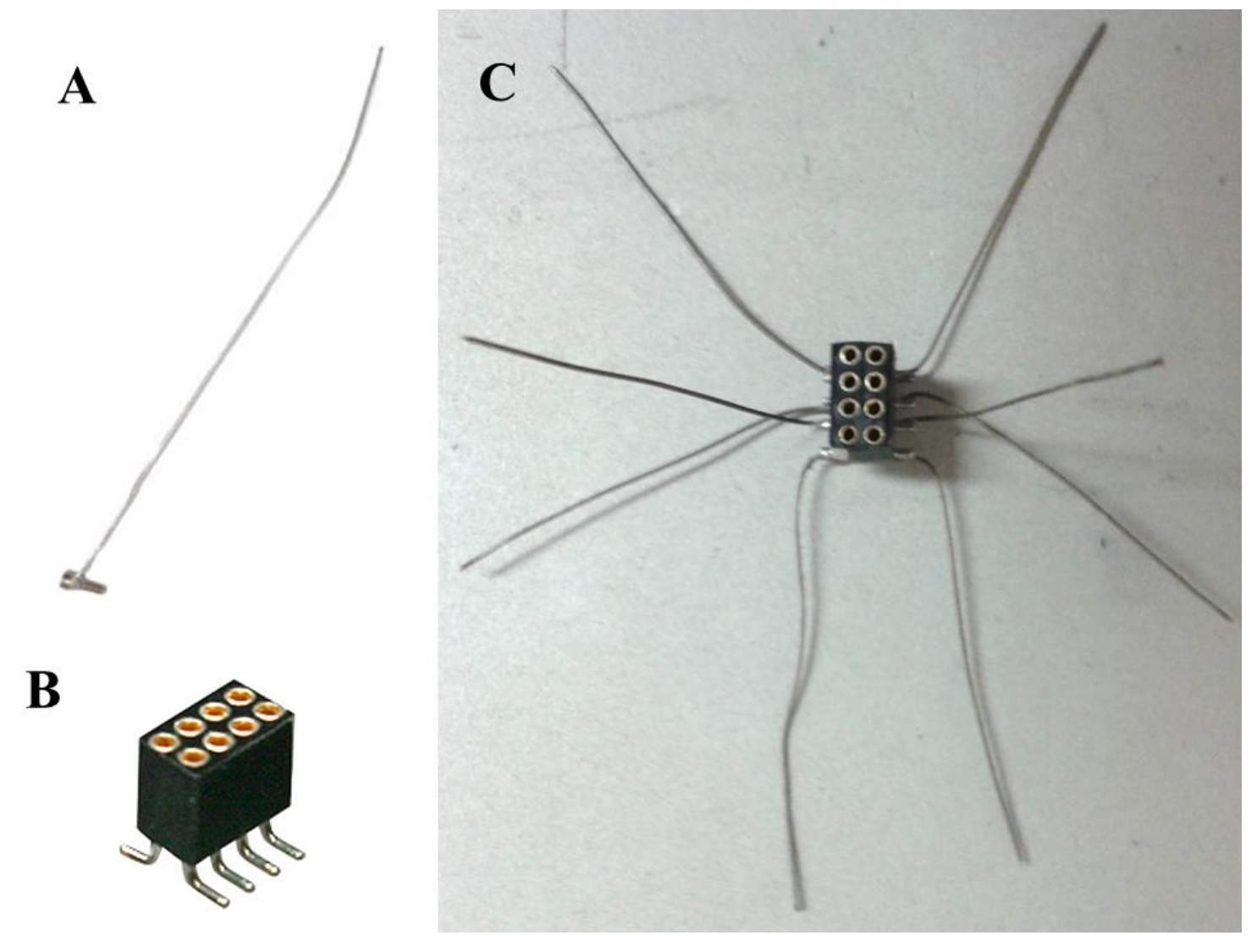

Figura 9. (A) Eletrodo. (B) Conector de oito pinos em $90^{\circ}$. (C) Conector com fios de prata soldados aos pinos para garantir melhor contato com os eletrodos. Esses componentes foram adquiridos da Pinnacle Technologies e utilizados na aquisição dos registros eletroencefalográficos.

As coordenadas de inserção dos eletrodos receberam os nomes de pontos frontais, pontos parietais e pontos occipitais, para fazerem referência aos pontos da montagem do Sistema Internacional 10-20 de eletroencefalografia em humanos. Os pontos frontais correspondem aos dois eletrodos posicionados no córtex motor primário, sendo um deles no hemisfério esquerdo, chamado de eletrodo referência (Shared/EEG Common) e o outro, no hemisfério direito, chamado de eletrodo terra (AGND), que é responsável por minimizar ruídos externos e de movimentação dos sujeitos experimentais. Os pontos parietais são os dois eletrodos no córtex somatossensorial primário e os pontos occipitais são os dois eletrodos no córtex visual primário, um em cada hemisfério respectivamente. Os eletrodos intrahipocampais foram posicionados no 
extrato de células piramidais da camada CA1 da formação hipocampal nos hemisférios direito e esquerdo, de acordo com as medidas de referência apresentadas na tabela 3. A figura 10 indica os locais para o posicionamento de cada eletrodo e da cânula-guia e um esquema do padrão de configuração do conector acoplado aos eletrodos de registro.

Tabela 3. Medidas de referência para o implante dos eletrodos corticais e intrahipocampais em camundongos segundo o Atlas Estereotáxico de Paxinos \& Franklin (2001).

\begin{tabular}{cccc} 
& Dorsoventral & Mesolateral & Anteroposterior \\
Frontais & - & $\pm 1,5 \mathrm{~mm}$ & $+1 \mathrm{~mm}$ \\
Parietais & - & $\pm 2 \mathrm{~mm}$ & $-1 \mathrm{~mm}$ \\
Intrahipocampais & $-1,3 \mathrm{~mm}$ & $-+1,8 \mathrm{~mm}$ & $-2,2 \mathrm{~mm}$ \\
Occipitais & - & $\pm 3 \mathrm{~mm}$ & $-3 \mathrm{~mm}$ \\
\hline
\end{tabular}

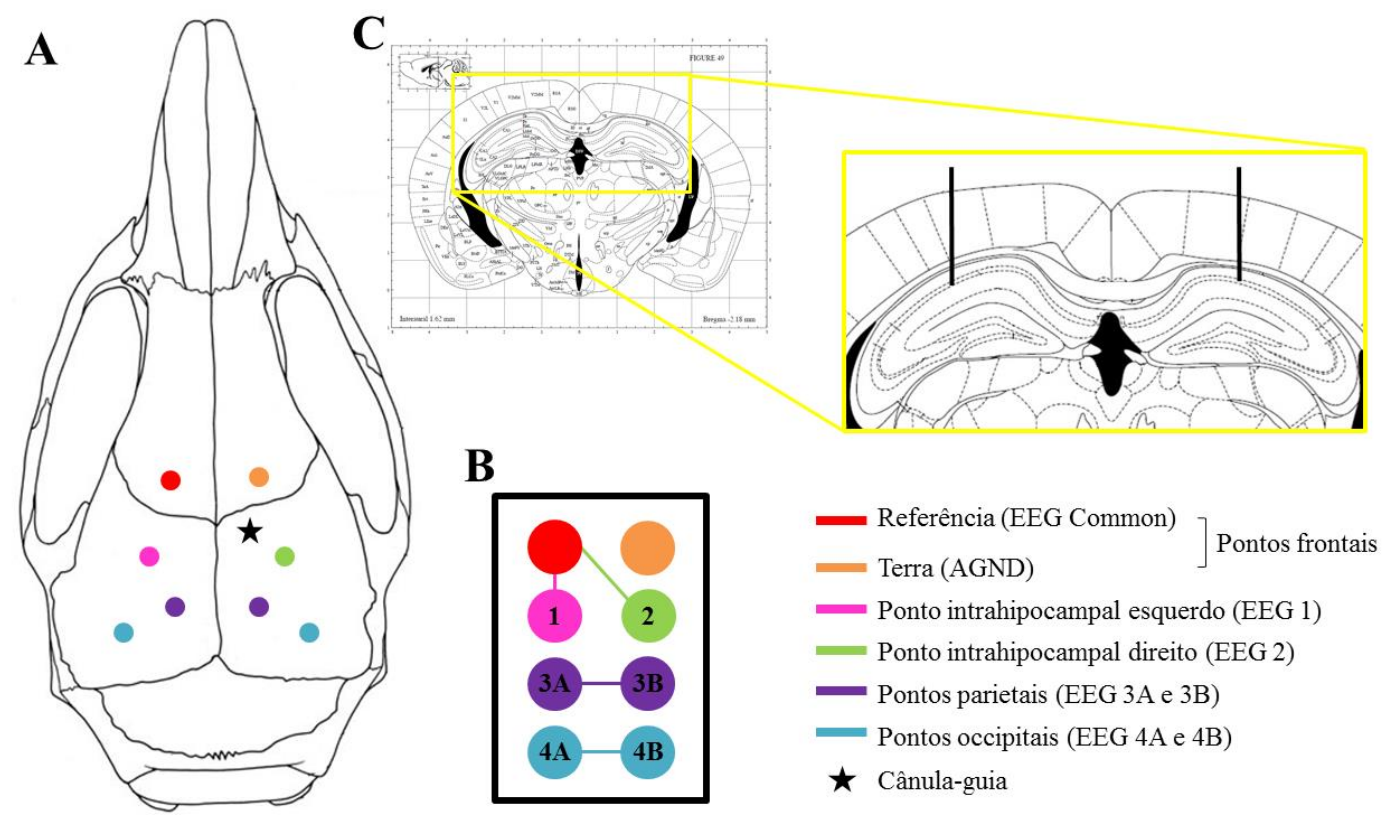

Figura 10. Representação esquemática do posicionamento dos eletrodos, da cânula-guia e do conector para os registros EEGs nos camundongos. (A) Superfície dorsal do crânio de um camundongo com os locais de implante dos eletrodos e da cânula indicados. (B) Padrão de configuração do conector acoplado ao sistema de registros EEGs. (C) Indicação do local de implantação dos eletrodos intrahipocampais nas CA1, modificada do Atlas Estereotáxico de Paxinos \& Franklin (2001). 


\section{b. Registros eletroencefalográficos e comportamentais}

Durante o período de tratamento (15-20 dias pós SE), foi realizado um monitoramento amostral de dois sujeitos experimentais de cada grupo (Sadio; Doente; Tratado com Neuropolybina - 3,75 nmol e DZP) por um sistema de registros por vídeoEEG (Pinnacle Technologies, EUA), que permite correlacionar o comportamento exibido pelo camundongo ao perfil eletroencefalográfico adquirido. $\mathrm{O}$ monitoramento das CRE foi realizado nas primeiras duas horas após a administração do tratamento com o veículo, o peptídeo Neuropolybina ou o fármaco DZP.

O registro de EEG foi coletado por meio de um conector associado a um cabo blindado (8413-M, Pinnacle Technologies, EUA). O cabo é conectado a um comutador elétrico (Swivel 8408, Pinnacle Technologies, EUA), que mantém o contato elétrico mesmo quando o camundongo efetua giros de $360^{\circ}$, garantindo a liberdade de movimento, sem restrições (Figura 11b). Os sinais são amplificados (100x) e filtrados no conector com quatro canais (8406-SE4, Pinnacle Technologies, EUA) na cabeça do camundongo, garantindo a entrega de dados livres de artefatos em uma taxa de amostragem de 200-2000 Hz para cada canal. O sistema de condicionamento e aquisição de dados 8401-HS amplifica secundariamente e filtra os dados antes de enviálos para o software Sirenia ${ }^{\circledR}$ (Pinnacle Technologies, EUA). Além disso, foi desenvolvida uma gaiola de Faraday (Figura 11a), que é colocada ao redor do sistema de cabos onde o camundongo permanece acoplado, para que os ruídos eletromagnéticos externos (principalmente, na frequência de $60 \mathrm{~Hz}$ ) sejam bloqueados e não interfiram na aquisição de dados. A figura 11 ilustra o sistema de aquisição e os seus componentes durante o registro da atividade elétrica cerebral de um camundongo em um dos experimentos realizados nesse trabalho. 


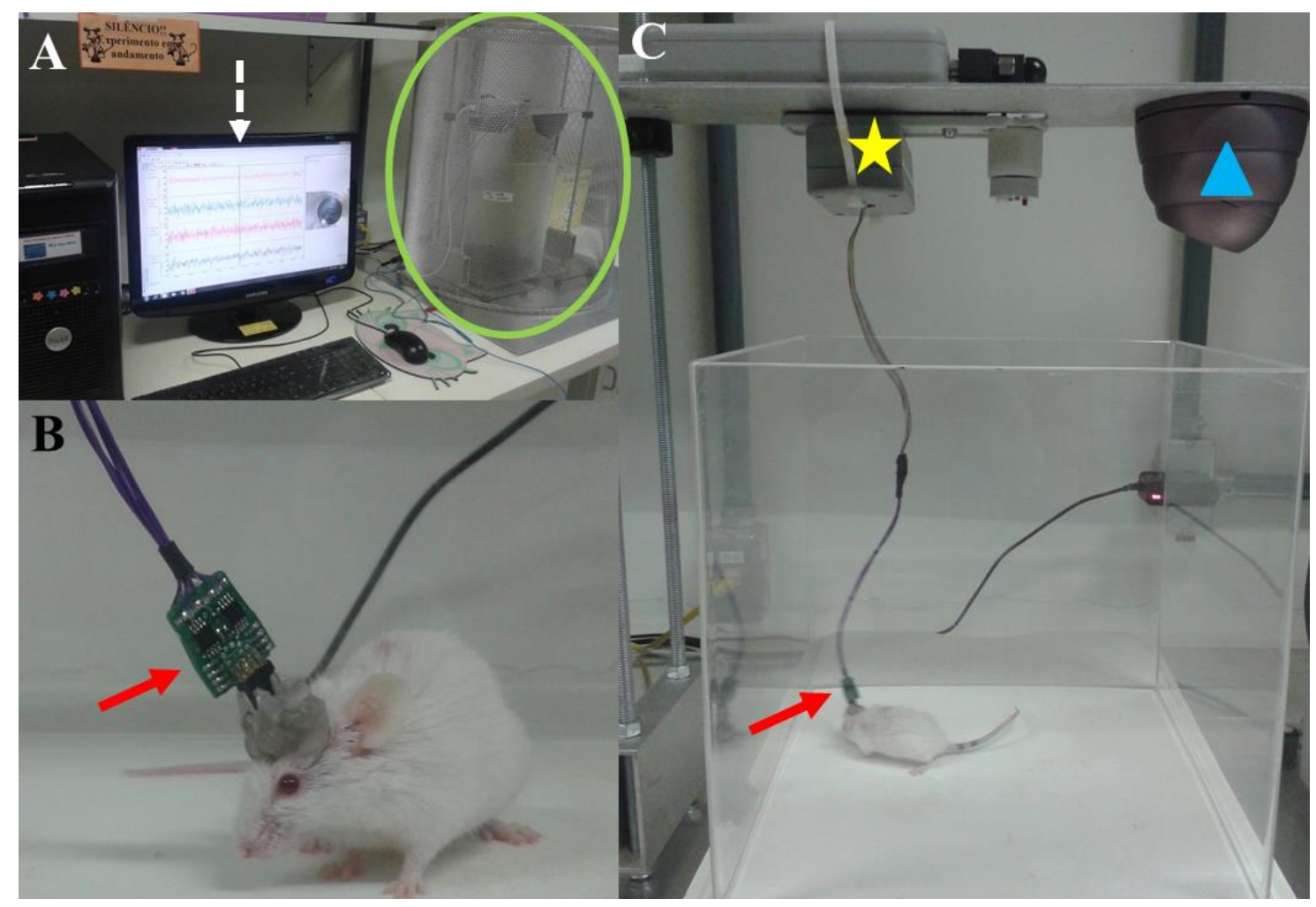

Figura 12. Sistema de registros eletroencefalográficos para camundongos. (A) Software Sirenia ${ }^{\circledR}$ recebendo os dados referentes à atividade elétrica do animal, recebida por quatro canais de aquisição (seta tracejada branca). O círculo verde evidencia a gaiola de Faraday que realiza a blindagem eletromagnética. (B) Camundongo acoplado ao conector (seta vermelha) que amplifica e filtra os sinais. (C) Animal sendo filmado com uma câmera digital (triângulo azul) e registrado pelo sistema de aquisição e condicionamento de dados que filtra e amplifica os sinais secundariamente (estrela amarela).

No início do experimento, o conector da cabeça do camundongo foi acoplado ao cabo com o cuidado para que as devidas conexões fossem realizadas. O software apresenta os dados dos quatro canais de aquisição. O registro de cada canal do eletroencefalograma é realizado tomando-se a diferença de potencial entre dois eletrodos (derivação). Portanto, os canais 1 e 2 apresentam as derivações dos pinos EEG 1 e EEG 2, conectados ao eletrodo intrahipocampal esquerdo e direito da montagem referencial e o pino EEG Common, conectado ao eletrodo de referência, respectivamente. Com os canais 3 e 4 , o registro é o resultado da derivação do lado esquerdo e o direito de cada ponto da montagem bipolar (Tabela 4). 
O filtro de alta frequência utilizado para realçar ou eliminar atividades de frequências mais altas sem afetar a atividade de frequência mais baixas foi de $1 \mathrm{~Hz}$, enquanto que o filtro de baixa frequência, usado para eliminar atividades de frequências mais baixas sem afetar as de frequência mais altas, foi de $40.000 \mathrm{~Hz}$.

Para a análise do padrão epileptiforme após os tratamentos, os primeiros 300 segundos de registro foram desconsiderados, pois os animais estavam agitados devido a manipulação do experimentador. Foram contabilizadas as latências para estabelecimento da primeira crise generalizada, quando os quatro canais de aquisição registraram um padrão ictal sincronizado de espículas agudizadas e com ondas de amplitude 10x maior que as ondas observadas na atividade basal. As latências para estabelecimento da primeira crise focal, observada em um ou dois canais de registro, também foram contabilizadas em um período amostral de 30 minutos para cada animal.

Tabela 4. Relação entre os eletrodos, os pinos conectores e os canais de registro do sistema de eletroencefalografia em camundongos.

\begin{tabular}{ccc} 
Ponto do eletrodo & Pino do conector & Canal \\
\hline Intrahipocampal esquerdo & EEG 1 & 1 \\
Intrahipocampal direito & EEG 2 & 2 \\
Parietais esquerdo e direito & EEG 3A e 3B & 3 \\
Occipitais esquerdo e direito & EEG 4A e 4B & 4 \\
\hline
\end{tabular}

\subsection{Análises histológicas}

As análises relacionadas à citoarquitetura da formação hipocampal dos sujeitos experimentais submetidos aos subtratamentos foram realizadas após a eutanásia, perfusão transcardial e retirada do tecido encefálico. Os encéfalos passaram por etapas de fixação e crioproteção antes de serem seccionados para a produção de lâminas 
histológicas que foram submetidas às técnicas de coloração de Nissl e de imunohistoquímica/imunofluorescência (IHQ/IF).

A técnica de coloração de Nissl foi utilizada para evidenciar a presença de neurônios nas regiões de interesse, uma vez que o corante concentra-se especificamente na substância de Nissl, material granular presente no interior dos neurônios. A técnica de IHQ/IF foi utilizada para evidenciar a marcação fluorescente de GFAP, expressas exclusivamente em astrócitos no SNC. Mais detalhes de cada etapa estão descritos nos subtópicos a seguir.

\subsubsection{Perfusão transcardial}

Os sujeitos experimentais foram submetidos à anestesia profunda com tiopental sódico (60 mg. $\mathrm{kg}^{-1}$, i.p.; Cristália, Brasil) 24 horas após o término dos ensaios, ou seja, no $20^{\circ}$ dia de experimento. Subsequentemente à anestesia, a caixa toráxica foi aberta e o coração exposto para a realização da perfusão transcardial. O ventrículo esquerdo cardíaco recebeu um influxo de solução tampão fosfato de sódio (PBS; diluído em água destilada; apêndice A), seguido por solução fixadora de formaldeído a 4\% (diluído em PBS; Vetec, Brasil), drenados através de uma secção do átrio direito. O volume de cada solução infundida foi de $10 \mathrm{~mL}$, em um período de $5 \mathrm{~min}$.

\subsubsection{Fixação}

Após o procedimento de perfusão, os encéfalos dos sujeitos experimentais foram extraídos da caixa craniana e refixados em formaldeído a $4 \%$ por um período de $48 \mathrm{~h}$ e armazenados a $4^{\circ} \mathrm{C}$. Subsequentemente, os encéfalos foram armazenados em solução desidratante de sacarose a 30\% (diluída em PBS; Sigma-Aldrich ${ }^{\circledR}$, EUA) a $4^{\circ} \mathrm{C}$ por $48 \mathrm{~h}$, a fim de prevenir perda da citoarquitetura do tecido encefálico (crioproteção).

\subsubsection{Secção do tecido cerebral}


Após o período de incubação, os encéfalos foram seccionados horizontalmente em $50 \mu \mathrm{m}$ de espessura cada fatia em solução de sacarose a 30\%, com o auxílio de um vibrátomo (KD-400 Vibration Microtome, Zhejiang Jinhua Kedi Instrumental, China) conforme a figura 12 .

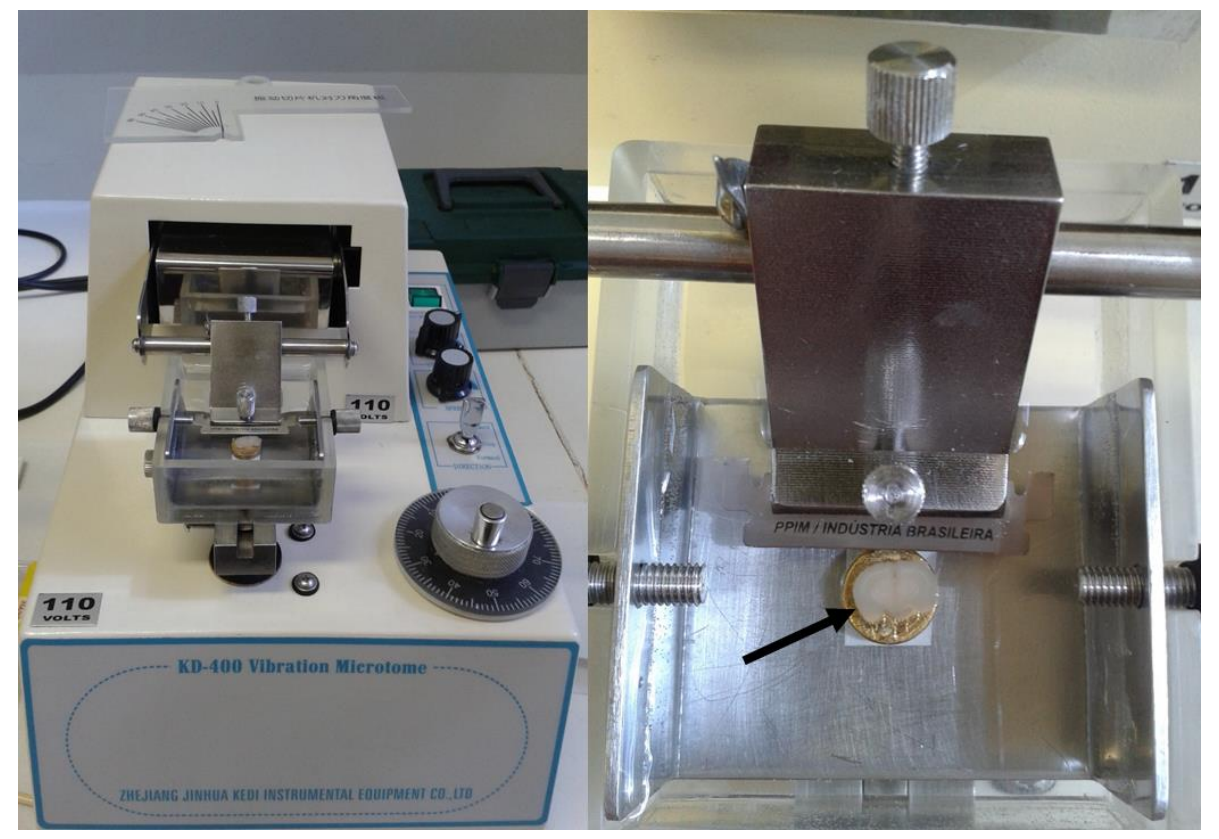

Figura 12. Vibrátomo utilizado para a secção dos encéfalos (seta preta) dos animais experimentais.

As regiões de interesse foram seccionadas segundo referências do Atlas Estereotáxico de Paxinos \& Franklin (2001): secções entre -0,02 e -0,34 mm (Figura 13) no sentido ântero-posterior a partir do bregma para o ventrículo lateral e secções entre 1,7 e $-2,7$ mm (Figura 14), para a formação hipocampal. Foram feitos cortes de referência no lado direito de cada encéfalo para posterior identificação da lateralidade da formação hipocampal durante as análises. As secções foram armazenadas em placas de 24 poços, em solução anti-congelante a $4^{\circ} \mathrm{C}$ até a montagem das lâminas. 


\subsubsection{Montagem das lâminas}

Os cortes de tecido encefálico foram distendidos em lâminas de vidro (Exacta, Brasil) previamente gelatinizadas com solução de gelatina (Vetec, Brasil) e cromosulfato de potássio (Carlo Erba Reagents, França) para serem submetidas à coloração de Nissl e em lâminas silanizadas StarFrost ${ }^{\circledR}$ (Knittel Glass, Alemanha) para serem submetidas às técnicas de IHQ/IF. Para a coloração de Nissl, foi confeccionada uma lâmina com cinco secções da formação hipocampal e uma lâmina com três secções do VL de cada animal e para a IHQ/IF foi produzida uma lâmina com cinco secções da formação hipocampal de cada animal experimental.

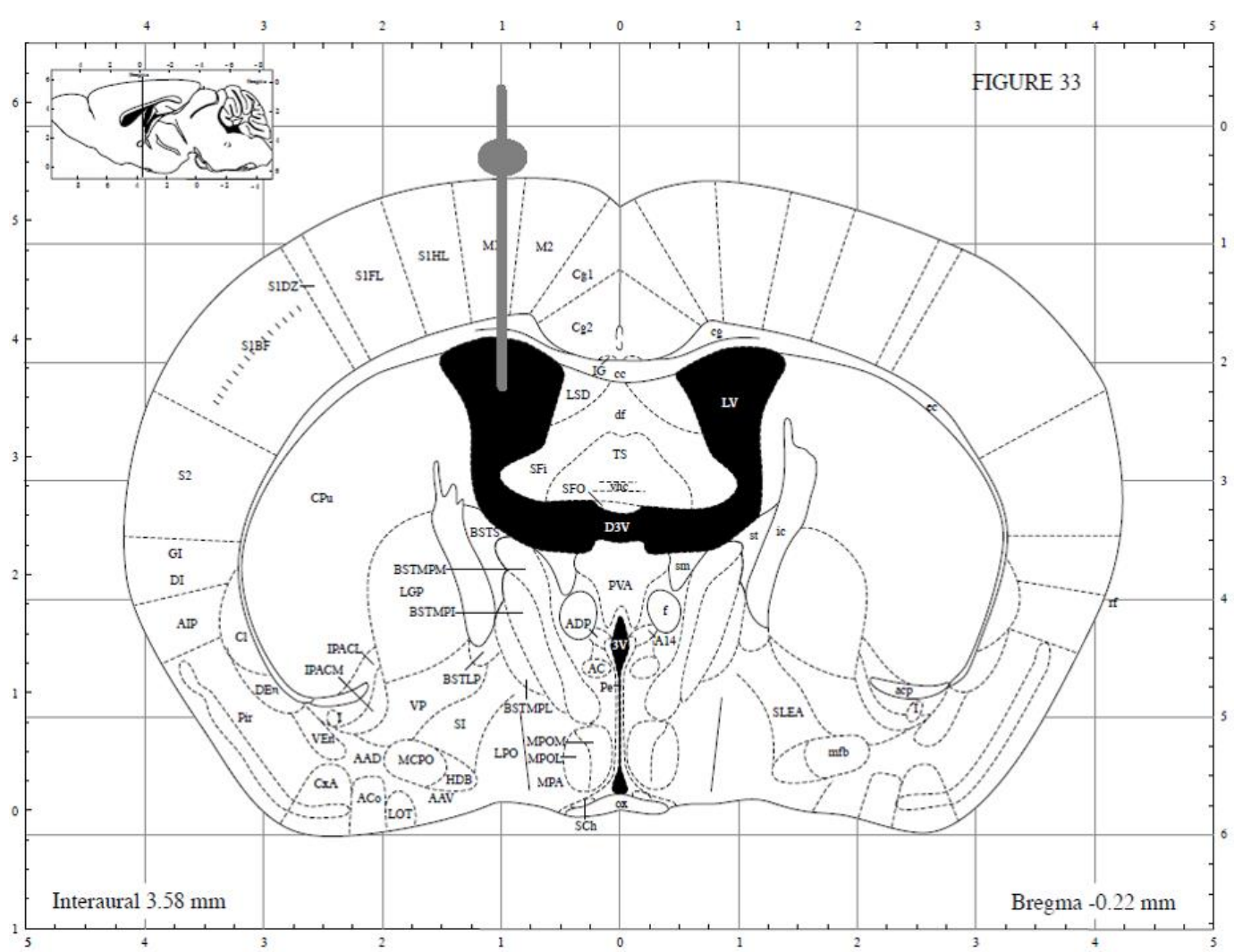

Figura 13. Prancha que evidencia o ventrículo lateral de camundongos marcado em preto com a cânula posicionada no ventrículo lateral direito, modificada do Atlas Estereotáxico de Paxinos \& Franklin (2001). 


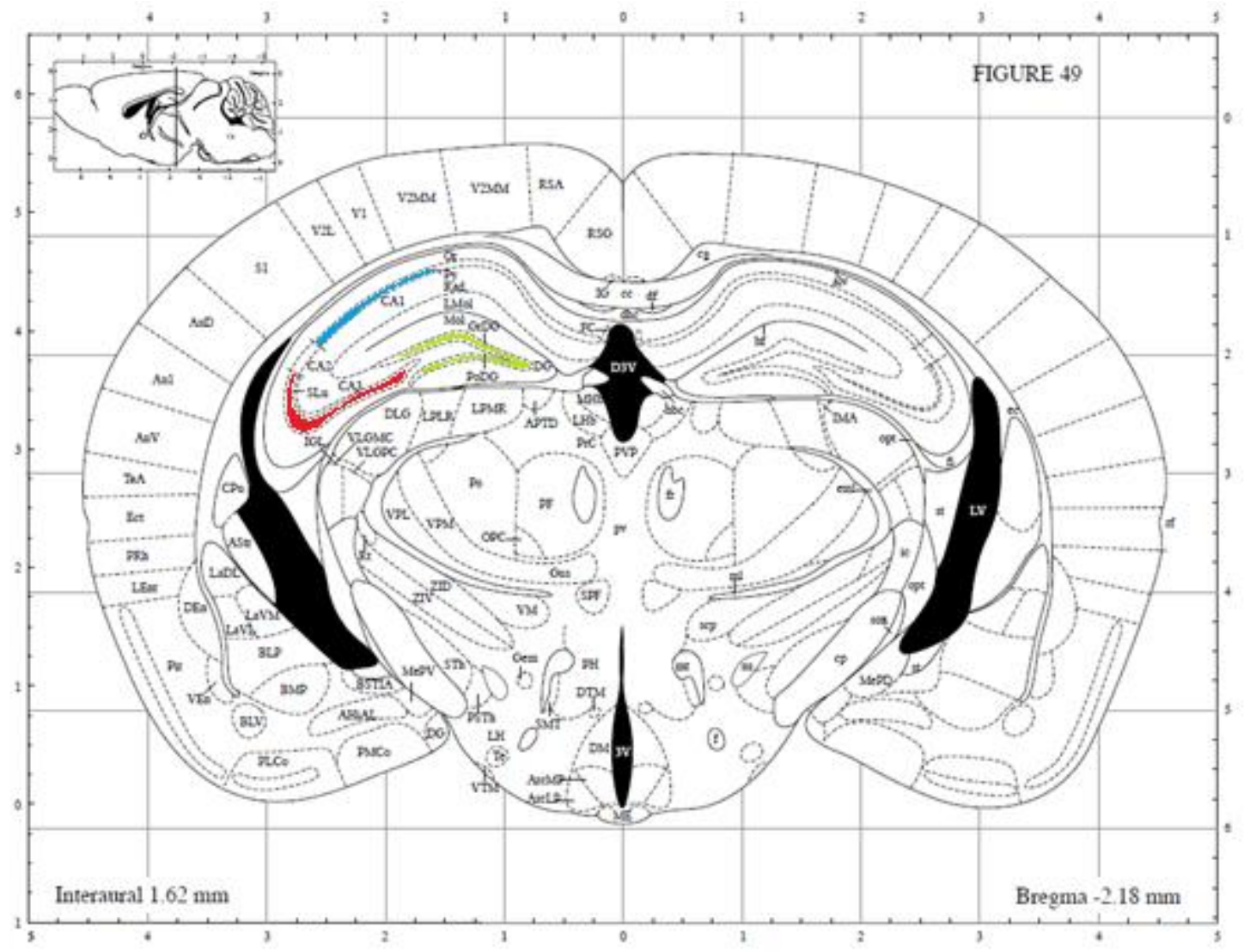

Figura 14. Secção coronal representativa da formação hipocampal de camundongos, modificado do Atlas Estereotáxico de Paxinos \& Franklin (2001). A região azul correponde à camada de células piramidais de CA1, a região vermelha, de CA3 e a região verde corresponde à camada de células granulares do giro denteado.

\subsubsection{Coloração de Nissl}

Para a técnica de coloração de Nissl, o corante que oferece melhores resultados ao evidenciar a substância de Nissl é o violeta de cresila, o mesmo utilizado neste trabalho. Ele se concentra na substância de Nissl, estrutura muito abundante em células neuronais, pois é composta por RNA ribossomal associado ao retículo endoplasmático rugoso no corpo celular e dendritos dos neurônios. Em neurônios lesados e em regeneração, a substância de Nissl se rompe e se redistribui pela periferia do corpo celular, processo chamado de cromatólise. Essa técnica foi utilizada para a visualização dos ventrículos laterais dos animais, para constatação do posicionamento da cânula-guia 
de administração e para visualização dos núcleos neuronais dos extratos piramidais das regiões CA1, CA3 e do hilus do giro denteado, tornando possível a estimativa da densidade de células neuronais.

As lâminas com os cortes de tecido encefálico referentes à região da formação hipocampal e do ventrículo lateral foram secas em estufa a $58^{\circ} \mathrm{C}$ por 30 minutos para serem submetidas à técnica histológica de coloração de Nissl. As lâminas foram colocadas em um suporte de plástico acetal e submersas na cuba com água destilada por três vezes, sendo depois recobertas com a solução do corante de Nissl (Acetato de cresil violeta; Sigma-Aldrich ${ }^{\circledR}$, Brasil; apêndice B) por 30 minutos. Na sequência, as lâminas foram lavadas cinco vezes em água destilada para a retirada do excesso de corante e imersas em solução de álcool etílico (Vetec, Brasil) de 50 e $70 \%$ por cinco vezes cada. Em seguida, foram imersas rapidamente em uma solução diferenciadora (1 mL de ácido acético em $100 \mathrm{~mL}$ de álcool etílico absoluto), sendo depois recobertas com soluções de etanol a 70, 96 e 100\% (v/v, em água destilada) por 1 minuto cada. Subsequentemente, os cortes foram imersos em solução de xilol (Dinâmica ${ }^{\circledR}$, Brasil) duas vezes sendo que cada passo durou 1 minuto. Ao final, as lâminas com os cortes foram recobertas com lamínula de vidro (Exacta, Brasil), sendo utilizado Entellan ${ }^{\circledR}\left(\operatorname{Merck}_{K} G a A^{\odot}\right.$, Alemanha) como meio de montagem.

\subsubsection{Imunohistoquímica e imunofluorescência}

Para a técnica de imunohistoquímica e imunofluorescência foi utilizado um anticorpo que se liga à GFAP e um corante específico para material genético (DNA e RNA). Após o SE induzido por pilo, ocorre uma intensa astrogliose, ou seja, um aumento no número de astrócitos devido à morte de neurônios causada pela lesão da formação hipocampal. Essa técnica foi utilizada para visualizar essas células gliais, tornando possível sua estimativa nas regiões da CA1, CA3 e hilus do giro denteado. 
As lâminas com os cortes de tecido encefálico foram colocadas em um suporte de plástico acetal e submersas em cubas com PBS por dez minutos, por duas vezes. Para a etapa de permeabilização dos tecidos, as lâminas foram submersas em solução PBST 0,8\% (PBS + Triton $^{\circledR}$ X-100, Sigma-Aldrich ${ }^{\circledR}$, Brasil) por uma hora. O Triton ${ }^{\circledR}$ X-100 é um detergente que rompe as membranas plasmáticas para possibilitar a ligação dos anticorpos às proteínas específicas.

Em seguida, as lâminas foram lavadas em PBS por cinco minutos, três vezes e submersas em solução de bloqueio de ligações não específicas (gelatina de peixe 0,5\% NutraWay ${ }^{\circledR}$, Brasil + glicina 0,3 M, Dinâmica ${ }^{\circledR}$, Brasil, solubilizadas em PBS) por uma hora. A adição de glicina nessa etapa tem o objetivo de diminuir a autofluorescência adquirida pela incubação em formaldeído no período de fixação dos tecidos.

Na sequência, as lâminas foram lavadas em PBS novamente por cinco minutos, três vezes e incubadas com o anticorpo anti-GFAP conjugado para astrócitos, 1:1000 (ab49874, Abcam $^{\circledR}$, EUA) diluído em protein block (leite desnatado 10\% Molico ${ }^{\circledR}$, Nestlé, Brasil + BSA 1\% Fresenius Hemocare, Brasil + glicina 0,3 M + PBS). O anticorpo foi pipetado em cima de cada fatia $(150 \mu \mathrm{L})$, mantida em agitação suave, no escuro, a $22^{\circ} \mathrm{C}$ por uma hora. Após a incubação do anticorpo, as lâminas foram lavadas em PBS por cinco minutos, três vezes.

Ao final, uma gota do corante DAPI (Fluoroshield Mounting Medium With DAPI, ab104139, Abcam ${ }^{\circledR}$, EUA) foi colocada sobre cada fatia para a marcação do material genético nos núcleos das células e após 5 minutos, as lâminas foram recobertas com lamínula de vidro.

Como controle da especificidade de ligação, secções foram submetidas ao mesmo protocolo com a omissão do anticorpo anti-GFAP. 


\subsubsection{Produção de imagens para análise}

As análises das secções de tecido encefálico foram realizadas após a produção de imagens utilizando uma câmera digital (DFC310 FX, Leica Microsytems, Alemanha) conectada a um microscópio de epifluorescência (DM 2000, Leica Microsystems, Alemanha) e a um computador (Figura 15). O software Leica Application Suite - LAS (Leica Microsystems, Alemanha) foi utilizado na produção das imagens.

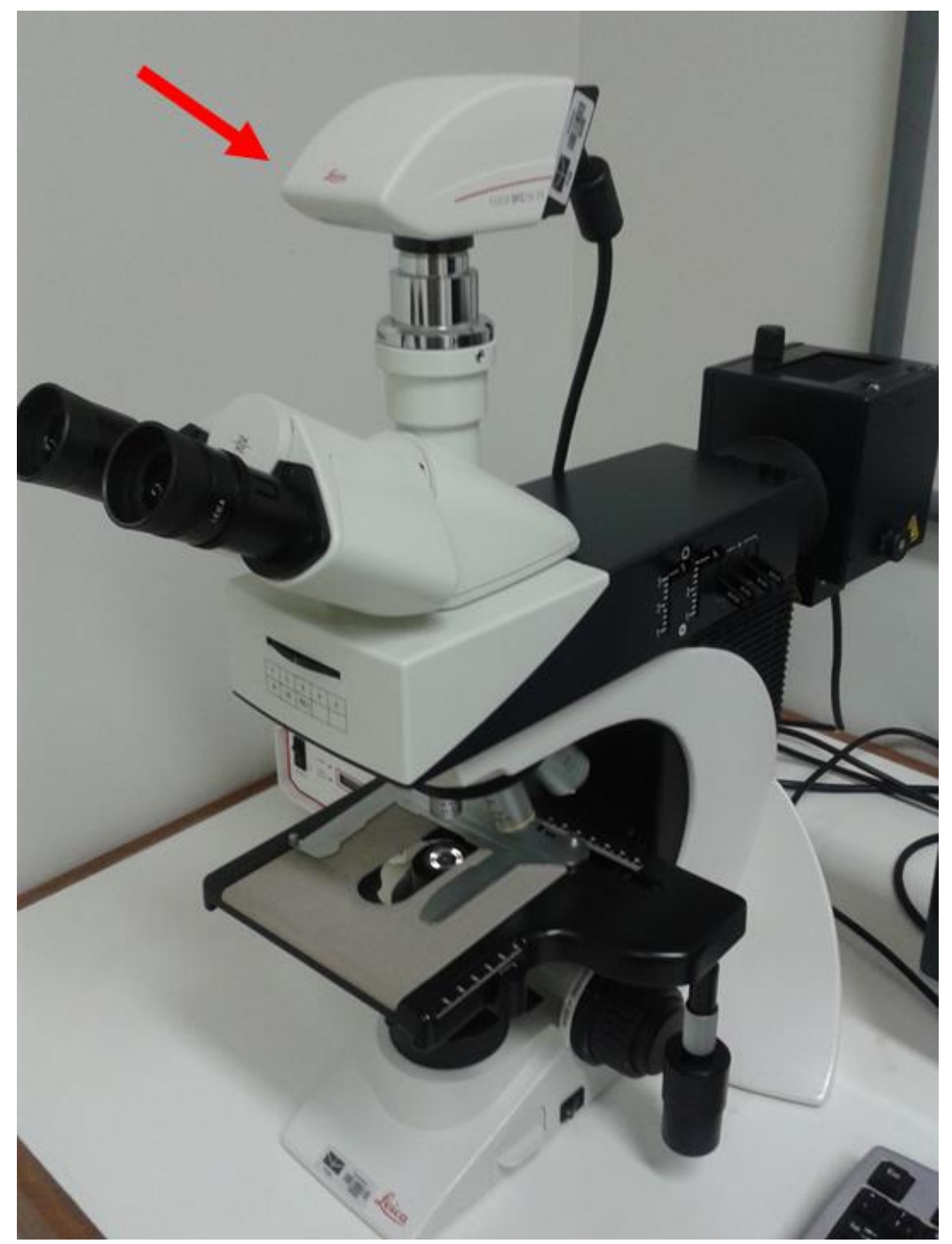

Figura 15. Microscópio de epifluorescência conectado a uma câmera digital (seta vermelha). As imagens foram produzidas com o auxílio do software LAS (Leica Microsystems, Alemanha). 


\section{a. Análise do posicionamento da cânula}

Para considerar os sujeitos experimentais que estavam com a cânula-guia posicionada corretamente no VL e que receberam a administração dos compostos na região de interesse, foram produzidas imagens utilizando uma lente objetiva com aumento de $4 \mathrm{x}$.

\section{b. Análise semiquantitativa do dano neural}

Para a análise semiquantitativa do dano neural, foram capturadas sete imagens de regiões delimitadas da camada de células piramidais das regiões CA1, CA3 e células granulares do GD para cada lado da formação hipocampal de cada camundongo (aumento de 200x para as camadas CA1 e CA3 e o para o GD foi utilizado o aumento de 400x), segundo o esquema ilustrado na figura 16.

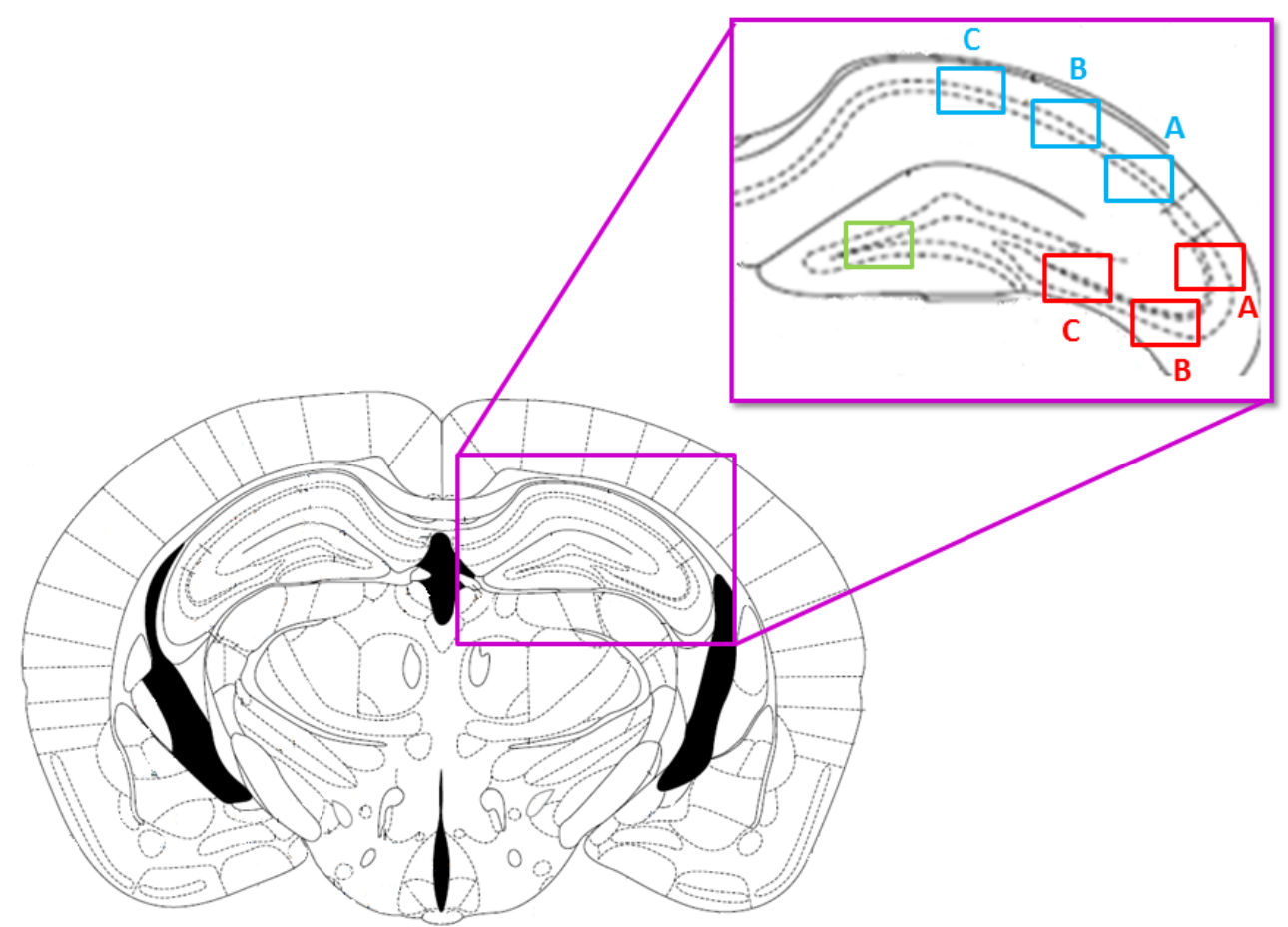

Figura 16. Representação esquemática das imagens obtidas para análise do dano neuronal, modificada do Atlas Estereotáxico de Paxinos \& Franklin (2001). O extrato piramidal de CA1 está delimitado pelos quadrados azuis, CA3 pelos vermelhos e a camada de células granulares do hilus do giro denteado está no quadrado verde. 
A diferença de densidade óptica foi medida com auxílio do software ImageJ (National Institute of Health - NIH, EUA), e calculada a partir da fórmula a seguir:

$$
\log _{10} \frac{255}{(255-V C)}
$$

Onde VC é o valor de cinza dado por:

$$
D O_{\text {área }}-D O_{\text {fundo }}
$$

Onde $\mathrm{DO}_{\text {área }}$ é a medida de densidade óptica de uma região delimitada do extrato celular calculada pelo software e $\mathrm{DO}_{\text {fundo }}$ é a densidade de uma região fora do extrato celular (Sestito et al., 2011).

\section{c. Análise quantitativa de astrogliose}

Para a análise quantitativa de astrogliose, foram capturadas sete imagens de regiões delimitadas da camada de células piramidais das regiões CA1, CA3 e células granulares do GD para cada lado da formação hipocampal de cada animal (nos mesmos aumentos para cada região conforme citado anteriormente). Foram utilizados dois cubos diferentes de fluorescência, o A para a visualização da fluorescência azul do DAPI, que excita em comprimentos de $360 \mathrm{~nm}$ e emite em comprimentos de $460 \mathrm{~nm}$ e o cubo N2.1, para a visualização da fluorescência vermelha do anti-GFAP conjugado ao fluoróforo $\mathrm{Cy} 3^{\circledR}$, que excita em $552 \mathrm{~nm}$ e emite em $565 \mathrm{~nm}$.

A contagem de astrócitos corados foi realizada manualmente com auxílio do software ImageJ (National Institute of Health - NIH, EUA).

Na figura 17 é apresentado um resumo de todas as etapas da metodologia seguida para a realização do presente trabalho. 


\subsection{Análises estatísticas}

Os resultados foram analisados com o auxílio do software GraphPad Prism® 6.0 para Mac (San Diego, EUA). Os dados foram submetidos à análise de distribuição normal (Shapiro-Wilk, Kolmogorov-Smirnov e D'Agostino \& Pearson). Para a caracterização da duração das CRE foi utilizado o teste estatístico ANOVA de uma via, seguido do pós-teste Tukey para distribuições normais de variâncias semelhantes, considerando-se $\mathrm{p}<0,05$. Para a análise do grau de severidade das CRE, do número de CRE apresentadas pelos sujeitos experimentais e para a caracterização da latência das crises eletroencefalográficas focais e generalizadas foi utilizado o teste Kruskal-Wallis, seguido do pós-teste Dunn.

Os valores obtidos a partir das medidas de densidade óptica e da contagem de astrócitos das lâminas histológicas foram submetidos à ANOVA de uma via, seguido do pós-teste Tukey para comparação entre os grupos. 


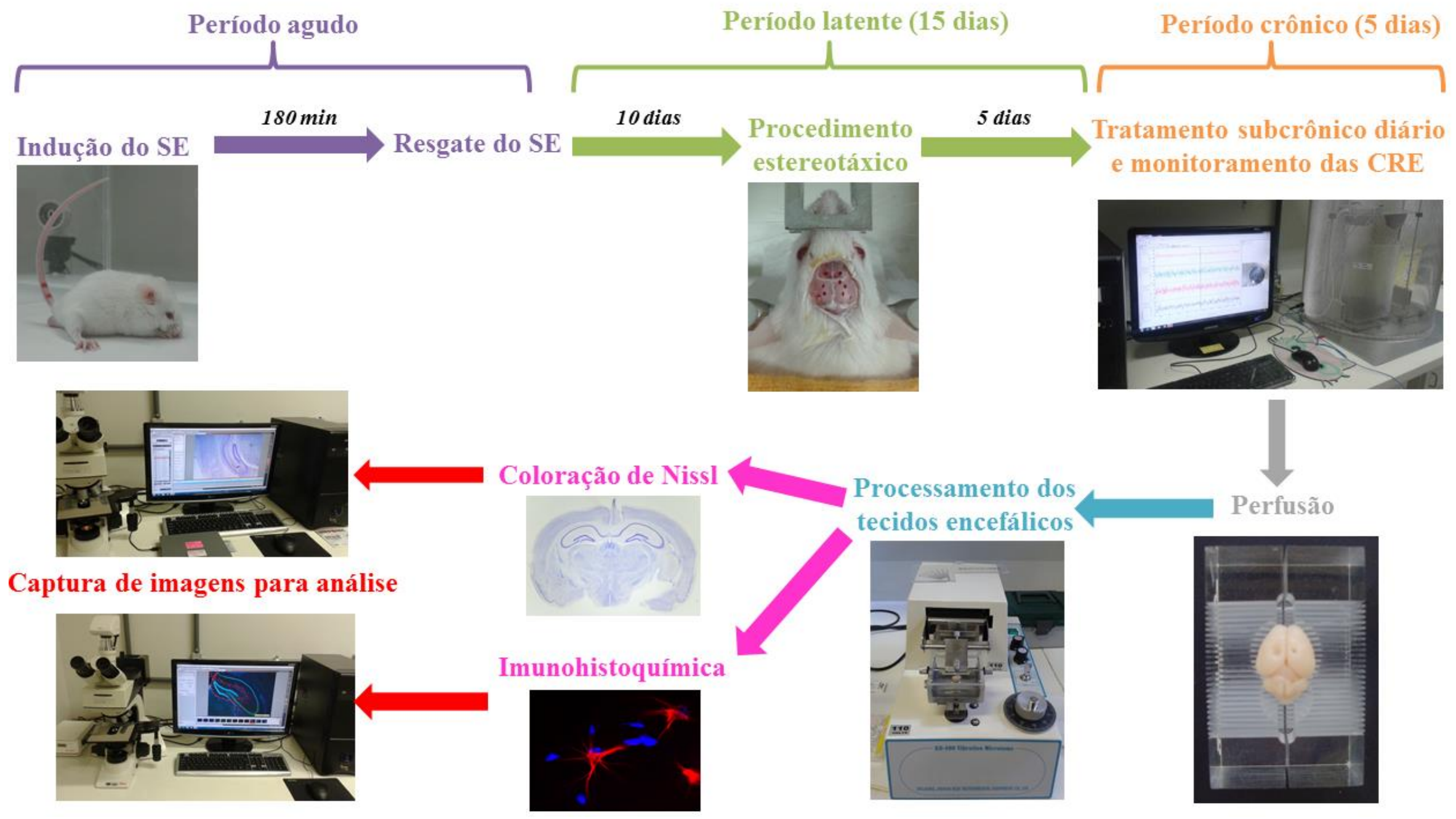

Figura 17. Fluxograma ilustrando toda a metodologia empregada para a realização desse trabalho. 
RESULTADOS 


\section{RESULTADOS}

\subsection{O peptídeo Neuropolybina}

O peptídeo Neuropolybina (Figura 18), sintetizado com base na sequência do composto Ppnp7 encontrado na peçonha da vespa social Polybia paulista (Couto et al., 2012a), só foi utilizado nos experimentos após ter sua massa molecular, grau de pureza e sequência de aminoácidos confirmados por espectrometria de massas MALDITOF/TOF e sequenciamento De Novo. A cada seis meses, as análises mostraram que o grau de pureza, a massa molecular (1203,6 Da) e a sequência do peptídeo (Pyr-Gln-TrpGln-Pro-Gln-Leu-His-Arg-OH) se mantiveram estáveis, conforme os espectros das figuras 19 e 20.

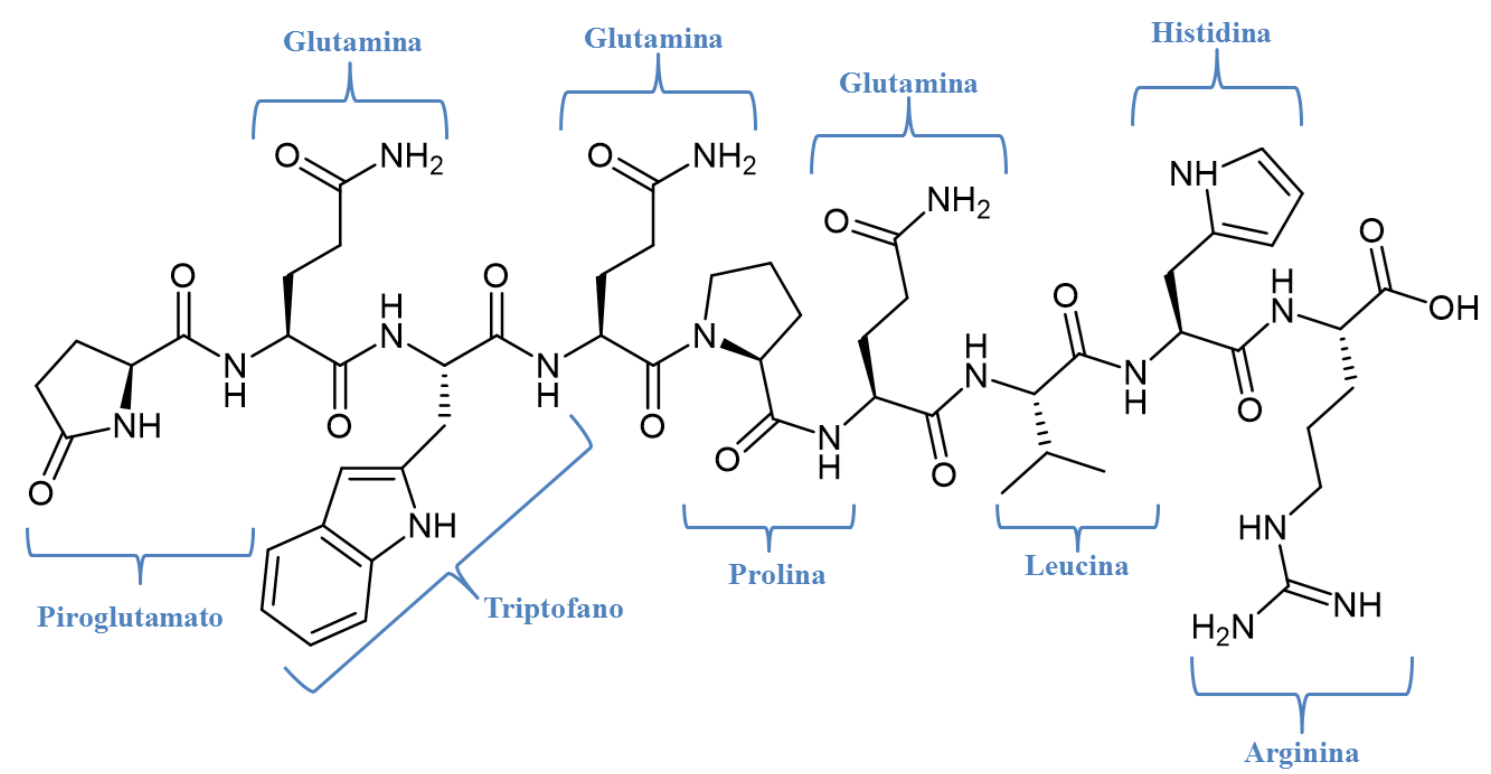

Figura 18. Representação da estrutura linear do peptídeo Neuropolybina, com cada um dos nove aminoácidos que o constitui indicados em azul. 


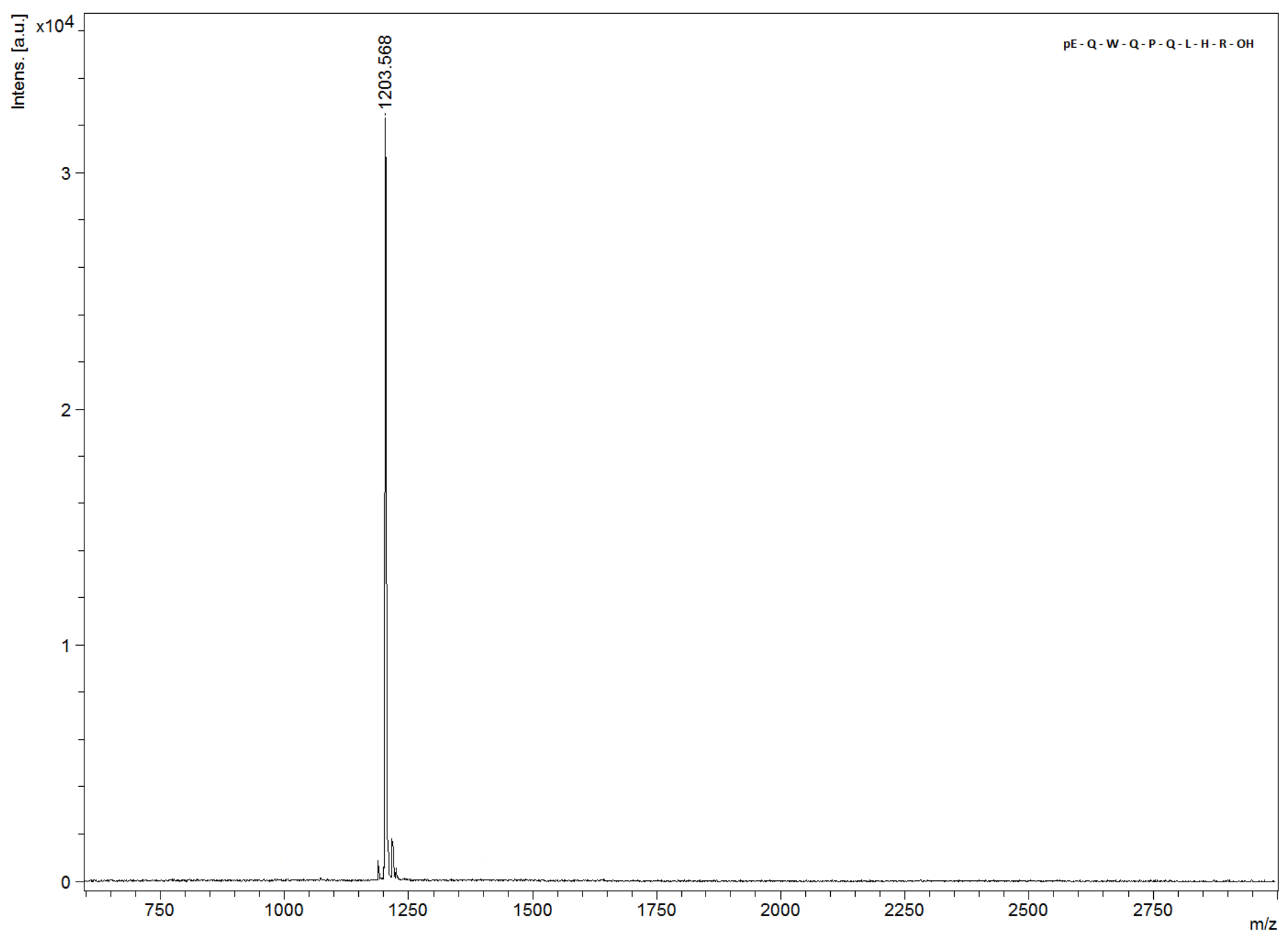

Figura 19. Perfil do espectro de massas MALDI-TOF/TOF do peptídeo Neuropolybina para confirmação da massa monoisotópica $[\mathrm{M}+\mathrm{H}]^{+}$, mostrando o alto grau de pureza do composto referente ao pico de m/z 1203,568 Da. 


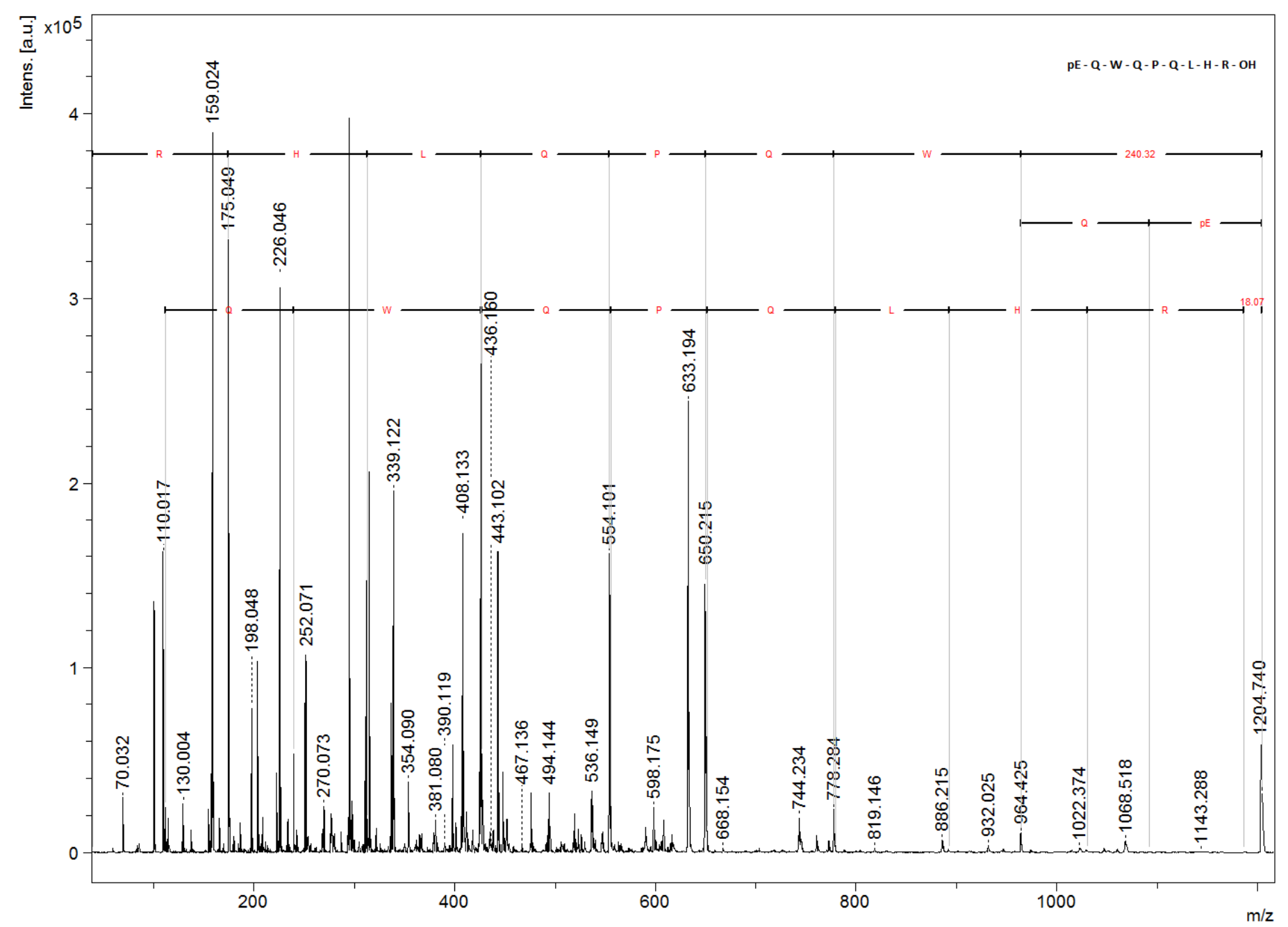

Figura 20. Espectro do sequenciamento De Novo do peptídeo Neuropolybina obtido por espectrometria de massas MALDI-TOF/TOF. Em vermelho, os resíduos de aminoácidos após a fragmentação, que constituem a séries b e y-íons. 


\subsection{Número de animais utilizados}

Foram utilizados nesse estudo, 65 camundongos, dos quais 19 (29,2 \%) desenvolveram o SE e vieram à óbito, $3(4,6 \%)$ desenvolveram o SE mas morreram durante a cirurgia de implantação da cânula-guia, 3 (4,6 \%) desenvolveram o SE, sobreviveram após a cirurgia, mas perderam o capacete no último dia de tratamento e foram descartados das análises, 2 (3,1\%) estavam com as cânulas-guia posicionadas incorretamente e também foram descartados das análises e, por último, $38(58,5 \%)$ desenvolveram o SE, sobreviveram e estavam com as cânulas corretas (Figura 21), sendo, portanto, considerados neste estudo. Não foram observados camundongos que não apresentaram SE ou que o cessaram espontaneamente.

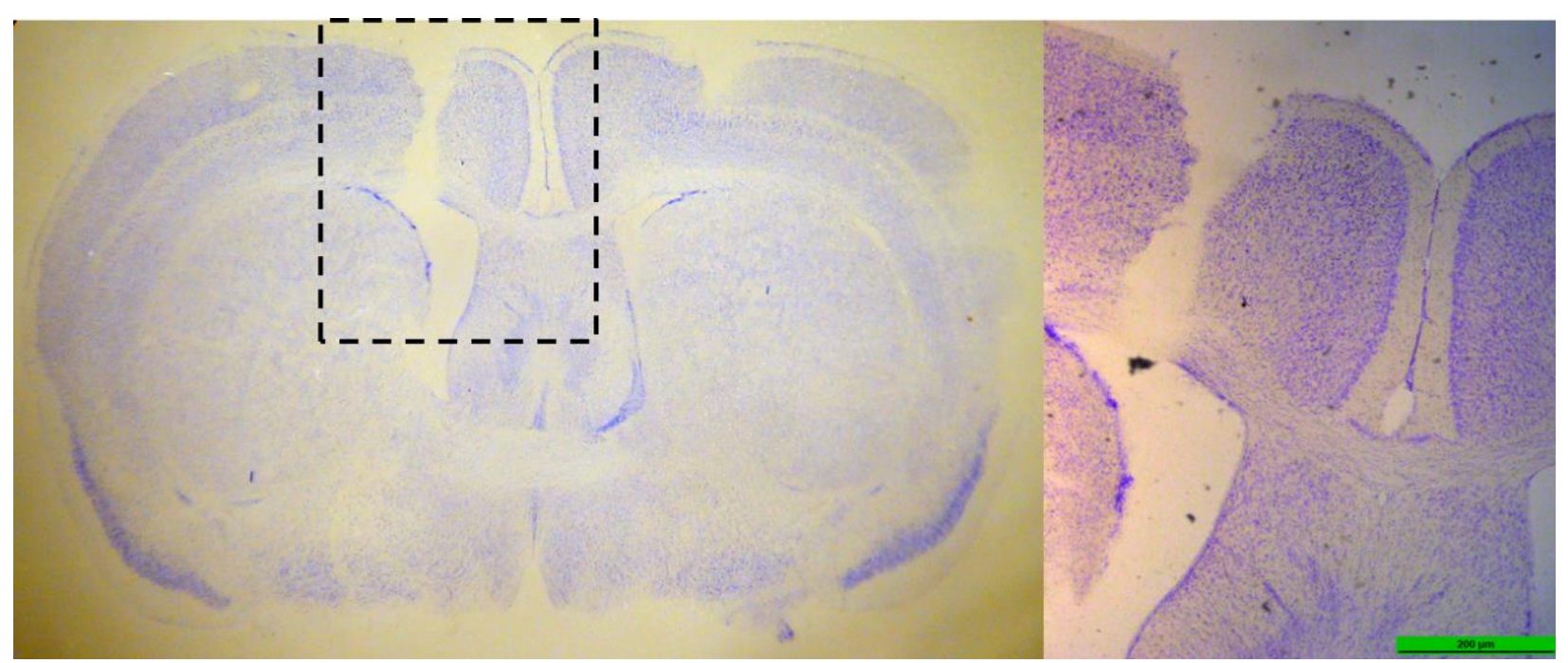

Figura 21. Secção do tecido encefálico submetida à coloração de Nissl, demonstrando o correto posicionamento da cânula-guia de administração do veículo e do peptídeo em estudo no ventrículo lateral direito. Somente os sujeitos experimentais com a cânula posicionada corretamente foram considerados nas análises.

\subsection{Indução do SE}

Poucos minutos após a administração da pilocarpina, os camundongos apresentaram manifestações como piloereção, diarreia e sinais da estimulação colinérgica periférica (aumento das secreções). Cerca de oito minutos, os camundongos desenvolveram respostas 
comportamentais estereotipadas, como: acinesia, automatismos faciais, tremores e enrijecimento da cauda, que rapidamente progrediram para crises motoras límbicas e para manutenção do SE (Figura 22). O SE foi definido como a presença de crises contínuas e intermitentes sem a recuperação espontânea do sujeito experimental (Buckmaster \& Haney, 2012), marcadas pela presença de mioclonia dos membros anteriores e a latência para o estabelecimento do SE foi de 10 a 15 minutos após a administração de pilocarpina.

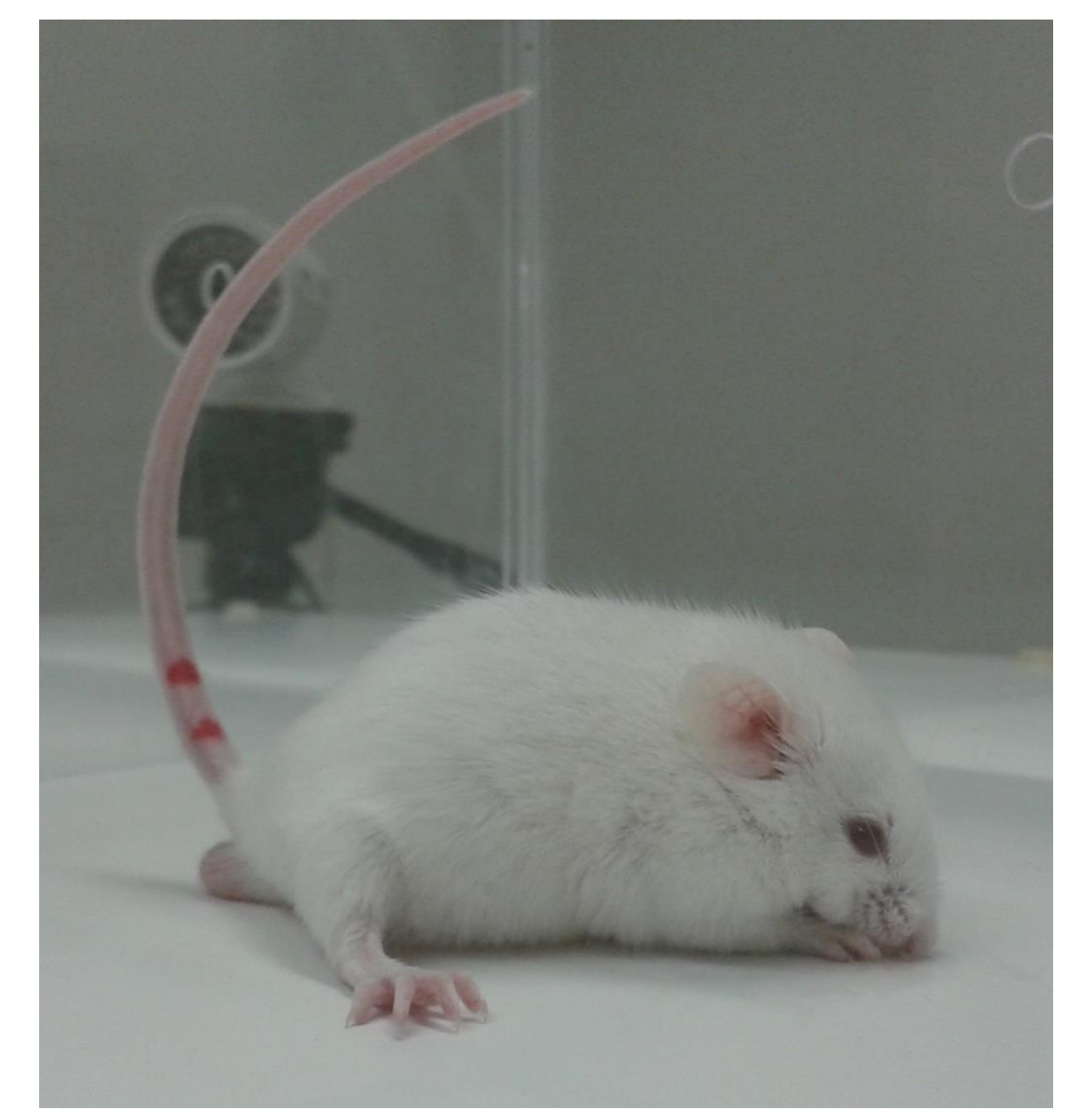

Figura 22. Camundongo apresentando hipertonia intensa da cauda, um dos sinais de progressão para o Status Epilepticus após a administração sistêmica de pilocarpina. 


\subsection{Avaliação da atividade antiepiléptica do peptídeo}

\subsubsection{Duração das CRE}

Os resultados obtidos quanto à duração das crises recorrentes e espontâneas após o tratamento subcrônico com o peptídeo Neuropolybina durante o período de crises recorrentes e espontâneas do modelo de ELT induzido por pilocarpina está representado na figura 23.

Em relação à duração das CRE apresentadas pelos sujeitos experimentais, o tratamento com o peptídeo diminuiu significativamente o tempo em que os animais estiveram em crise. Os dados passaram no teste de normalidade Kolmogorov-Smirnov e a ANOVA revelou que o tratamento com o peptídeo, em ambas as concentrações testadas, diminuiu significativamente a duração das CRE na fase tardia no primeiro dia de observação (Figura 23a). O tratamento com DZP também reduziu a duração das CRE nos camundongos tratados em relação ao grupo doente nas duas fases $[\mathrm{F}(4,25)=22,17 ; \mathrm{p}<0,0001]$.

No segundo dia, não foram observadas diferenças entre os grupos doentes e tratados com o peptídeo nas duas fases do dia (Figura 23b) $[\mathrm{F}(4,25)=13,98 ; \mathrm{p}<0,0001]$. No entanto, na fase tardia do terceiro dia (Figura 23c), a duração das CRE dos tratados com a maior concentração do peptídeo foi estatisticamente diferente em relação aos doentes $[F(4,25)=30,22 ; p<0,0001]$. O grupo DZP também apresentou diferenças em relação ao grupo doente nas duas fases do segundo e terceiro dias.

No quarto dia (Figura 23d), a duração das CRE foi reduzida nos camundongos tratados com a maior concentração do peptídeo, na fase pós $[\mathrm{F}(4,25)=40,52 ; \mathrm{p}<0,0001]$. No último dia de tratamento (Figuras 23e), a duração das CRE foi reduzida nos tratados com a maior concentração do peptídeo em ambas as fases, em relação ao grupo doente $[\mathrm{F}(4,25)=68,69 ; \mathrm{p}<0,0001]$. $\mathrm{O}$ grupo DZP também apresentou diferenças em relação ao grupo doente e em relação aos grupos tratados com o peptídeo em ambas as fases do quarto e quinto dias. 
A

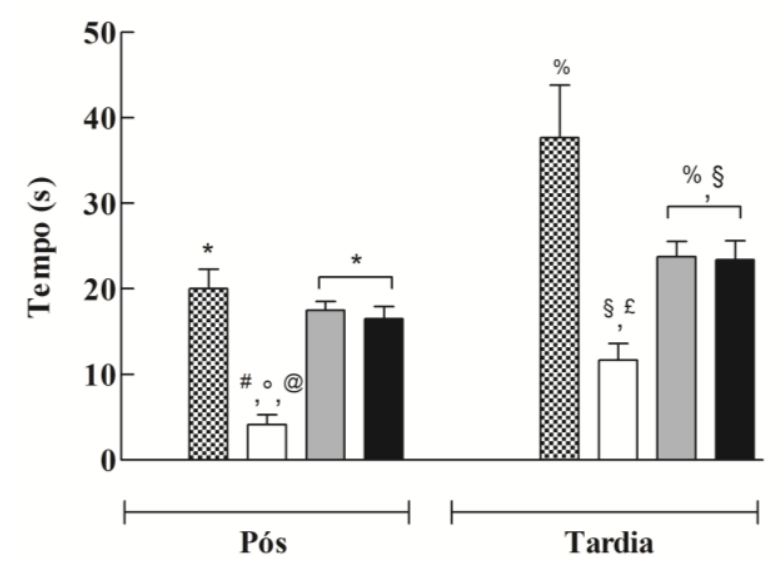

D
B

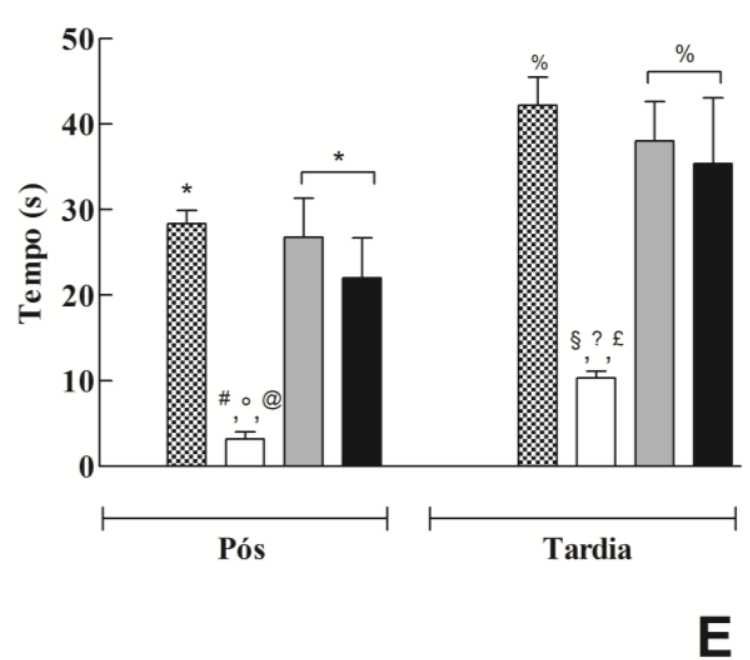

E
C

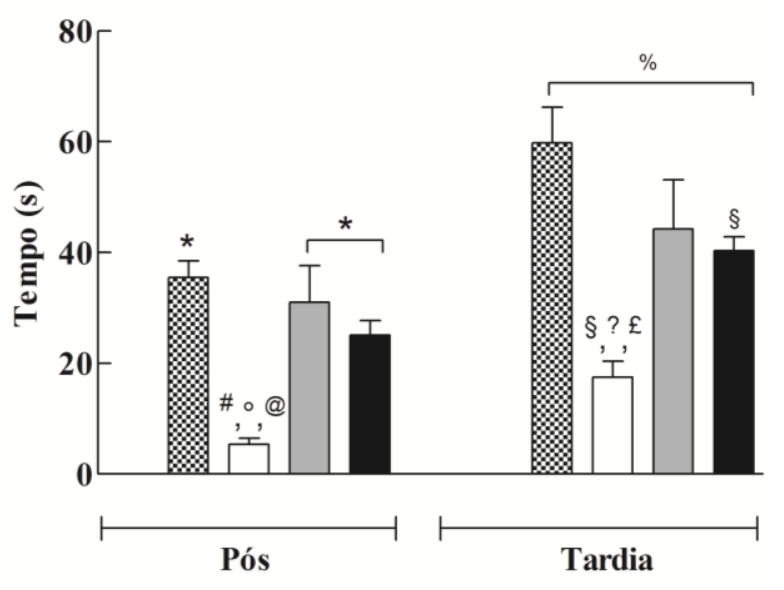

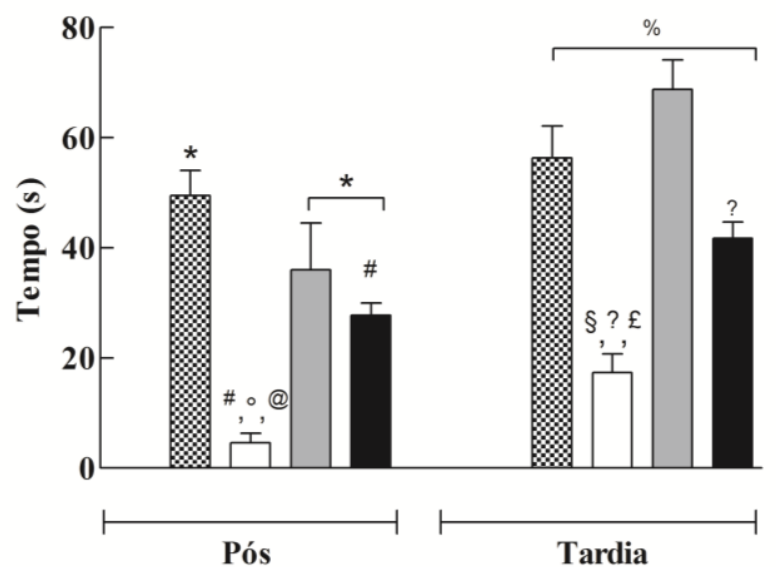

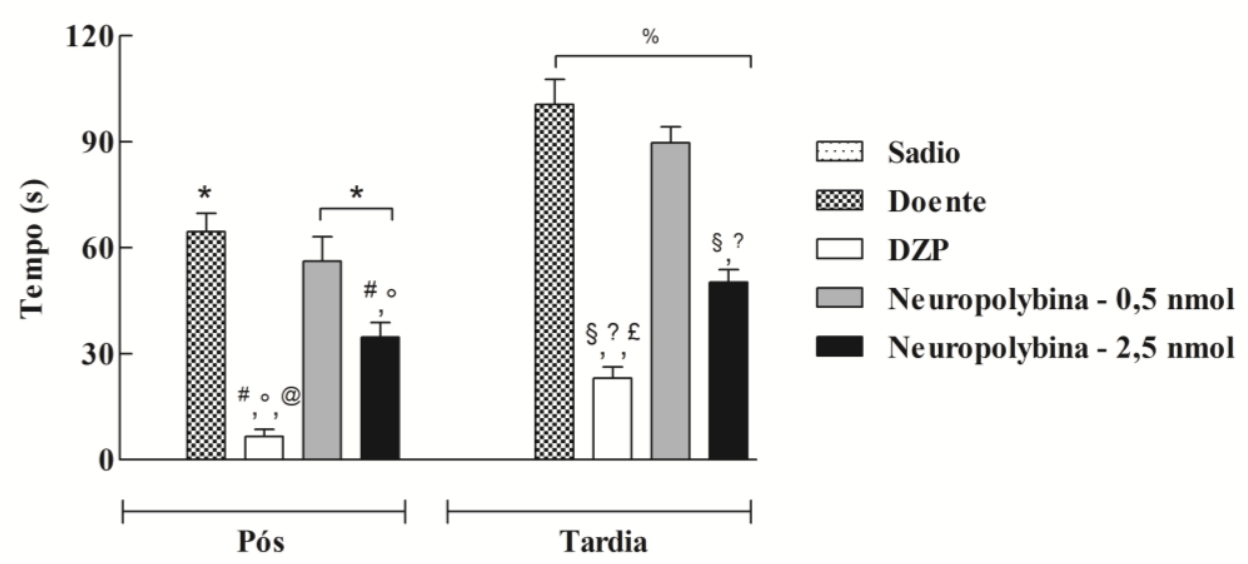

Figura 23. Duração das CRE em cada fase ao longo dos cinco dias de tratamento, em segundos, nos grupos controles e experimentais (n= 4-8) após a administração independente de duas concentrações de Neuropolybina. A fase "pós" se refere às primeiras cinco horas logo após a administração do peptídeo e a fase "tardia", às cinco horas restantes de observação. Os dados passaram pelo teste de normalidade Kolmogorov-Smirnov e foram submetidos à ANOVA de uma via, seguido do pós-teste Tukey, sendo considerado p<0,05. (A) Dia 1 de tratamento subcrônico; (B) Dia 2; (C) Dia 3; (D) Dia 4 e (E) Dia 5. *: comparado ao controle sadio (pós), \#: comparado ao grupo doente (pós), ${ }^{\circ}$ : comparado aos tratados com 0,5 nmol de Neuropolybina (pós), @: comparado aos tratados com 2,5 nmol de Neuropolybina (pós), \%: comparado ao grupo sadio (tardia), §: comparado ao grupo doente (tardia), ?: comparado ao grupo Neuropolybina 0,5 nmol (tardia), £: comparado ao grupo Neuropolybina 2,5 nmol (tardia). 


\subsubsection{Número de CRE}

Os resultados obtidos quanto ao número de crises recorrentes e espontâneas após o tratamento com o peptídeo Neuropolybina durante o período crônico do modelo de ELT induzido por pilocarpina estão representados na figura 24.

Em relação ao número total de crises nas duas fases de cada dia, separadamente, o tratamento com o peptídeo em ambas as concentrações testadas não diminuiu significativamente o número de CRE tanto na fase pós, quanto na fase tardia ao longo dos cinco dias de monitoramento. O teste de Kruskal-Wallis e o pós-teste de Dunn revelaram que somente o grupo tratado com DZP apresentou diferenças significativas com relação ao grupo doente no terceiro e no quinto dias, durante a fase tardia (Figura $24 \mathrm{c}$ e 24e) $[\mathrm{K}=55,52 ; \mathrm{p}<0,0001$ e $\mathrm{K}=55,52 ; \mathrm{p}<0,0001$, respectivamente $]$. 
A

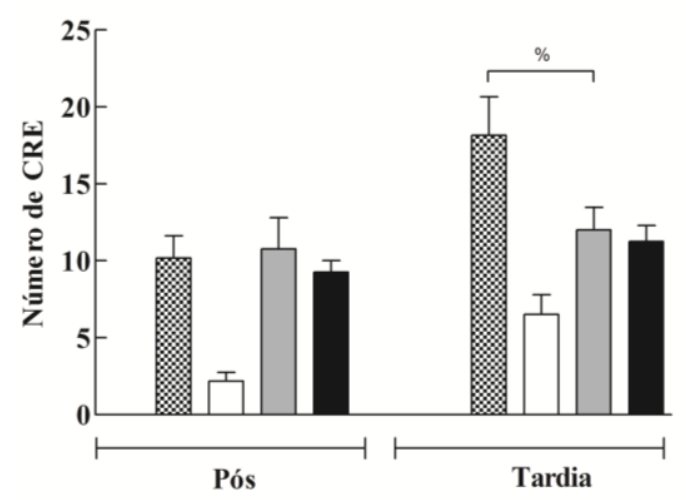

B

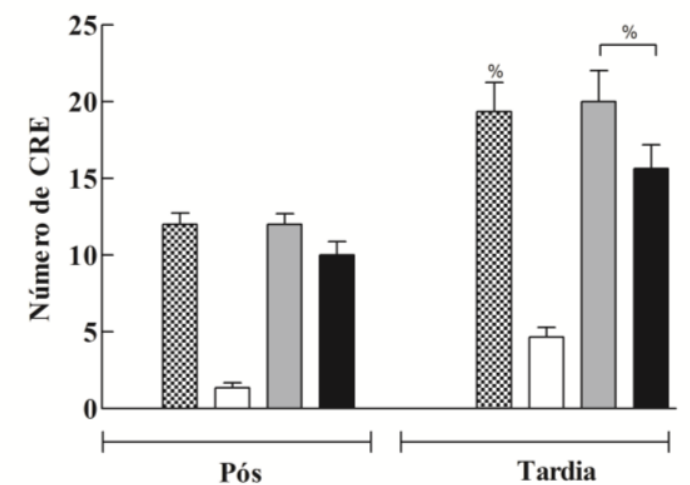

Pós
C
D

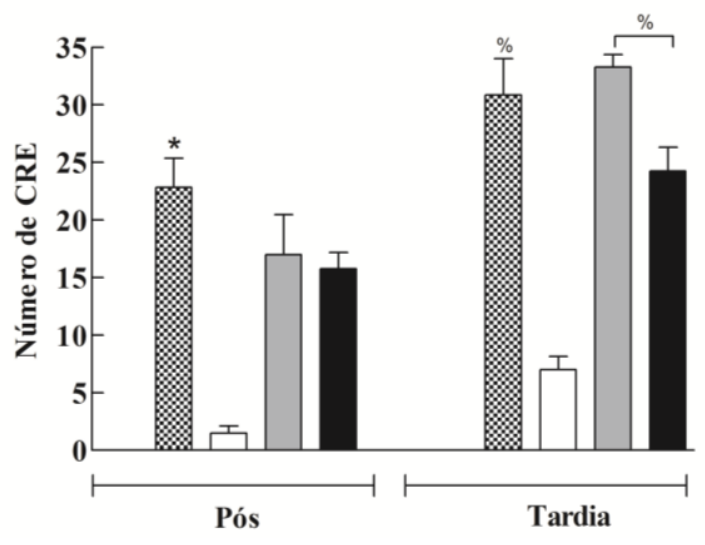

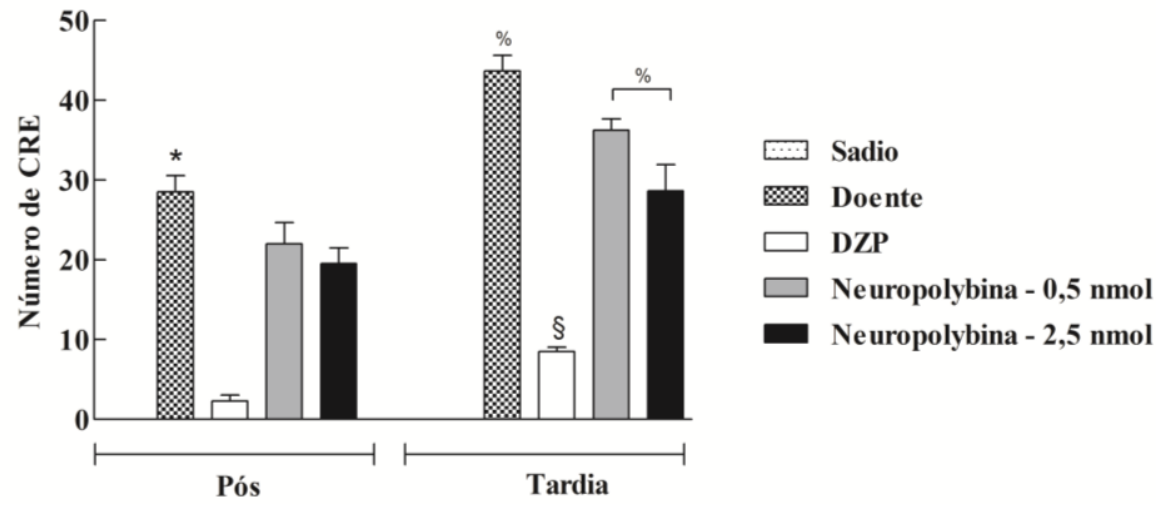

Pós

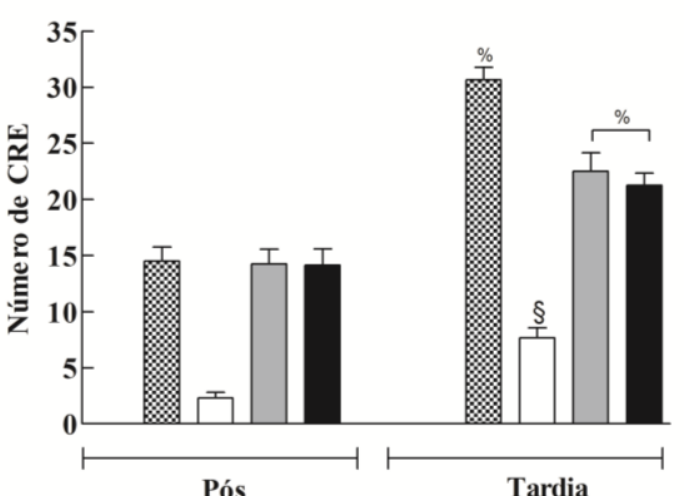

ós

E

Figura 24. Número total de CRE em cada fase ao longo dos cinco dias de tratamento, nos grupos controles e experimentais (n= 4-8) após a administração independente de duas concentrações de Neuropolybina. A fase "pós" se refere às primeiras cinco horas logo após a administração do peptídeo e a fase "tardia", às cinco horas restantes de observação. Os testes estatísticos utilizados foram o teste de Kruskal-Wallis e o pós-teste de Dunn, sendo considerado p<0,05. (A) Dia 1 de tratamento subcrônico; (B) Dia 2; (C) Dia 3; (D) Dia 4 e (E) Dia 5. *: comparado ao controle sadio (pós), \%: comparado ao grupo sadio (tardia), §: comparado ao grupo doente (tardia). 


\subsubsection{Grau de severidade das CRE}

Os resultados obtidos quanto à crise máxima observada após o tratamento com o peptídeo Neuropolybina durante o período crônico do modelo de ELT induzido por pilocarpina estão representados na figura 25.

Em relação ao grau de severidade das CRE apresentadas pelos sujeitos experimentais durante o período observado, o teste de Kruskal-Wallis e o pós-teste de Dunn revelaram que o tratamento com o peptídeo em ambas as concentrações testadas não amenizou a severidade CRE tanto na fase pós, quanto na fase tardia ao longo dos cinco dias de tratamento $[\mathrm{K}=26,5 ; \mathrm{p}<0,0001]$. 
A

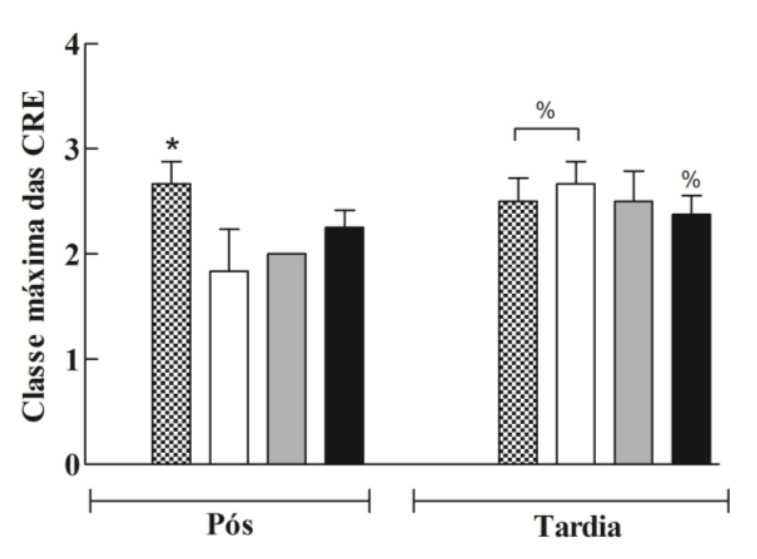

B

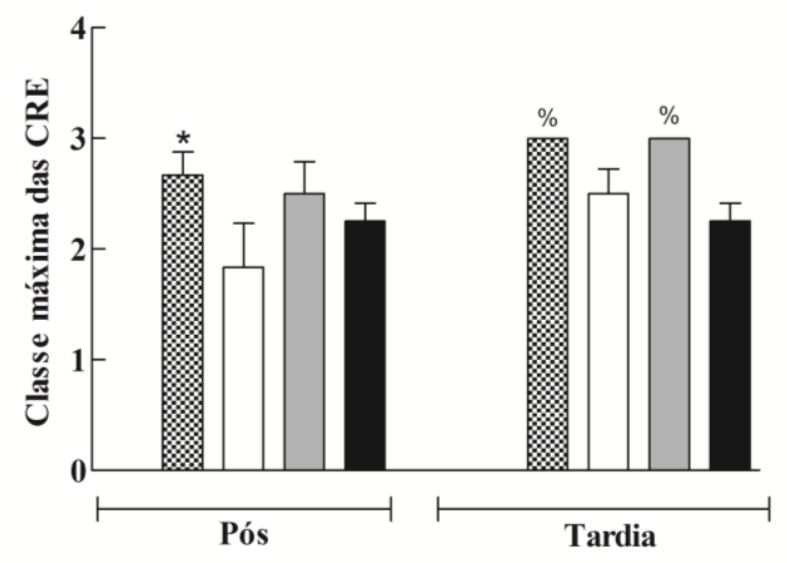

C

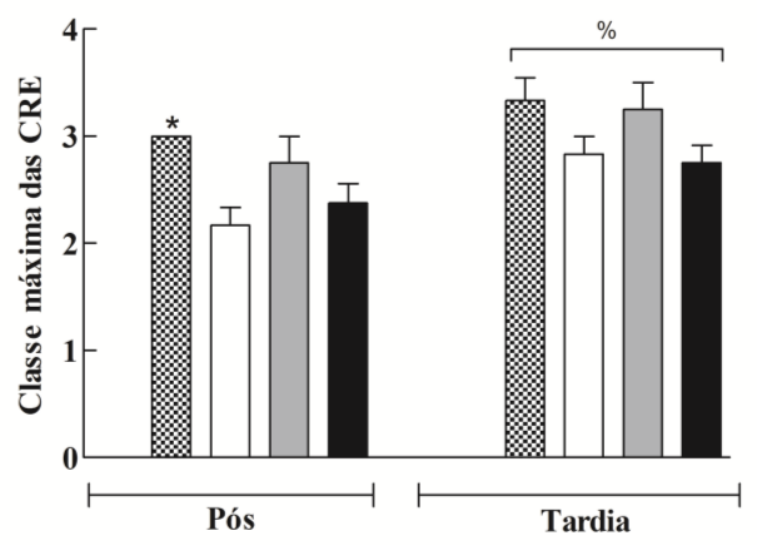

D

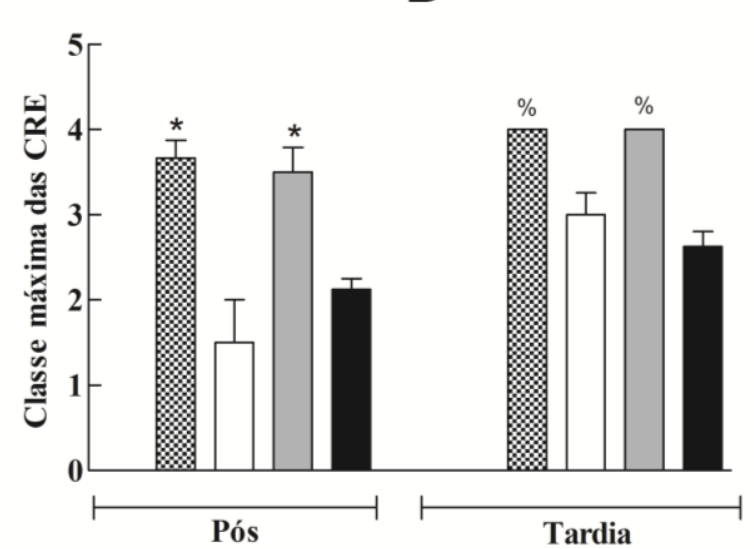

$\mathbf{E}$
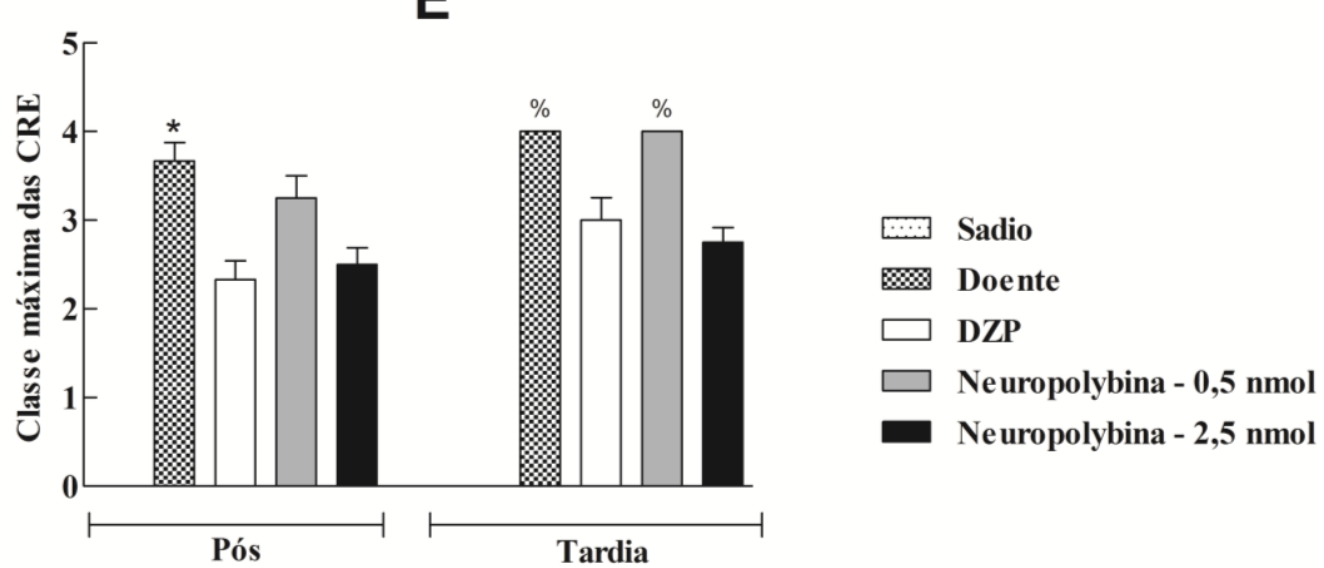

Figura 25. Classe máxima das CRE em cada fase ao longo dos cinco dias de tratamento, nos grupos controles e experimentais (n= 4-8) após a administração independente de duas concentrações de Neuropolybina. A fase "pós" se refere às primeiras cinco horas logo após a administração do peptídeo e a fase "tardia", às cinco horas restantes de observação. Os testes estatísticos utilizados foram o teste de Kruskal-Wallis e o pós-teste de Dunn, sendo considerado p<0,05. (A) Dia 1 de tratamento subcrônico; (B) Dia 2; (C) Dia 3; (D) Dia 4 e (E) Dia 5. *: comparado ao controle sadio (pós), \%: comparado ao grupo sadio (tardia). 


\subsection{Avaliação dos padrões epileptiformes por vídeo-EEG}

Os resultados obtidos quanto à caracterização da latência para estabelecimento das crises eletroencefalográficas generalizadas e focais observadas após o tratamento com o peptídeo Neuropolybina durante o período crônico do modelo de ELT induzido por pilocarpina estão representados nas figuras 26 a 30.

Em relação à latência das crises generalizadas apresentadas pelos sujeitos experimentais durante todo o período observado, o teste de Kruskal-Wallis e o pós-teste de Dunn revelaram que os tratamentos com o peptídeo e com o DZP aumentaram a latência para o aparecimento da primeira crise eletroencefalográfica detectada nos quatro canais de registro do sistema de aquisição por vídeo-EEG com relação ao grupo doente (Figura 26) [K=27,44; $\mathrm{p}<0,0001]$.

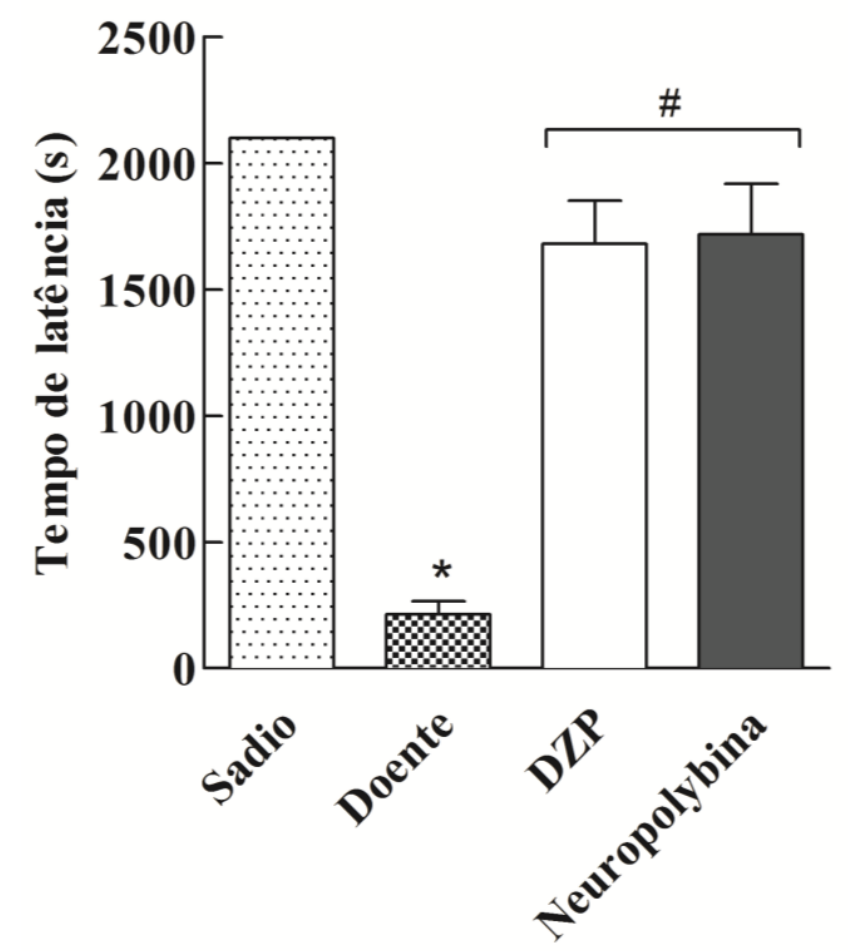

Figura 26. Latência para estabelecimento das crises eletroencefalográficas generalizadas nos cinco dias de tratamento, nos grupos controles e experimentais $(n=2)$ após a administração i.c.v. de Neuropolybina, na concentração de 3,75 nmol. Os testes estatísticos utilizados foram o teste de Kruskal-Wallis e o pósteste de Dunn, sendo considerado p<0,05. *: comparado ao controle sadio, \#: comparado ao grupo controle doente. 
Em relação à latência das crises focais apresentadas pelos sujeitos experimentais durante todo o período observado, o teste de Kruskal-Wallis e o pós-teste de Dunn revelaram que o tratamento com DZP aumentou a latência para o aparecimento da primeira crise eletroencefalográfica focal detectada pelo sistema de aquisição por vídeoEEG com relação ao grupo doente (Figura 27) [K=27,44; $\mathrm{p}<0,0001]$. Os grupos doente e tratados com Neuropolybina também apresentaram diferenças estatisticamente significativas com relação ao grupo controle sadio.

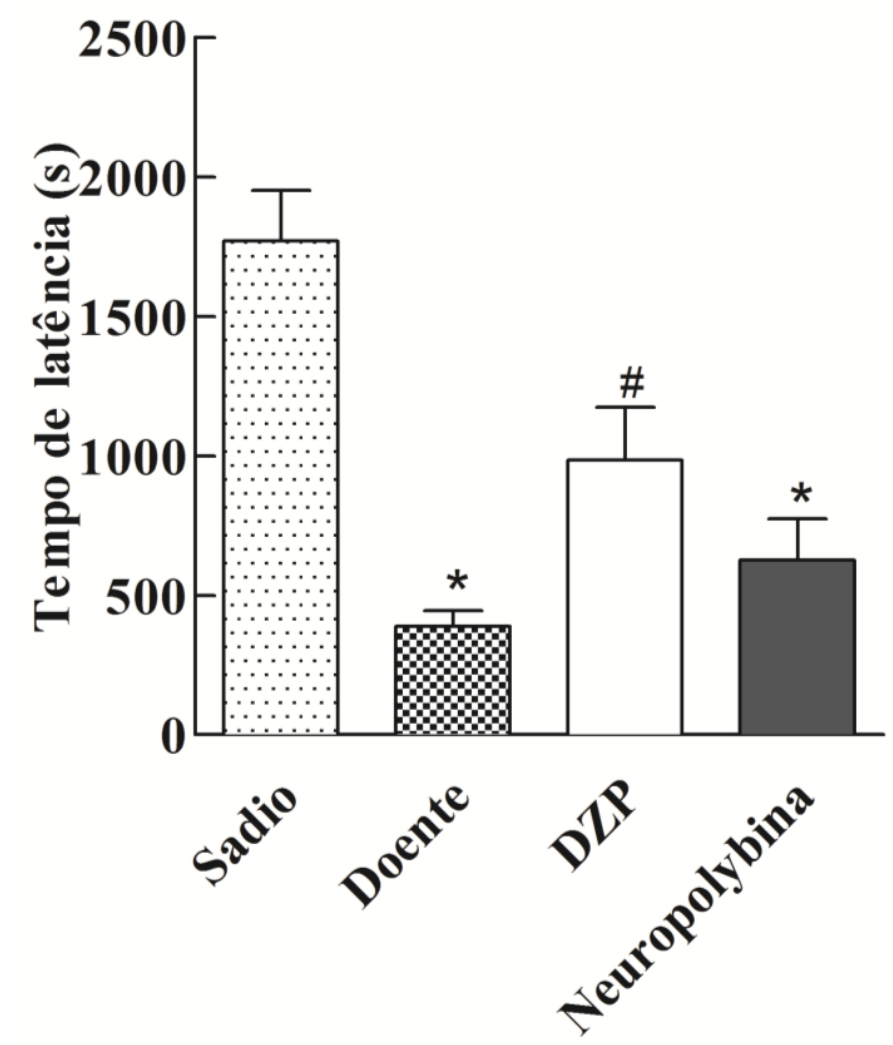

Figura 27. Latência para estabelecimento das crises eletroencefalográficas focais nos cinco dias de tratamento, nos grupos controles e experimentais $(n=2)$ após a administração i.c.v. de Neuropolybina, na concentração de 3,75 nmol. Os testes estatísticos utilizados foram o teste de Kruskal-Wallis e o pós-teste de Dunn, sendo considerado $\mathrm{p}<0,05$. *: comparado ao controle sadio, \#: comparado ao grupo controle doente. 


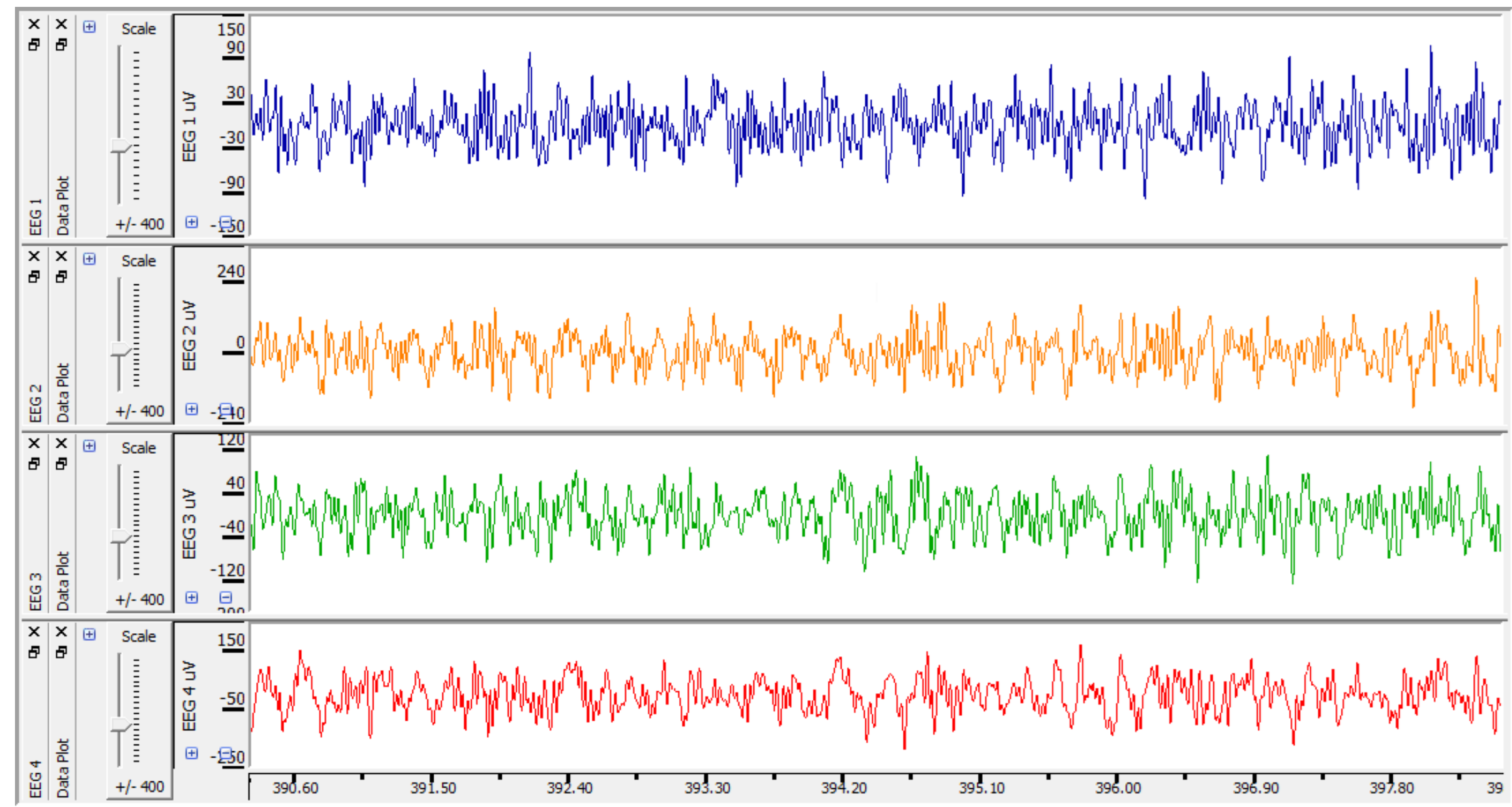

Figura 28. Representação ilustrativa do perfil eletroencefalográfico de um animal sadio sem detecção de descargas epileptiformes sincronizadas. A montagem referencial dos eletrodos intrahipocampais bilaterais (EEG 1 e 2) e bipolar dos eletrodos corticais (EEG 3 e 4) gera as derivações observadas separadamente em cada um dos quatro canais de aquisição. 


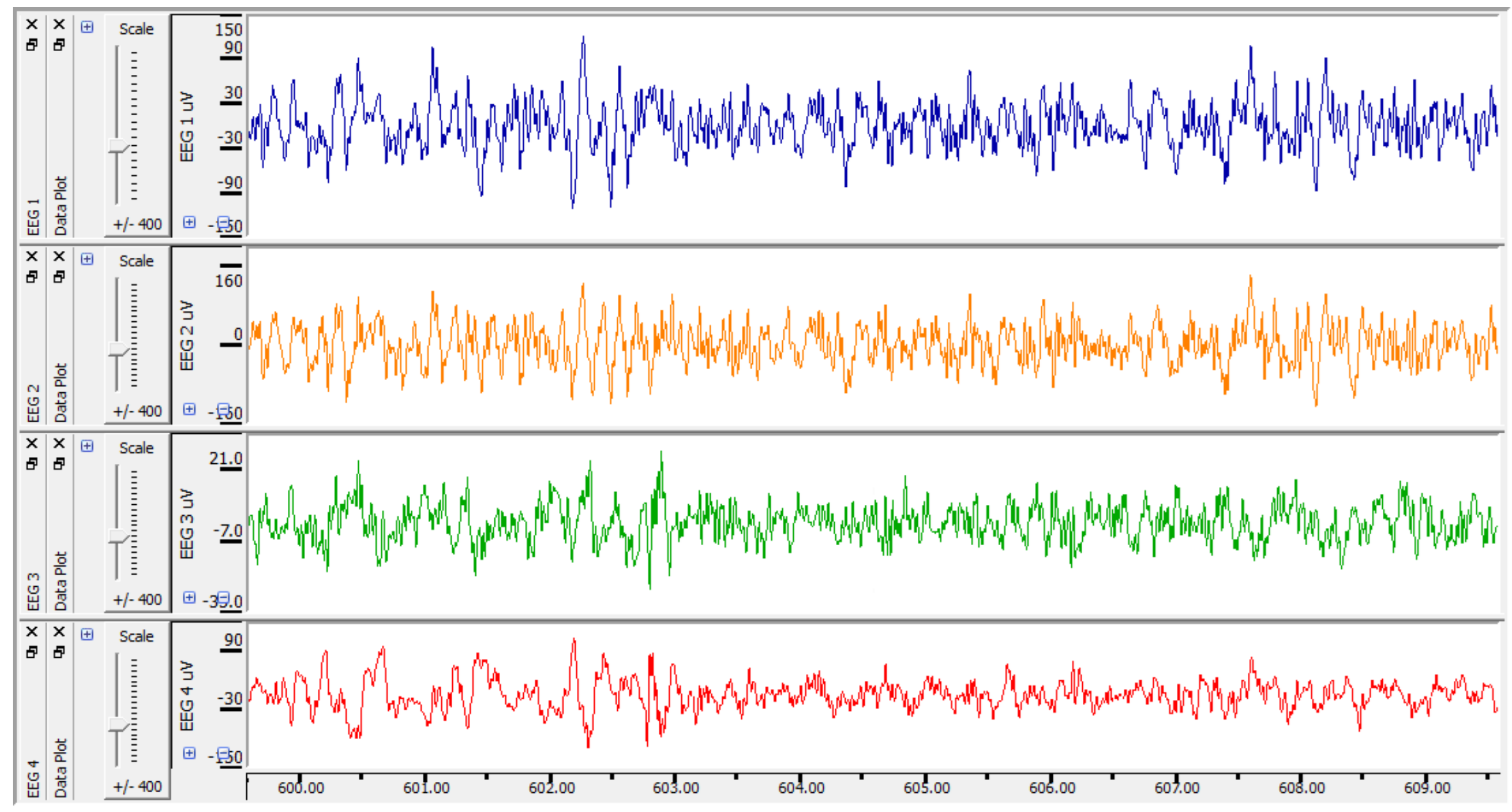

Figura 29. Representação ilustrativa do perfil eletroencefalográfico ictal de um animal doente com presença de paroxismos epileptiformes caracterizados pela presença de espículas agudizadas, hipersincronizadas e de amplitude elevada nos quatro canais de registro, correspondendo a uma crise generalizada. A montagem referencial dos eletrodos intrahipocampais bilaterais (EEG 1 e 2) e bipolar dos eletrodos corticais (EEG 3 e 4) gera as derivações observadas separadamente em cada um dos quatro canais de aquisição. 


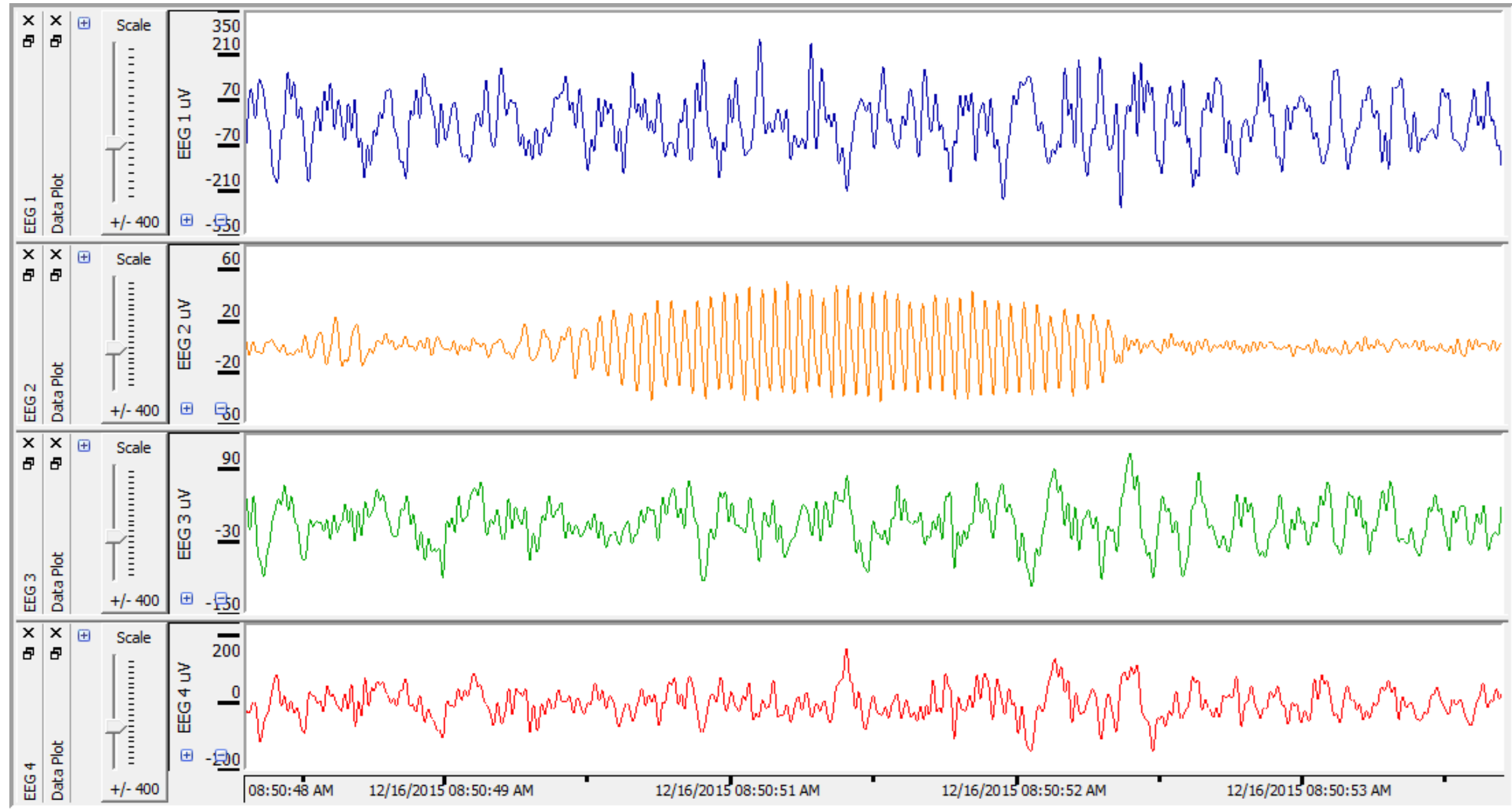

Figura 30. Representação ilustrativa do perfil eletroencefalográfico de um animal tratado com a presença de espículas de alta frequência no canal 2 (formação hipocampal do hemisfério direito) correspondendo a uma crise focal. A montagem referencial dos eletrodos intrahipocampais bilaterais (EEG 1 e 2) e bipolar dos eletrodos corticais (EEG 3 e 4) gera as derivações observadas separadamente em cada um dos quatro canais de aquisição. 


\subsection{Avaliação do dano neural}

Os resultados obtidos quanto à avaliação da integridade das camadas de células piramidais de CA1 e CA3 e da camada de células granulares do Hilus do Giro Denteado (HGD) após o tratamento subcrônico com o peptídeo Neuropolybina durante o período crônico do modelo de ELT induzido por pilocarpina estão representados nas figuras 31 a 34.

Em relação à análise de densidade óptica, o tratamento com o peptídeo na maior concentração testada diminuiu significativamente a morte de células na camada CA3 do lado direito da formação hipocampal (Figura 31b). Os dados passaram no teste de normalidade Kolmogorov-Smirnov e a ANOVA revelou que o grupo tratado com a concentração de 2,5 nmol do peptídeo Neuropolybina apresentou diferenças estatisticamente significativas com relação ao grupo doente, conforme demonstrado na figura $33[\mathrm{~F}(7,49)=11,73 ; \mathrm{p}<0,0001]$. Nas demais regiões não foram observadas diferenças estatisticamente significativas entre a densidade de células dos camundongos tratados com o peptídeo e doentes e entre os dois lados da formação hipocampal [CA1: $F(7,49)=9,156 ; p<0,0001$. HGD: $F(7,48)=0,9883 ; p=0,4510]$. 



Figura 31. Diferença de densidade óptica entre as três regiões de interesse dos dois hemisférios da formação hipocampal (n=5-10). Os dados passaram pelo teste de normalidade Kolmogorov-Smirnov e foram submetidos à ANOVA de uma via, seguido do pós-teste Tukey, sendo considerado p<0,05. (A) Camada de células piramidais de CA1. (B) Camada de células piramidais de CA3. (C) Camada de células granulares do Hilus do Giro Denteado. *: comparado ao controle sadio (lado direito), \#: comparado ao grupo doente (lado direito), ${ }^{\circ}$ : comparado aos tratados com 0,5 nmol de Neuropolybina (lado direito), \%: comparado ao grupo sadio (lado esquerdo), ?: comparado ao grupo Neuropolybina $0,5 \mathrm{nmol}$ (lado esquerdo), ns: diferença não-significativa. 

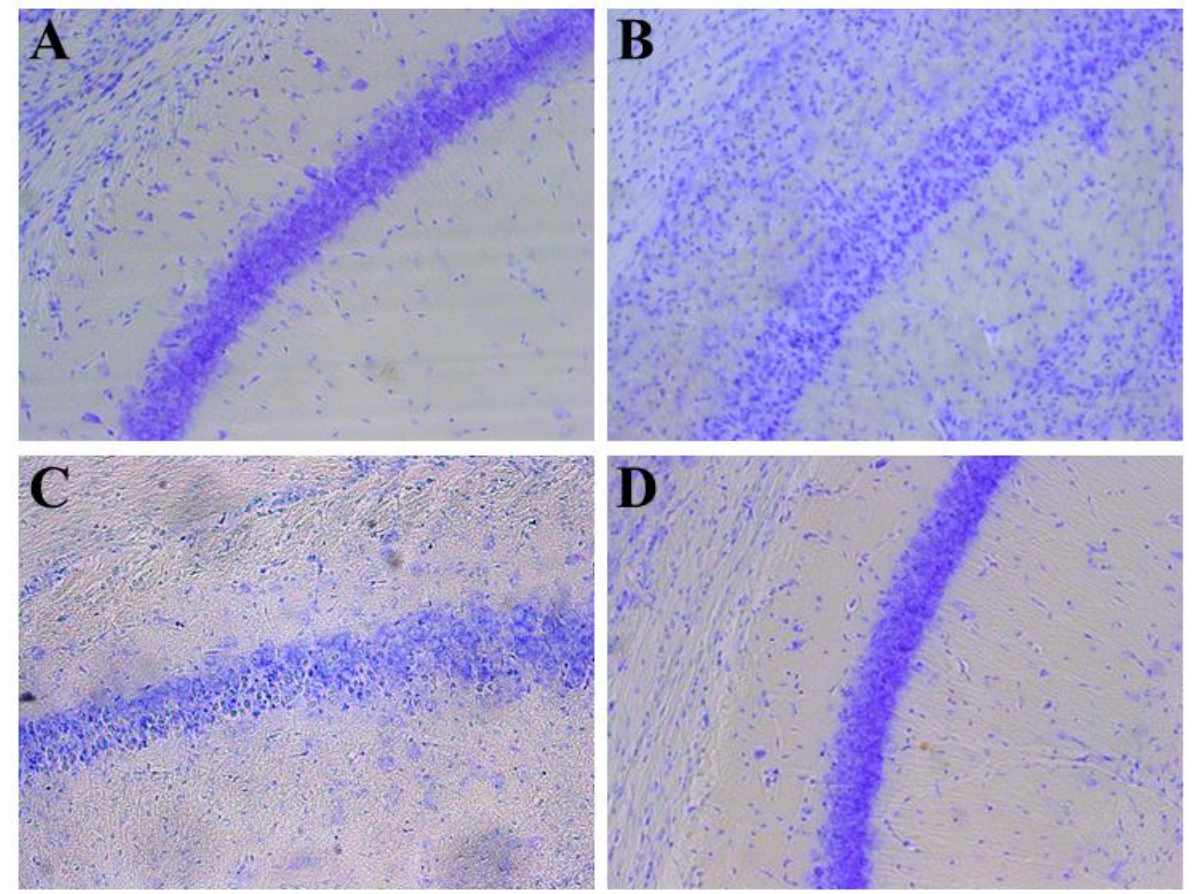

Figura 32. Imagens representativas de secções coronais da camada CA1 da formação hipocampal de camundongos dos grupos experimentais (aumento de 200x) submetidas à técnica de coloração de Nissl. (A) Sadio. (B) Doente. (C) Tratado com 0,5 nmol de Neuropolybina. (D) Tratado com 2,5 nmol de Neuropolybina.
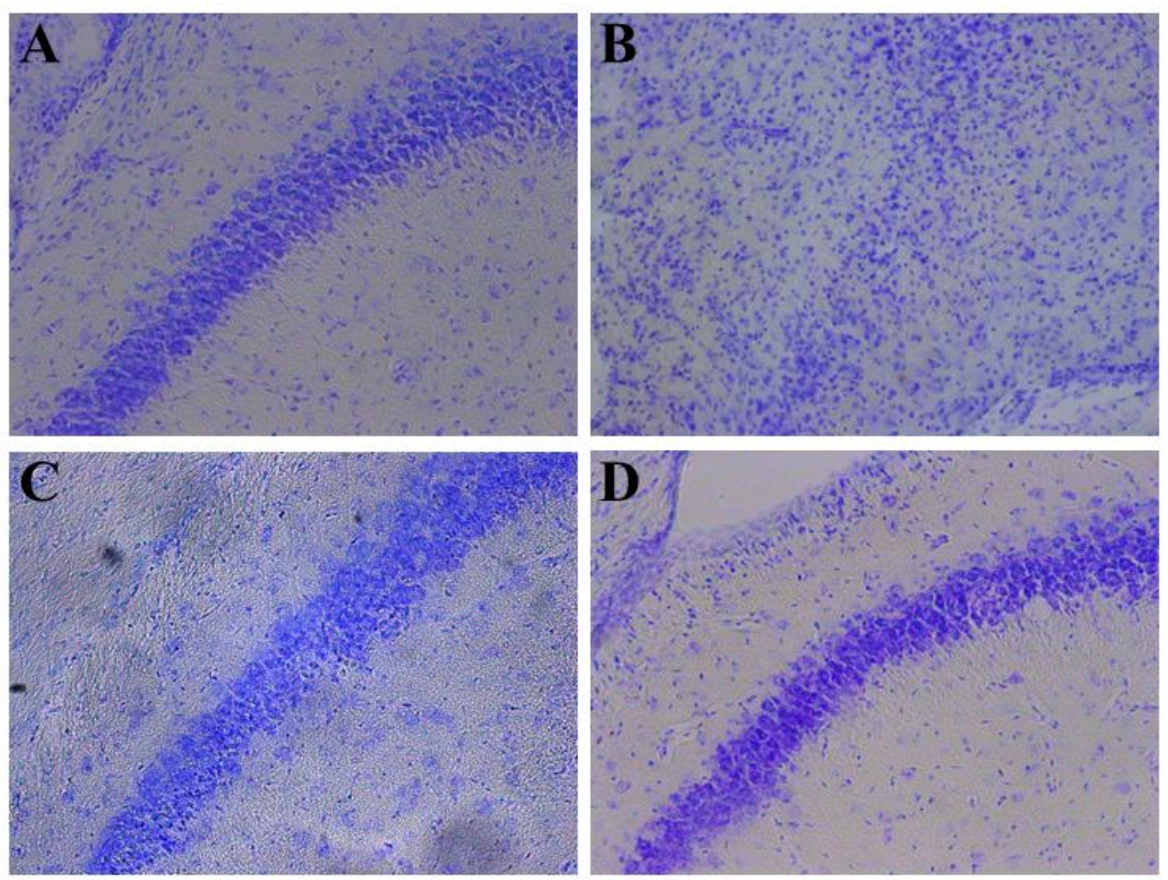

Figura 33. Imagens representativas de secções coronais da camada CA3 da formação hipocampal de camundongos dos grupos experimentais (aumento de 200x) submetidas à técnica de coloração de Nissl. (A) Sadio. (B) Doente. (C) Tratado com 0,5 nmol de Neuropolybina. (D) Tratado com 2,5 nmol de Neuropolybina. 

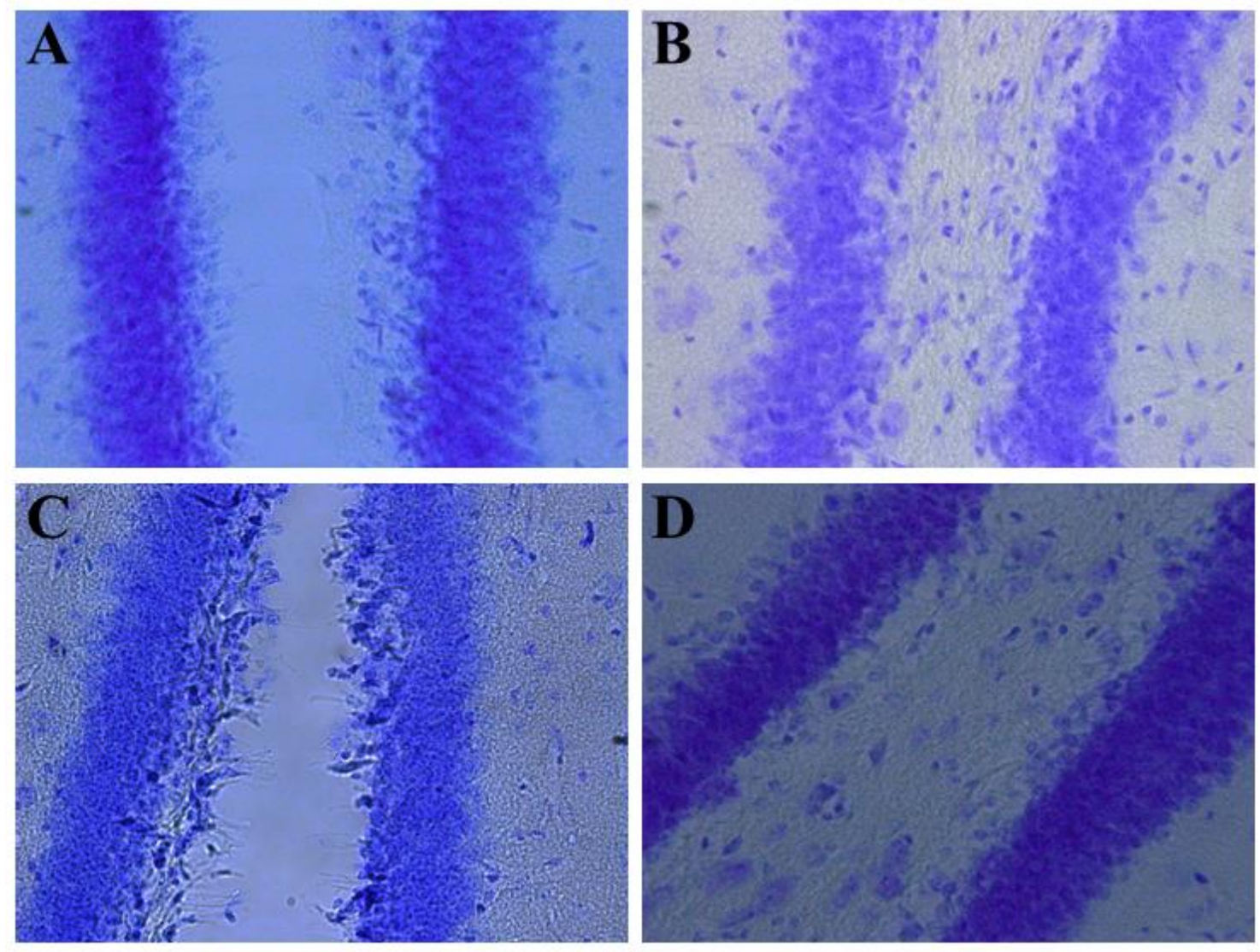

Figura 34. Imagens representativas de secções coronais da camada de células granulares do Hilus do Giro Denteado da formação hipocampal de camundongos dos grupos experimentais (aumento de 400x) submetidas à técnica de coloração de Nissl. (A) Sadio. (B) Doente. (C) Tratado com 0,5 nmol de Neuropolybina. (D) Tratado com 2,5 nmol de Neuropolybina.

\subsection{Avaliação de astrogliose}

Os resultados obtidos quanto à avaliação da astrogliose nas camadas de células piramidais de CA1 e CA3 e da camada de células granulares do Hilus do Giro Denteado (HGD) após o tratamento com o peptídeo Neuropolybina durante o período crônico do modelo de ELT induzido por pilocarpina estão representados nas figuras 35 a 38 .

Em relação à quantificação de astrócitos, o tratamento subcrônico com o peptídeo na maior concentração testada diminuiu significativamente o número de astrócitos nas três regiões observadas e nos dois lados da formação hipocampal (Figura 35). Os dados 
passaram no teste de normalidade Kolmogorov-Smirnov e a ANOVA revelou que para a região CA1 (Figura 35a), o grupo tratado com a concentração de 2,5 nmol do peptídeo Neuropolybina apresentou diferenças estatisticamente significativas com relação ao grupo doente, tanto para o lado direito quanto para o lado esquerdo, enquanto que o tratamento com DZP só mostrou diferenças estatisticamente diferentes no lado esquerdo do grupo doente $[F(9,59)=8,626 ; p<0,0001]$.

Para as regiões CA3 e HGD (Figura 35b e 35c), os grupos tratados com a concentração de 2,5 nmol do peptídeo Neuropolybina e com DZP apresentaram diferenças estatisticamente significativas com relação ao grupo doente, para ambos os lados da formação hipocampal [CA3: $F(9,58)=12,53$; $p<0,0001$ e $\operatorname{HGD:~} F(9,86)=$ $13,10 ; \mathrm{p}<0,0001]$. 
A

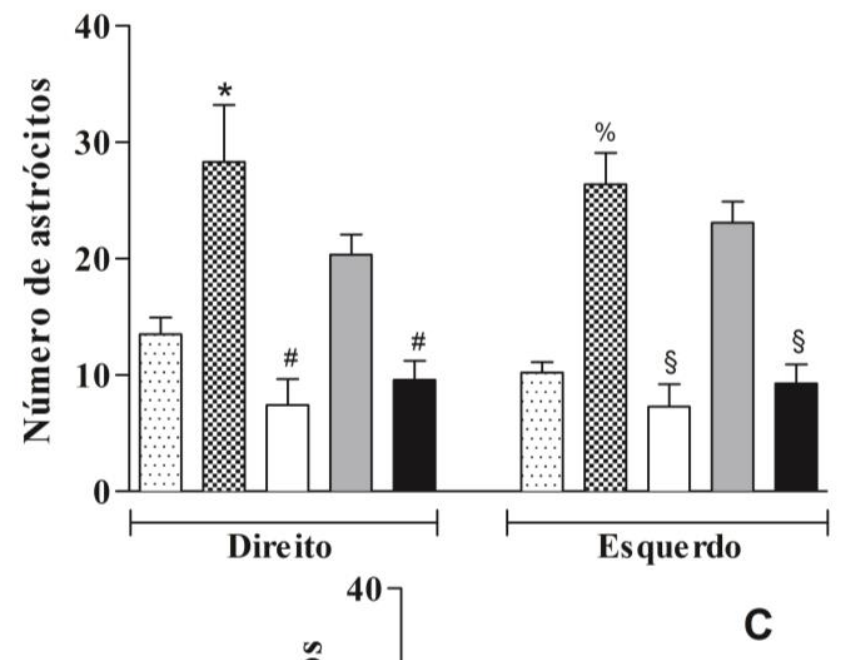

B

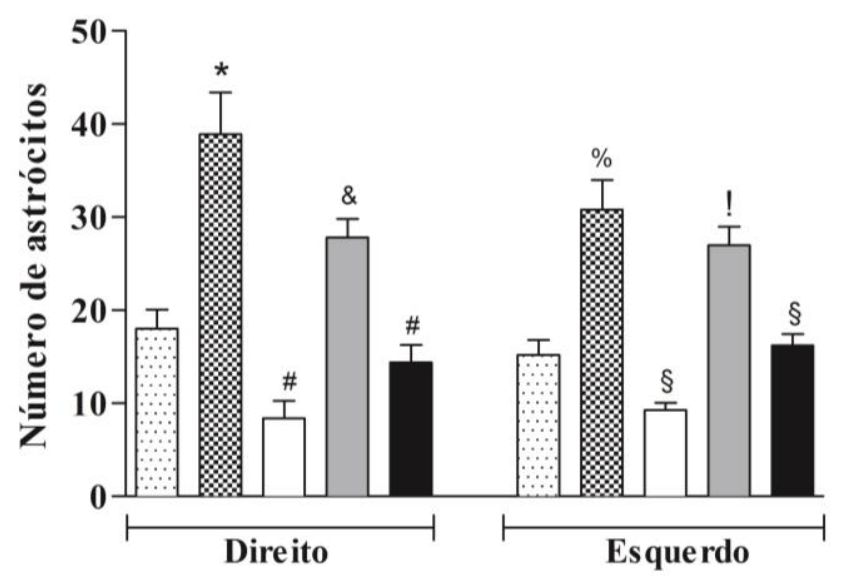

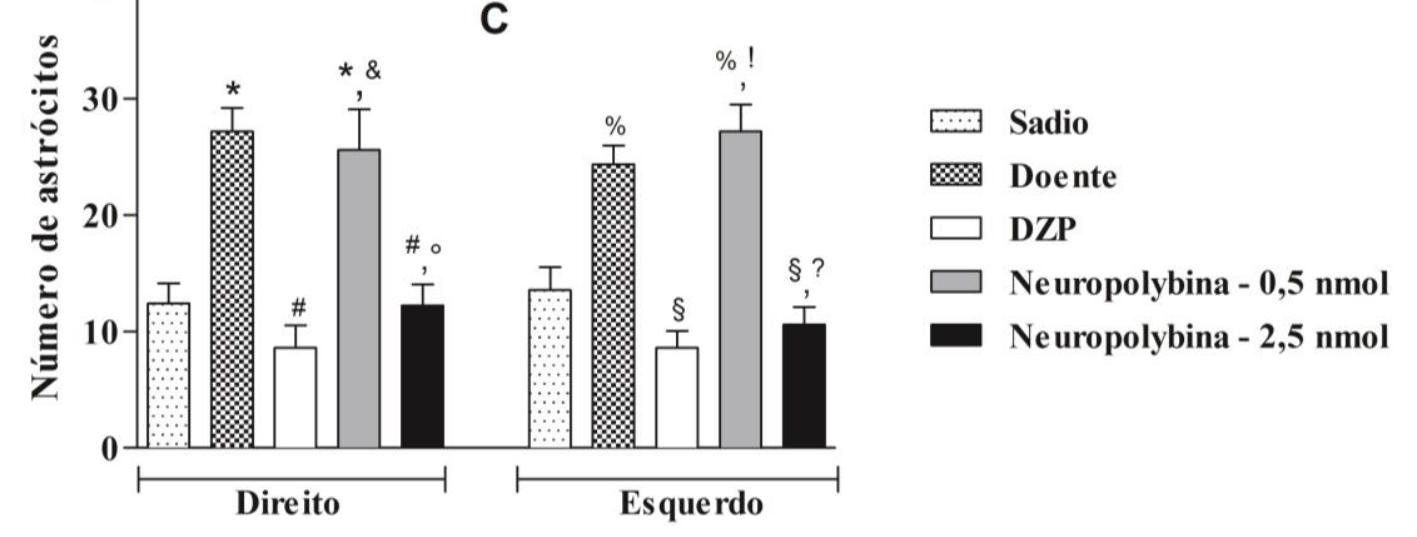

Figura 35. Número de astrócitos imunorreativos à proteína GFAP contabilizados nas três regiões de interesse dos dois hemisférios da formação hipocampal (n=5-10). Os dados passaram pelo teste de normalidade Kolmogorov-Smirnov e foram submetidos à ANOVA de uma via, seguido do pós-teste Tukey, sendo considerado p<0,05. (A) Camada CA1. (B) Camada CA3. (C) Hilus do Giro Denteado. *: comparado ao controle sadio (lado direito), \#: comparado ao grupo doente (direito), \&: comparado ao grupo tratado com DZP (direito), ${ }^{\circ}$ : comparado aos tratados com $0,5 \mathrm{nmol}$ de Neuropolybina (direito), \%: comparado ao grupo sadio (lado esquerdo), $\S$ : comparado ao grupo doente (esquerdo), !: comparado ao grupo tratado com DZP (esquerdo), ?: comparado ao grupo Neuropolybina 0,5 nmol (esquerdo). 


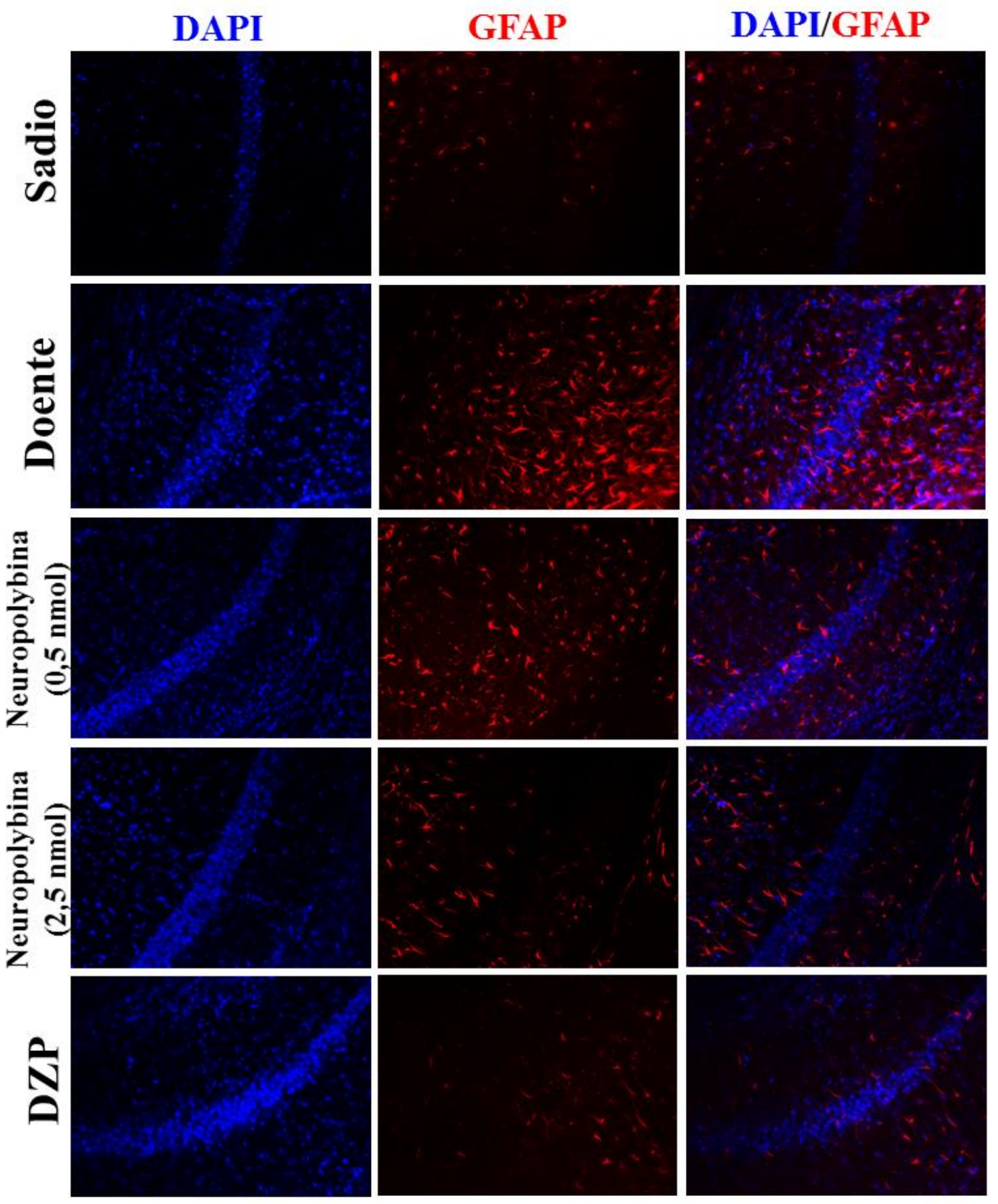

Figura 36. Imagens representativas de secções coronais da camada CA1 da formação hipocampal de camundongos dos grupos experimentais (aumento de 200x) submetidas à técnica de imunohistoquímica/imunofluorescência. Os núcleos celulares foram marcados com DAPI (azul) e os astrócitos com anti-GFAP (vermelho). 


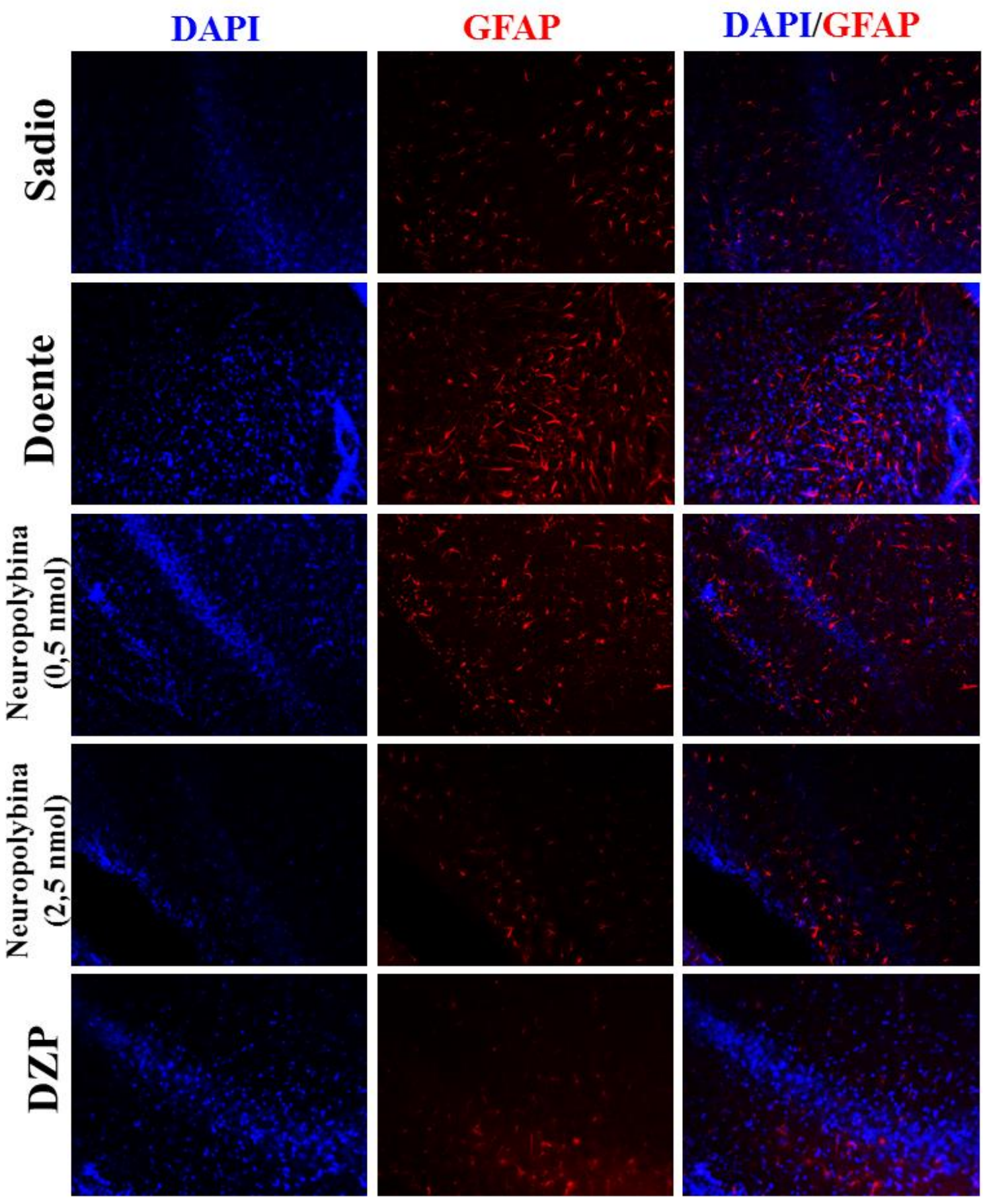

Figura 37. Imagens representativas de secções coronais da camada CA3 da formação hipocampal de camundongos dos grupos experimentais (aumento de 200x) submetidas à técnica de imunohistoquímica/imunofluorescência. Os núcleos celulares foram marcados com DAPI (azul) e os astrócitos com anti-GFAP (vermelho). 


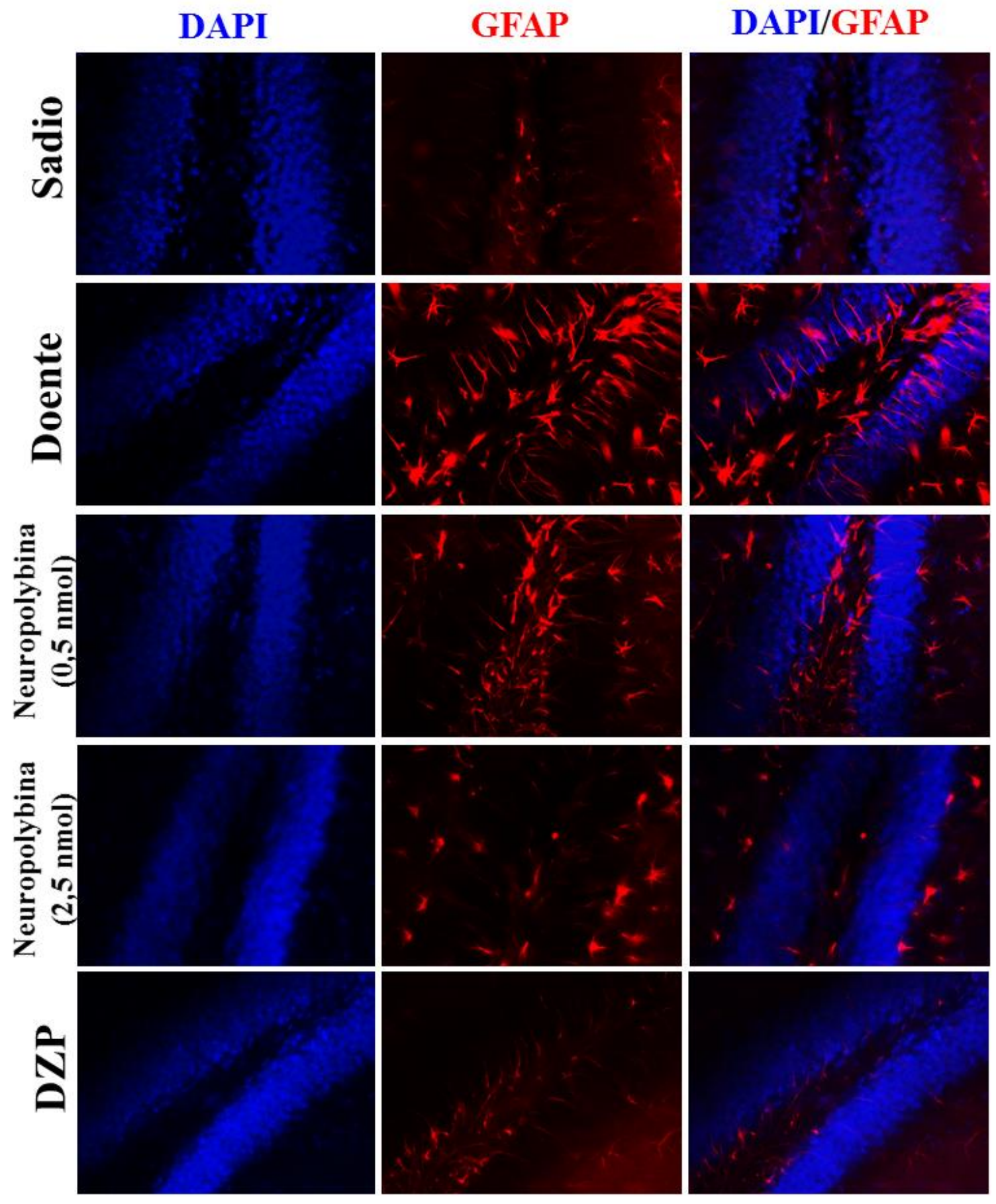

Figura 38. Imagens representativas de secções coronais da camada de células granulares do Hilus do Giro Denteado da formação hipocampal de camundongos dos grupos experimentais (aumento de 400x) submetidas à técnica de imunohistoquímica/imunofluorescência. Os núcleos celulares foram marcados com DAPI (azul) e os astrócitos com anti-GFAP (vermelho). 
DISCUSSÃO 


\section{DISCUSS ÃO}

A Epilepsia do Lobo Temporal é uma doença neurológica implacavelmente progressiva e um dos tipos de Epilepsia mais refratários à terapia farmacológica. Ela é alvo de inúmeras pesquisas que visam o desenvolvimento de fármacos capazes de impedir sua gênese e/ou as alterações moleculares dos substratos neurais que levam ao agravamento desse quadro. Nesse contexto, o presente trabalho teve como objetivo identificar a ação antiepiléptica do peptídeo Neuropolybina isolado a partir da peçonha da vespa social Polybia paulista no modelo murino de ELT.

Os modelos experimentais baseados, principalmente, em roedores são uma ferramenta de excelência nesse cenário. Eles são capazes de mimetizar nos sujeitos experimentais a maioria dos eventos moleculares e comportamentais que são observados na prática clínica em humanos (Kandratavicius et al., 2014; Barker-Haliski et al., 2015). No âmbito de estudo de condições epilépticas de difícil controle, modelos que induzem a ocorrência de crises epilépticas recorrentes e espontâneas subsequentes a um insulto inicial têm sido validados nos últimos anos (Depaulis \& Hamelin, 2015; Lévesque et al., 2015). Ademais, com a utilização desses modelos, foi possível avançar no conhecimento acerca do processo de epileptogênese e no desenvolvimento de abordagens terapêuticas que previnam o surgimento de Epilepsia (Pitkänen \& Engel, 2014).

A cascata de alterações celulares envolvidas nesse quadro inicia-se a partir de um insulto (status epilepticus), que leva a uma ativação excessiva de receptores excitatórios. Esse fenômeno é considerado crítico e acredita-se que logo após a injúria, o processo de epileptogênese se inicie (Löscher et al., 2015). Em humanos e animais, o período após o insulto é caracterizado pela ausência de crises e, portanto, denominado 
período latente. No entanto, os componentes do tecido cerebral sofrem um intenso processo de neuroplasticidade que o torna capaz de se excitar de forma sincronizada e autossustentada, resultando no desenvolvimento de uma condição epiléptica. O período latente pode variar de dias a anos para se estabelecer até culminar na geração de crises espontâneas, característica que torna esse tipo de Epilepsia uma doença crônica (Acharya et al., 2008; Staley, 2015).

Os modelos agudos de estimulação elétrica ou química são alternativas relevantes na pesquisa e bastante utilizados no screening de compostos com eficácia terapêutica (White \& Löscher, 2014). Essa foi uma das ferramentas utilizadas na identificação e caracterização do potencial antiepiléptico do peptídeo Neuropolybina por Couto e colaboradores em 2012 e por Silva em 2014. No entanto, os modelos agudos não reproduzem a complexidade observada no quadro clínico de uma pessoa com Epilepsia. Os modelos crônicos são, portanto, mais aptos e podem oferecer uma pletora de abordagens para o desenvolvimento de fármacos mais eficazes e específicos para o tratamento de um dos tipos de Epilepsias que mais desafiam a comunidade médica, além de contribuírem para o maior entendimento dessa condição que ainda é obscura (Sloviter \& Bumanglag, 2013; Simonato et al., 2014; Lidster et al., 2016).

O modelo crônico de ELT induzido por pilocarpina foi escolhido a fim de aprofundar o conhecimento acerca da ação do peptídeo Neuropolybina no tratamento da Epilepsia. Entretanto, encontramos algumas dificuldades ao longo do desenvolvimento desse trabalho. A primeira delas foi uma taxa de mortalidade de quase $30 \%$ dos camundongos, logo após a indução do SE, fator que contribuiu para a utilização de um maior número de camundongos nos experimentos. Uma alta taxa de sujeitos experimentais resistentes ao desenvolvimento do SE é relatada na literatura (Buckmaster \& Haney, 2012). No entanto, isso não foi observado no presente trabalho, 
pois todos os camundongos que receberam a administração de pilo desenvolveram o SE e as alterações morfológicas provenientes dessa condição. Para isso, foi necessário padronizar, previamente, a dose de pilocarpina suficiente para induzir o SE no maior número de camundongos e sem leva-los a óbito. As doses mais utilizadas variam de 280 a 450 mg. $\mathrm{kg}^{-1}$ (Curia et al., 2008), no entanto, foram muito altas para nossos camundongos. Além disso, foi observada uma elevada morbidez nos camundongos logo após a indução do SE, fazendo com que o experimentador mantivesse um cuidado pósinsulto por alguns dias, hidratando e alimentando os camundongos mais debilitados até sua completa recuperação.

Outra dificuldade enfrentada foi a padronização da via de administração do tratamento com Neuropolybina. Ele é um composto peptídico de fácil síntese, devido ao seu tamanho, conformação linear e ausência de modificações pós-traducionais, como amidação na extremidade C-terminal. Além disso, as três glutaminas, aminoácido altamente polar e a presença de moléculas de nitrogênio nos grupamentos funcionais dos demais aminoácidos que constituem a cadeia peptídica desse composto, contribuem para a formação de ligações de hidrogênio com moléculas de água, facilitando sua solubilização em soluções hidrofílicas, como as soluções fisiológicas. Ademais, foi observada uma alta estabilidade do composto durante o período experimental, quando mantido solubilizado em água deionizada e em temperaturas em torno de $-20{ }^{\circ} \mathrm{C}$, uma vez que as análises de espectrometria de massas confirmaram sua preservação. Essas características reforçam os investimentos no uso desse peptídeo como terapia. No entanto, até o momento, não foi possível identificar as interações do peptídeo Neuropolybina com a barreira hematoencefálica e chegar até a dose de administração sistêmica capaz de produzir os mesmos efeitos observados após a administração direta no SNC. Foram realizados testes prévios de administração intranasal e intraperitoneal 
com diversas doses do peptídeo e foi avaliada a sua capacidade de proteção contra crises agudas induzidas por alguns agentes químicos, mas em nenhum dos testes ele demonstrou a mesma eficiência observada nos dados obtidos após a administração intracerebroventricular. Os dados referentes a essa etapa não foram divulgados no presente trabalho, pois decidimos continuar utilizando a administração i.c.v., assim como o trabalho de Silva (2014).

Para tanto, a realização de um procedimento cirúrgico de implantação de um aparato que permita a administração do peptídeo diretamente no SNC faz-se necessária. Os camundongos são animais sensíveis e de metabolismo elevado e precisam ser anestesiados com altas doses de anestésicos, o que pode levá-los a óbito. Portanto, essa etapa também contribui para a diminuição do número de sujeitos durante o período experimental.

Vale ressaltar que o eletroencefalograma é a principal técnica para avaliação, estudo e diagnóstico da epilepsia. Portanto, o seu uso faz-se suficiente e necessário para a categorização e avaliação do padrão epileptiforme nesse modelo. Em roedores, o registro de EEG é feito a partir da inserção de eletrodos corticais e/ou profundos e no presente estudo, foram inseridos oito eletrodos nos camundongos, além da cânula-guia de administração. Uma vez que esse modelo envolve alterações morfológicas e consequentemente, alterações na atividade elétrica neuronal da formação hipocampal, dois eletrodos foram implantados nessa região a fim de verificar se o peptídeo seria capaz de alterar sua excitabilidade. O procedimento de implantação de eletrodos também é realizado após um procedimento cirúrgico com a anestesia geral e exige extrema destreza e treinamento do experimentador para que as perdas sejam minimizadas. Durante essa etapa, nenhum camundongo foi perdido. A eletroencefalografia é uma técnica refinada e o sistema de aquisição de registros 
utilizado para a realização desse trabalho é especifico para camundongos, elevando o custo dos experimentos e restringindo o número de animais que podem ser experimentados.

As diferentes avaliações realizadas a fim de identificar a ação do peptídeo na atenuação e na redução da duração e do número de CRE foram realizadas após 20 dias de experimento. Em relação à duração das CRE, é interessante ressaltar que a administração de $210 \mathrm{mg} \cdot \mathrm{kg}^{-1}$ de pilocarpina foi capaz de produzir, após um insulto inicial 15 dias, CRE com duração total de mais de 450 segundos em um período de cinco dias. O peptídeo Neuropolybina foi capaz de diminuir significativamente o tempo em que os animais estiveram em crise de maneira dose-dependente ao longo dos cinco dias de observação, demonstrando seu efeito antiepiléptico no modelo crônico testado. Para essa variável, o benzodiazepínico Diazepam também se mostrou eficiente em reduzir as CRE, no entanto, induziu uma sedação expressiva nos camundongos, comprometendo sua atividade geral espontânea. Contrariamente, o peptídeo Neuropolybina não induziu alterações notórias na atividade geral e motora dos sujeitos experimentais, conforme já relatado por Couto (2012a) e Silva (2014).

Por ser tratar de um modelo que causa danos progressivos à medida que as crises tornam-se mais frequentes, a avaliação do efeito do tratamento com o peptídeo ao longo de cada dia foi de extrema importância. Para isso, a análise foi dividida por cada dia, permitindo-se constatar que as CRE foram se agravando com o passar dos dias. No grupo doente, os camundongos triplicaram o tempo que estiveram em crise do primeiro ao último dia de observação, enquanto que o peptídeo manteve seu efeito antiepiléptico, diminuindo, consideravelmente, o tempo em crise dos animais tratados com a maior concentração. Interessantemente, o fármaco DZP apresentou eficiência similar ao longo de todos os dias de observação. 
Um dos desafios superados nesse trabalho foi padronizar a dose de pilo também capaz de agravar a condição crônica dos sujeitos experimentais. Cada crise não tratada contribui para o agravamento, maior duração e número de crises futuras apresentadas pelos pacientes (Cross, 2014; Köhling, 2014). No modelo utilizado, essa característica também foi discretamente observada, e o peptídeo Neuropolybina manteve sua eficácia na diminuição da duração das crises ao longo dos dias, reforçando seu caráter terapêutico. No entanto, o período de observação de cinco dias foi curto para a detecção do agravamento da classe e do número de crises, impedindo maiores conclusões sobre a ação do peptídeo nesse parâmetro.

Por ser um peptídeo ainda pouco estudado, seu tempo de ação não foi elucidado até o presente momento. Nesse contexto, foi feita uma avaliação logo após a sua administração e após um período de 5 horas, período em que se notaram diferenças no comportamento dos camundongos tratados em comparação ao inicio da observação. Esperava-se que o peptídeo tivesse sofrido metabolização, e com isso, seus níveis plasmáticos estariam reduzidos nessa fase, diminuindo sua eficácia. Contrariamente ao esperado, o peptídeo mostrou-se eficiente em reduzir a duração das crises na fase tardia.

A análise eletroencefalográfica é muito rica em informações e complementa as observações comportamentais. Nesse quesito, essa análise ofereceu uma ampliação acerca do desempenho do peptídeo no controle das CRE. Os camundongos doentes apresentam registros ictais com ondas altamente sincronizadas, de frequência e amplitude elevadas durante parte considerável do período amostral e nos quatro canais de registro, diferentemente dos camundongos sadios. No entanto, os sadios apresentaram sutis descargas paroxísticas correspondentes às crises focais nos locais de implantação dos eletrodos profundos. A introdução de eletrodos na formação hipocampal pode produzir efeitos pró-epileptogênicos por si só ou devido à ruptura da 
barreira hematoencefálica que gera um extravasamento de albumina, microhemorragias locais e inflamação (Klein et al., 2015). Além disso, os camundongos que não passaram pela indução do SE não apresentaram sincronia de disparos nas regiões monitoradas e os camundongos tratados com DZP apresentaram um perfil eletroencefalográfico semelhante, com reduzida quantidade de tempo em crise focal e generalizada. As crises generalizadas observadas nos animais tratados com Neuropolybina levaram mais tempo para aparecer em comparação às observadas nos doentes e as crises focais se iniciaram preferencialmente no lado esquerdo da formação hipocampal.

As técnicas de imunohistoquímica e imunofluorescência são amplamente utilizadas para evidenciar componentes particulares dessa condição patológica, pois oferecem uma gama de interpretações nesse contexto, apesar do custo elevado. Além disso, um segundo desafio foi a padronização dessa etapa do trabalho. O escopo, inicialmente, era realizar uma tripla marcação fluorescente de neurônios, astrócitos e núcleos celulares na formação hipocampal dos sujeitos experimentais submetidos aos tratamentos. Essas células sofrem as alterações mais evidentes após o processo de epileptogênese. $\mathrm{O}$ trauma gerado pelo SE causa a morte dos neurônios e as células da glia passam por um processo denominado astrogliose e invadem as camadas de células neuronais, reparando os neurônios e restaurando os danos gerados, por meio de uma complexa resposta celular imune (Robel et al., 2015; Steinhäuser et al., 2015; Wilcox et al., 2015). Portanto, o intuito era realizar a contagem desses dois tipos celulares, com o intuito de monitorar os efeitos do peptídeo Neuropolybina na manutenção da citoarquitetura da região mais afetada pela ocorrência das CRE. No entanto, não foi possível padronizar a metodologia em tempo hábil para o término do trabalho e a técnica de coloração de Nissl foi inserida no estudo, pois oferece informações semelhantes às obtidas pela técnica de marcação fluorescente de neurônios. 
A diferença de densidade óptica entre as camadas de células e as regiões de fundo das secções de tecido encefálico foi a medida mais adequada para a análise estimada do número de neurônios presentes na formação hipocampal após os tratamento, uma vez, que as secções de $50 \mu \mathrm{m}$ continham grande sobreposição de células, impedindo a contagem de cada uma delas. Foram encontradas diferenças notórias na região CA3 das secções de tecido coradas com Nissl, evidenciadas pelas diferenças na densidade de células entre os camundongos doentes e tratados. A camada CA1 sofreu desorganização celular evidente e a região CA3 sofreu acentuada lesão após o SE, indicando que o modelo experimental proposto foi adequado, pois produziu alterações morfológicas distintas em comparação aos sujeitos experimentais que não foram submetidos à indução da lesão.

A quantificação de astrócitos imunorreativos à GFAP revelou uma intensa proliferação de células gliais nas regiões monitoradas, contribuindo como um indício histológico adicional para a eficiência da lesão causada pela indução de SE por pilocarpina e é um fator consistente com a redução de neurônios observada. O tratamento com o peptídeo Neuropolybina apresentou um efeito anti-proliferativo nesse quesito e merece ser melhor investigado, no âmbito de uma abordagem neuroprotetora.

Os resultados obtidos após os testes em um modelo de Epilepsia mais complexo, reforçam o efeito antiepiléptico do peptídeo Neuropolybina. Ele tem se mostrado uma importante ferramenta farmacológica com eficácia e pode representar uma alternativa terapêutica às Epilepsias de difícil controle. Nesse contexto, uma avaliação mais detalhada acerca do perfil eletroencefalográfico obtido após o tratamento deve ser realizada, assim como, uma avaliação mais longa de seus efeitos no período crônico do modelo de ELT induzido por pilocarpina. 
CONCLUSÕES 


\section{CONCLUSÕES}

A administração sistêmica de pilocarpina induziu status epilepticus nos camundongos e, após 15 dias, facilitou a ocorrência de crises recorrentes e espontâneas além de alterações na citoarquitetura da formação hipocampal.

O peptídeo Neuropolybina apresentou atividade antiepilética eficiente na redução da duração total das crises recorrentes e espontâneas induzidas por pilocarpina em camundongos.

A análise de vídeo-EEG mostrou que a latência para o início das crises generalizadas e focais foi aumentada com o tratamento com o peptídeo.

$>\mathrm{O}$ perfil eletroencefalográfico dos animais doentes apresentou ondas sincronizadas, de alta frequência e amplitude elevada.

A diferença de densidade óptica revelou a presença de neurônios na camada CA3 da formação hipocampal de camundongos submetidos ao SE e tratados com o peptídeo.

A quantificação de astrogliose indicou uma diminuição da proliferação de astrócitos imurreativos à GFAP após o tratamento com o peptídeo Neuropolybina. 


\section{REFERÊNCIAS BIBLIOGRÁFICAS}




\section{REFERÊNCIAS BIBLIOGRAFICAS}

Acharya MM, Hattiangady B, Shetty AK: Progress in neuroprotective strategies for preventing epilepsy. Prog Neurobiol 2008, 84(4): 363-404.

Ali A, Dua Y, Constance JE, Franklin MR, Dudek FE. A once-per-day, drug-in-food protocol for prolonged administration of antiepileptic drugs in animal models. Epilepsia 2012, 53(1): 199-206.

Almeida L \& Soares-da-Silva P: Eslicarbazepine acetate (BIA 2093). Neurotherapeutics 2007, 4(1): 88-96.

Andersen P, Morris R, Amaral D, Bliss T, O'Keefe J. Historical Perspective: Proposed Functions, Biological Characteristics, and Neurobiological Models of the Hippocampus. In Andersen P, Morris R, Amaral D, Bliss T, O'Keefe J, editors. The hippocampus book. Oxford University Press; 2006. p. 9-31.

Arida RM, Scorza FA, Araujo Peres C, Cavalheiro EA: The course of untreated seizures in the pilocarpine model of epilepsy. Epilepsy Res 1999, 34(2): 99-107.

Auvin S \& Dupuis N: Outcome of status epilepticus. What do we learn from animal data? Epileptic Disord, 2014, 16(s1): S37-S43.

Barker-Haliski ML, Friedman D, French JA, White HS: Disease modification in epilepsy: from animal models to clinical applications. Drugs 2015, 75(7): 749767.

Berg AT, Berkovic SF, Brodie MJ, Buchhalter J, Cross JH, van Emde Boas W, Engel J, French J, Glauser TA, Mathern GW, ... \& Scheffer IE: Revised terminology and concepts for organization of seizures and epilepsies: report of the ILAE Commission on Classification and Terminology, 2005-2009. Epilepsia 2010, 51(4): 676-685.

Berg AT \& Scheffer IE: New concepts in classification of the epilepsies: entering the 21st century. Epilepsia 2011, 52(6): 1058-1062.

Blackburn-Munro G, Dalby-Brown W, Mirza NR, Mikkelsen JD, Blackburn-Munro RE: Retigabine: chemical synthesis to clinical application. CNS Drug Rev 2005, 11(1): 1-20.

Blümcke I, Thom M, Aronica E, Armstrong DD, Bartolomei F, Bernasconi A, Bien CG, Cendes F, Coras R, Cross JH, Jacques TS, Kahane P, Mathern GW, Miyata H, Moshé S, Oz B, Özkara Ç, Perucca E, Sisodiya S, Wiebe S, Spreafico R: 
International consensus classification of hippocampal sclerosis in temporal lobe epilepsy: a Task Force report from the ILAE Commission on Diagnostic Methods. Epilepsia 2013, 54(7): 1315-1329.

Brandt C, Heile A, Potschka H, Stoehr T, Löscher W: Effects of the novel antiepileptic drug lacosamide on the development of amygdala kindling in rats. Epilepsia 2006, 47(11): 1803-1809.

Bragin A, Benassi SK, Kheiri F, Engel J Jr: Further evidence that pathologic highfrequency oscillations are bursts of population spikes derived from recordings of identified cells in dentate gyrus. Epilepsia 2011, 52(1): 45-52.

Brodie MJ, Schachter SC, Kwan PKL: Fast facts: epilepsy. 2012. Albuquerque, New Mexico-USA: Health Press.

Buckmaster PS \& Haney MM: Factors affecting outcomes of pilocarpine treatment in a mouse model of temporal lobe epilepsy. Epilepsy Res 2012, 102(3):153-159.

Cavalheiro EA: The pilocarpine model of epilepsy. Ital J Neurol Sci 1995, 16(1-2): 33-37.

Cavalheiro EA, Santos NF, Priel MR: The pilocarpine model of epilepsy in mice. Epilepsia 1996, 37(10): 1015-1019.

Cendes F, Sakamoto AC, Spreafico R, Bingaman W, Becker AJ: Epilepsies associated with hippocampal sclerosis. Acta Neuropathol 2014, 128: 21-37.

Chakir A, Fabene PF, Ouazzani R, Bentivoglio M. Drug resistance and hippocampal damage after delayed treatment of pilocarpine-induced epilepsy in the rat. Brain Res Bull 2006, 71(1): 127-138.

Cho KO, Lybrand ZR, Ito N, Brulet R, Tafacory F, Zhang L, Good L, Ure K, Kernie SG, Birnbaum SG, Scharfman HE, Eisch AJ, Hsieh J. Aberrant hippocampal neurogenesis contributes to epilepsy and associated cognitive decline. Nat commun 2015, 6: 6606.

Couto LL: Atividade anticonvulsivante do Ppnp7, um neuropeptídeo isolado da peçonha da vespa social Polybia paulista. 2012a. 72 páginas. Dissertação de mestrado, Universidade de Brasília, Brasil.

Couto LL, Dos Anjos LC, Araújo MAF, Mourão CA, Schwartz CA, Ferreira LB, Mortari MR: Anticonvulsant and anxiolytic activity of the peptide fraction isolated from the venom of the social wasp Polybia paulista. Pharmacogn Mag 2012b, 8(32): 292-299. 
Covolan L \& Mello LEAM. Temporal profile of neuronal injury following pilocarpine or kainic acid-induced status epilepticus. Epilepsy Res 2000, 39(2): $133-52$.

Cross JH: Setting the scene: definition of prolonged seizures, acute repetitive seizures, and status epilepticus. Do we know why seizures stop? Epileptic Disorders 2014, 16(S1): S2-S5.

Curia G, Longo D, Biagini G, Jones RSG, Avoli M: The pilocarpine model of temporal lobe epilepsy. J Neurosci methods 2008, 172(2): 143-157.

De Boer HM, Mula M, Sander JW: The global burden and stigma of epilepsy. Epilepsy Behav 2008, 12(4): 540-546.

Depaulis A \& Hamelin S: Animal models for mesiotemporal lobe epilepsy: The end of a misunderstanding? Revиe neurologique 2015, 171(3): 217-226.

Doeser A, Dickhof G, Reitze M, Uebachs M, Schaub C, Pires NM, Bonifácio MJ, Soares-da-Silva P, Beck, H. Targeting pharmacoresistant epilepsy and epileptogenesis with a dual-purpose antiepileptic drug. Brain 2015, 138: 371387.

Dupuis N, Matagne A, Staelens L, Dournaud P, Desnous B, Gressens P, Auvin S: Antiictogenic and antiepileptogenic properties of brivaracetam in mature and immature rats. Epilepsia 2015, 56(5): 800-805.

Engel J, McDermott MP, Wiebe S, Langfitt JT, Stern JM, Dewar S, Sperling MR, Gardiner I, Erba G, Fried I, Jacobs M, Vinters HV, Mintzer S, Kieburtz K, Early Randomized Surgical Epilepsy Trial (ERSET) Study Group: Early surgical therapy for drug-resistant temporal lobe epilepsy: a randomized trial. JAMA 2012, 307(9): 922-930.

England MJ, Liverman CT, Schultz AM, Strawbridge LM: Epilepsy across the spectrum: Promoting health and understanding: A summary of the Institute of Medicine report. Epilepsy Behav 2012, 25(2): 266-276.

Ekenze OS \& Ndukuba AC: Perception of epilepsy among public workers: perspectives from a developing country. Epilepsy \& Behav 2013, 26(1): 87-90.

Errington AC, Coyne L, Stöhr T, Selve N, Lees G: Seeking a mechanism of action for the novel anticonvulsant lacosamide. Neuropharmacology 2006, 50(8): 10161029. 
Fisher RS, Boas WVE, Blume W, Elger C, Genton P, Lee P, Engel J: Epileptic Seizures and Epilepsy: Definitions Proposed by the International League Against Epilepsy (ILAE) and the International Bureau for Epilepsy (IBE). Epilepsia 2005, 46(4): 470-472.

Fisher RS, Acevedo C, Arzimanoglou A, Bogacz A, Cross JH, Elger CE, Engel-Jr J, Forsgren L, French JA, Glynn M, .. \& Wiebe, S: ILAE official report: a practical clinical definition of epilepsy. Epilepsia 2014, 55(4): 475-482.

Gao L, Xia L, Pan SQ, Xiong T, Li SC: Burden of epilepsy: A prevalence-based cost of illness study of direct, indirect and intangible costs for epilepsy. Epilepsy Res 2015, 110: 146-156.

Glien M, Brandt C, Potschka H, Löscher W. Effects of the novel antiepileptic drug levetiracetam on spontaneous recurrent seizures in the rat pilocarpine model of temporal lobe epilepsy. Epilepsia 2002, 43(4): 350-357.

Grabenstatter HL, Ferraro DJ, Williams PA, Chapman PL, Dudek FE. Use of chronic epilepsy models in antiepileptic drug discovery: the effect of topiramate on spontaneous motor seizures in rats with kainate-induced epilepsy. Epilepsia 2005, 46(1): 8-14.

Grabenstatter HL, Clark S, Dudek FE. Anticonvulsant effects of carbamazepine on spontaneous seizures in rats with kainate-induced epilepsy: comparison of intraperitoneal injections with drug-in-food protocols. Epilepsia 2007, 48(12): $2287-2295$.

Grone BP \& Baraban SC: Animal models in epilepsy research: legacies and new directions. Nature Neurosci 2015, 18(3): 339-343.

Hanada T, Hashizume Y, Tokuhara N, Takenaka O, Kohmura N, Ogasawara A, Hatakeyama S, Ohgoh M, Ueno M, Nishizawa Y: Perampanel: A novel, orally active, noncompetitive AMPA-receptor antagonist that reduces seizure activity in rodent models of epilepsy. Epilepsia 2011, 52(7): 1331-1340.

Hanada T, Ido K, Kosasa T: Effect of perampanel, a novel AMPA antagonist, on benzodiazepine-resistant status epilepticus in a lithium-pilocarpine rat model. Pharmacol res per 2014, 2(5): 1-8.

Haut SR: Seizure clustering. Epilepsy Behav 2006, 8(1): 50-55.

Jacoby A, Snape D \& Baker GA: Epilepsy and social identity: the stigma of a chronic neurological disorder. Lancet Neurol 2005, 4(3): 171-178. 
Kandratavicius L, Balista PA, Lopes-Aguiar C, Ruggiero RN, Umeoka EH, GarciaCairasco N, Bueno-Junior LS, Leite JP: Animal models of epilepsy: use and limitations. Neuropsychiatric Disease \& Treatment 2014, 10: 1693-1705.

Kenda BM, Matagne AC, Talaga PE, Pasau PM, Differding E, Lallemand BI, Frycia AM, Moureau FG, Klitgaard HV, Gillard MR, Fuks B, and Michel P: Discovery of 4-substituted pyrrolidone butanamides as new agents with significant antiepileptic activity. $J$ Med Chem 2004, 47(3): 530-549.

Kerr MP, Turky A, Huber B: The psychosocial impact of epilepsy in adults with an intellectual disability. Epilepsy Behav 2009, 15(2): S26-S30.

Kerr MP: The impact of epilepsy on patients' lives. Acta Neurol Scand 2012, 126(s194): 1-9.

Kiernan JA: Anatomy of the temporal lobe. Epilepsy Res Treat 2012, 2012: 1-12.

Klein S, Bankstahl $\mathrm{M}$, Löscher $\mathrm{W}$ : Inter-individual variation in the effect of antiepileptic drugs in the intrahippocampal kainate model of mesial temporal lobe epilepsy in mice. Neuropharmacology 2015, 90: 53-62.

Köhling R: Prolonged seizures: what are the mechanisms that predispose or cease to be protective? A review of animal data. Epileptic Disorders 2014, 16(S1): S23-S36.

Kuruba R, Hattiangady B, Shetty AK: Hippocampal neurogenesis and neural stem cells in temporal lobe epilepsy. Epilepsy Behav 2009, 14(1): 65-73.

Kurz JE, Moore BJ, Henderson SC, Campbell JN, Churn SB: A cellular mechanism for dendritic spine loss in the pilocarpine model of status epilepticus. Epilepsia 2008, 49(10): 1696-1710.

Kwan P, Arzimanoglou A, Berg AT, Brodie MJ, Allen Hauser W, Mathern G, Moshé SL, Perucca E, Wiebe S, French, J. Definition of drug resistant epilepsy: consensus proposal by the ad hoc Task Force of the ILAE Commission on Therapeutic Strategies. Epilepsia 2010, 51(6): 1069-1077.

Kwan P, Schachter SC, Brodie MJ: Drug-resistant epilepsy. $N$ Engl Med 2011, 365(10): 919-926.

Leite JP \& Cavalheiro EA: Effects of conventional antiepileptic drugs in a model of spontaneous recurrent seizures in rats. Epilepsy Res 1995, 20(2): 93-104.

Lévesque M, Salami P, Gotman J, Avoli M. Two seizure-onset types reveal specific patterns of high-frequency oscillations in a model of temporal lobe epilepsy. $J$ Neurosci 2012, 32(38): 13264-13272. 
Lévesque M, Avoli M, Bernard C: Animal models of temporal lobe epilepsy following systemic chemoconvulsant administration. J Neurosci methods 2015, 260: $45-52$.

Lidster K, Jefferys JG, Blümcke I, Crunelli V, Flecknell P, Frenguelli BG, Gray WP, Kamnski R, Pitkänen A, Ragan I, Shah, M, Simonato M, Trevelyan A, Volk H, Walker M, Yates N, Prescott MJ: Opportunities for improving animal welfare in rodent models of epilepsy and seizures. J Neurosci Methods 2016, 260: 2-25.

Löscher W, Hirsch LJ, Schmidt D: The enigma of the latent period in the development of symptomatic acquired epilepsy - Traditional view versus new concepts. Epilepsy Behav 2015, 52: 78-92.

Mameniskiene R, Sakalauskaite-Juodeikiene E \& Budrys V: People with epilepsy lack knowledge about their disease. Epilepsy Behav 2015, 46: 192-197.

Masia SL \& Devinsky O: Epilepsy and behavior: A brief history. Epilepsy Behav 2000, 1(1): 27-36.

Mathern GW \& Nehlig A: From the editors: Global awareness and International Epilepsy Day. Epilepsia 2015, 56(2): 167-167.

Mazarati A, Wu J, Shin D, Kwon YS, Sankar R: Antiepileptogenic and antiictogenic effects of retigabine under conditions of rapid kindling: an ontogenic study. Epilepsia 2008, 49(10): 1777-1786.

Mazzuferi M, Kumar G, Rospo C, Kaminski RM: Rapid epileptogenesis in the mouse pilocarpine model: video-EEG, pharmacokinetic and histopathological characterization. Experimental Neurol 2012, 238(2): 156-167.

Mello LEAM, Cavalheiro EA, Tan AM, Kupfer WR, Pretorius JK, Babb TL, Finch DM: Circuit mechanisms of seizures in the pilocarpine model of chronic epilepsy: cell loss and mossy fiber sprouting. Epilepsia 1993, 34(6): 985-995.

Monge-Fuentes V, Gomes FMM, Campos GAA, Silva JC, Biolchi AM, Dos Anjos LC, Gonçalves JC, Lopes KS, Mortari MR: Neuroactive compounds obtained from arthropod venoms as new therapeutic platforms for the treatment of neurological disorders. The Journal of Venomous Animals and Toxins Including Tropical Diseases 2015, 21(1): 1-9.

Mortari MR, Cunha AOS, Ferreira LB, Dos Santos WF: Neurotoxins from invertebrates as anticonvulsants: from basic research to therapeutic application. Pharmacol Ther 2007, 114(2): 171-183. 
Mula M \& Trimble MR: Antiepileptic drug-induced cognitive adverse effects. $C N S$ drugs 2009, 23(2): 121-137.

Mula M: Recent and future antiepileptic drugs and their impact on cognition: what can we expect? Expert Rev Neurother 2012, 12(6): 667-671.

Neves G, Cooke SF \& Bliss TV: Synaptic plasticity, memory and the hippocampus: a neural network approach to causality. Nature Rev Neurosci 2008, 9(1): 65-75.

Ngugi AK, Bottomley C, Kleinschmidt I, Sander JW, Newton CR: Estimation of the burden of active and life-time epilepsy: A meta-analytic approach. Epilepsia 2010, 51(5): 883-890.

Palleria C, Coppola A, Citraro R, Del Gaudio L, Striano S, De Sarro G, Russo E: Perspectives on treatment options for mesial temporal lobe epilepsy with hippocampal sclerosis. Expert opinion on pharmacotherapy 2015, 16(15): 23552371 .

Parent JM, Timothy WY, Leibowitz RT, Geschwind DH, Sloviter RS \& Lowenstein DH: Dentate granule cell neurogenesis is increased by seizures and contributes to aberrant network reorganization in the adult rat hippocampus. $J$ Neurosci 1997, 17(10): 3727-3738.

Paxinos GF \& Franklin KBJ: The Mouse Brain in stereotaxic coordinates. Second Edition. Academic Press; 2001.

Pitkänen A \& Lukasiuk K: Molecular and cellular basis of epileptogenesis in symptomatic epilepsy. Epilepsy behav 2009, 14(1): 16-25.

Pitkänen A \& Engel J: Past and present definitions of epileptogenesis and its biomarkers. Neurotherapeutics 2014, 11(2): 231-241.

Potschka H, Soerensen J, Pekcec A, Loureiro A, Soares-da-Silva P: Effect of eslicarbazepine acetate in the corneal kindling progression and the amygdala kindling model of temporal lobe epilepsy. Epilepsy res 2014, 108(2): 212-222.

Radzik I, Miziak B, Dudka J, Chrościńska-Krawczyk M, Czuczwar SJ: Prospects of epileptogenesis prevention. Pharmacological Reports 2015, 67(3): 663-668.

Remy S \& Beck H: Molecular and cellular mechanisms of pharmacoresistance in epilepsy. Brain 2006, 129(1): 18-35.

Robel S, Buckingham SC, Boni JL, Campbell SL, Danbolt NC, Riedemann T, Sutor B, Sontheimer H: Reactive astrogliosis causes the development of spontaneous seizures. The Journal of Neuroscience 2015, 35(8): 3330-3345. 
Schauwecker PE \& Steward O: Genetic determinants of susceptibility to excitotoxic cell death: implications for gene targeting approaches. Proc Nat Acad Sci 1997, 94(8): 4103-4108.

Schauwecker PE: Strain differences in seizure-induced cell death following pilocarpine-induced status epilepticus. Neurobiol Dis 2012, 45(1): 297-304.

Schmidt D \& Schachter SC: Drug treatment of epilepsy in adults. Bmj 2014, 348(254): 10-1136.

Scott RC: What are the effects of prolonged seizures in the brain? Epileptic Disord 2014, 16(s1): S6-S11.

Sestito RS, Trindade LB, De Souza RG, Kerbauy LN, Iyomasa MM, Rosa ML: Effect of isolation rearing on the expression of AMPA glutamate receptors in the hippocampal formation. $J$ Psychopharmacol 2011, 25(12): 1720-1729.

Sharma AK, Reams RY, Jordan WH, Miller MA, Thacker HL, Snyder PW. Mesial temporal lobe epilepsy: pathogenesis, induced rodent models and lesions. Toxicol Pathol 2007, 35(7): 984-99.

Shibley H \& Smith BN: Pilocarpine-induced status epilepticus results in mossy fiber sprouting and spontaneous seizures in C57BL/6 and CD-1 mice. Epilepsy Res 2002, 49(2): 109-120.

Shorvon SD: The etiologic classification of epilepsy. Epilepsia 2011, 52(6): 10521057.

Silva JC: Atividade antiepiléptica do peptídeo Neuropolybina e de um análogo: estudo eletroencefalográfico e potencial alvo farmacológico. 2014. 103 páginas. Dissertação de mestrado, Universidade de Brasília, Brasil.

Silva JC, Monge-Fuentes V, Gomes FMM, Lopes KS, Dos Anjos LC, Campos GAA, Arenas CJ, Biolchi AM, Gonçalves JC, Galante P, Campos LA, Mortari MR: Pharmacological Alternatives for the Treatment of Neurodegenerative Disorders: Wasp and Bee Venoms and Their Components as New Neuroactive Tools. Toxins 2015, 7(8): 3179-3209.

Simonato M, Löscher W, Cole AJ, Dudek FE, Engel J, Kaminski RM, Loeb JÁ, Scharfman H, Staley KJ, Velísek L, Klitgaard, H. Finding a better drug for epilepsy: preclinical screening strategies and experimental trial design. Epilepsia 2012, 53(11): 1860-1867.

Simonato M, Brooks-Kayal AR, Engel J, Galanopoulou AS, Jensen FE, Moshé SL, O’Brien TJ, Pitkänen A, Wilcox KS, French, J. A: The challenge and promise of 
anti-epileptic therapy development in animal models. The Lancet Neurology 2014, 13(9): 949-960.

Sinclair DB \& Snyder TJ: Corticosteroids for the treatment of Landau-Kleffner syndrome and continuous spike-wave discharge during sleep. Pediatr Neurol 2005, 32(5): 300-306.

Sloviter RS: Permanently altered hippocampal structure, excitability, and inhibition after experimental status epilepticus in the rat: the "dormant basket cell" hypothesis and its possible relevance to temporal lobe epilepsy. Hippocampus 1991, 1(1): 41-66.

Sloviter RS \& Bumanglag AV: Defining "epileptogenesis" and identifying "antiepileptogenic targets" in animal models of acquired temporal lobe epilepsy is not as simple as it might seem. Neuropharmacology 2013 69: 3-15.

Sofroniew MV: Molecular dissection of reactive astrogliosis and glial scar formation. Trends Neurosci 2009, 32(12): 638-647.

Spruston N \& McBain C. Structural and Functional Properties of Hippocampal Neurons. In Andersen P, Morris R, Amaral D, Bliss T, O'Keefe J, editors. The hippocampus book. Oxford University Press; 2006. p. 133-188.

Staley K: Molecular mechanisms of epilepsy. Nature neuroscience 2015, 18(3): 367372.

Steinhäuser C, Grunnet M, Carmignoto G: Crucial role of astrocytes in temporal lobe epilepsy. Neuroscience 2015, In press.

Téllez-Zenteno JF, Hernández-Ronquillo L, Buckley S, Zahagun R, Rizvi S: A validation of the new definition of drug-resistant epilepsy by the International League Against Epilepsy. Epilepsia 2014, 55(6): 829-834.

Thom M: Hippocampal sclerosis: progress since Sommer. Brain Pathol 2009, 19(4): 565-572.

Thom M: Review: Hippocampal sclerosis in epilepsy: a neuropathology review. Neuropathol Appl Neurobiol 2014, 40(5): 520-543.

Tober C, Rostock A, Rundfeldt C, Bartsch R: D-23129: a potent anticonvulsant in the amygdala kindling model of complex partial seizures. Eur $j$ pharmacol 1996, 303(3): 163-169.

Todman D: Epilepsy in the Graeco-Roman world: Hippocratic medicine and Asklepian temple medicine compared. J Histor Neurosci 2008, 17(4): 435-441. 
Turski WA, Cavalheiro EA, Schwarz M, Czuczwar SLJ, Kleinrok Z, Turski L: Limbic seizures produced by pilocarpine in rats: behavioral, electroencephalographic and neuropathological study. Behav Brain Res 1983a, 9(3): 315-335.

Turski WA, Czuczwar SJ, Kleinrok Z, Turski L: Cholinomimetics produce seizures and brain damage in rats. Experientia 1983b, 39(12): 1408-1411.

Turski WA, Cavalheiro EA, Bortolotto ZA, Mello LM, Schwarz M, Turski L: Seizures produced by pilocarpine in mice: a behavioral, electroencephalographic and morphological analysis. Brain Res 1984, 321(2): 237-253.

Vajda FJ \& Eadie MJ: The clinical pharmacology of traditional antiepileptic drugs. Epileptic Disorders 2014, 16(4): 395-408.

Velasco AL, Wilson CL, Babb TL, Engel Jr J: Functional and anatomic correlates of two frequently observed temporal lobe seizure-onset patterns. Neural Plast 2000, 7(1-2): 49-63.

Walker M, Chan D, Thom M. Hippocampus and Human Disease. In Andersen P, Morris R, Amaral D, Bliss T, O'Keefe J, editors. The hippocampus book. Oxford University Press; 2006. p.769-803.

Wetherington J, Serrano G, Dingledine R: Astrocytes in the epileptic brain. Neuron 2008, 58(2): 168-178.

White HS \& Löscher W: Searching for the ideal antiepileptogenic agent in experimental models: single treatment versus combinatorial treatment strategies. Neurotherapeutics 2014, 11(2): 373-384.

Wilcox KS, Gee JM, Gibbons MB, Tvrdik P \& White JA: Altered structure and function of astrocytes following status epilepticus. Epilepsy \& Behavior 2015, 49: 17-19.

Wilson JV \& Reynolds EH: Translation and analysis of a cuneiform text forming part of a Babylonian treatise on epilepsy. Med hist 1990, 34(02): 185-198.

World Health Organization (WHO). 2012. Epilepsy: Key Facts. Disponível em: <http://www.who.int/mediacentre/factsheets/fs999/en/>. Acessado em: 22 de janeiro de 2015.

Wolf P \& Koepp M: Reflex epilepsies. Handbook Clinic Neurol 2012, 107: 257-276.

Yuste R: Dendritic spines and distributed circuits. Neuron 2011, 71(5): 772-781. 


\section{ANEXOS E APÊNDICES}




\section{ANEXOS}

8.1 Anexo A - Espectro de massas fornecidos pela empresa AminoTech Pesquisa e Desenvolvimento Ltda e Relatório de qualidade fornecido pela empresa FastBio Ltda.

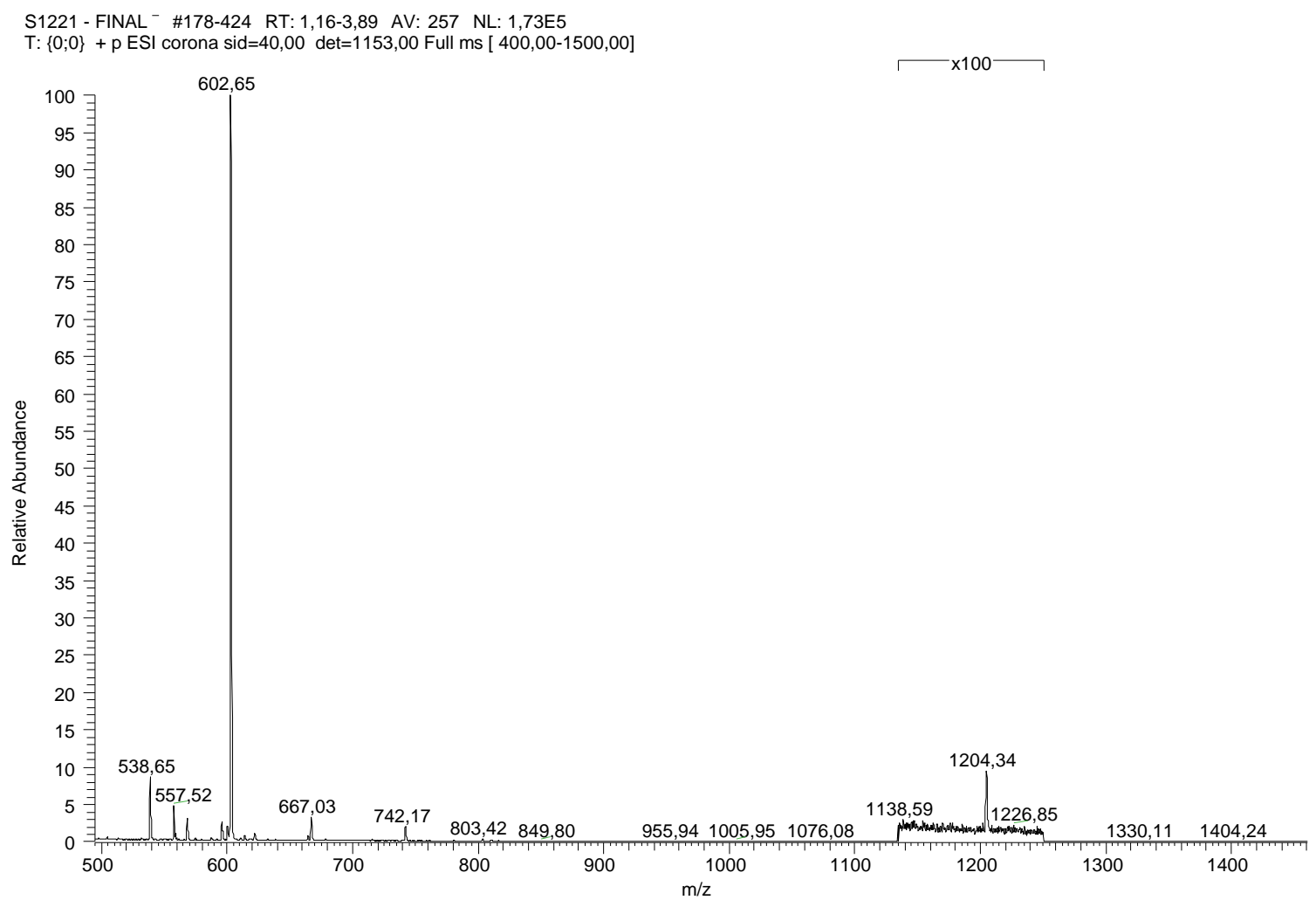




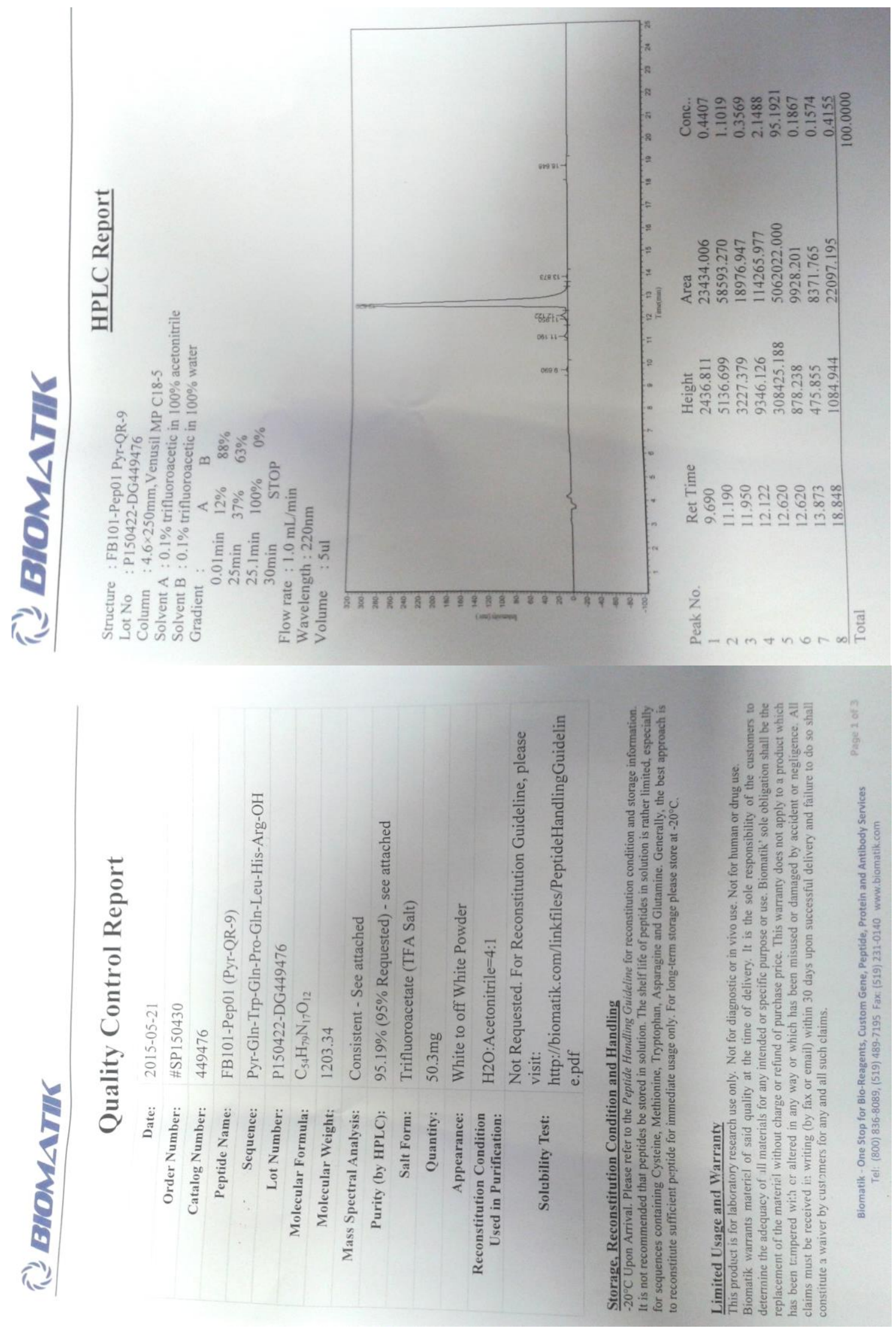




\subsection{Anexo B - Declaração da CEUA}

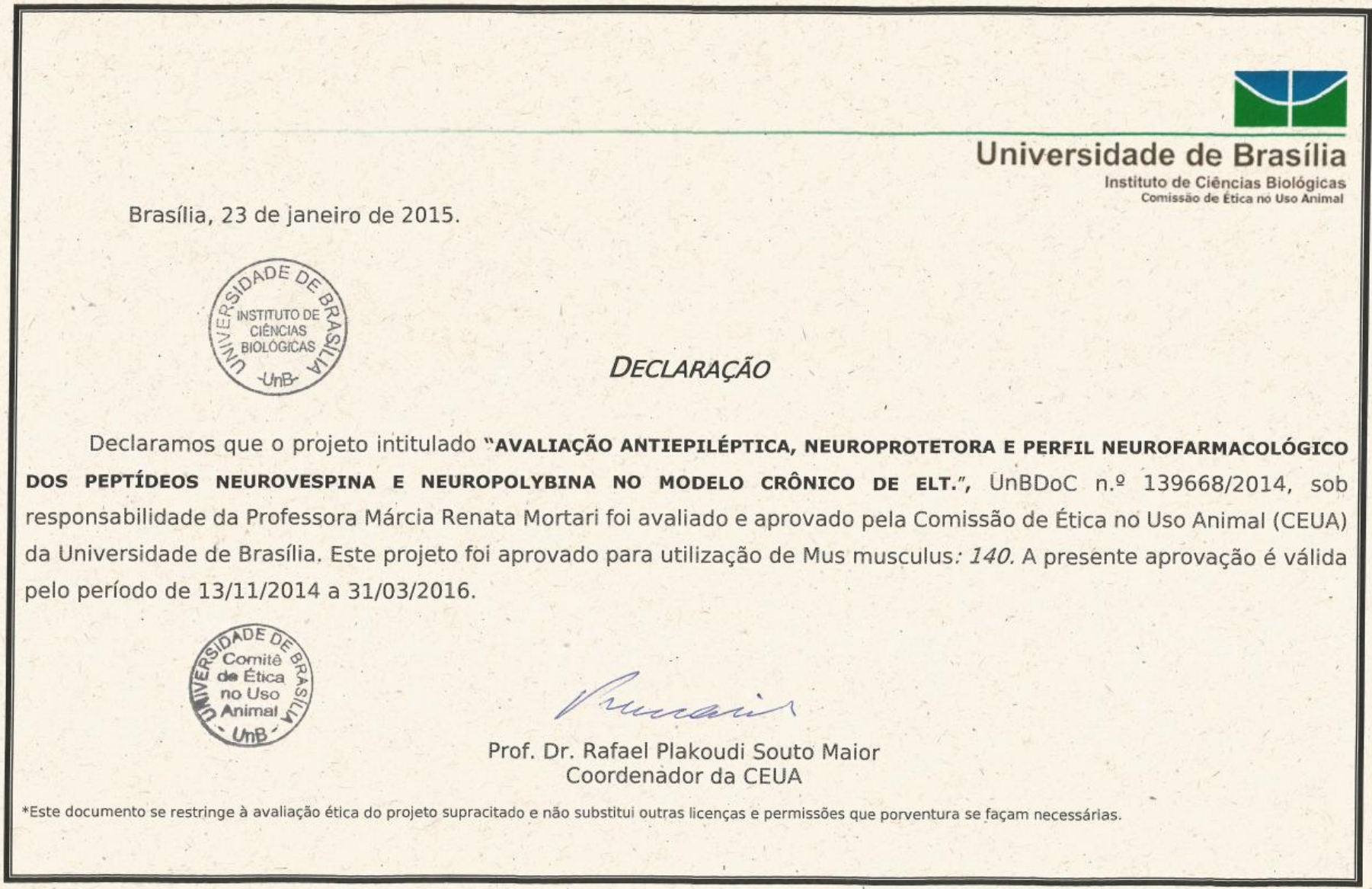




\subsection{Anexo C - Autorização de Acesso e de Remessa de Componente do}

\section{Patrimônio Genético}

\begin{tabular}{|c|c|}
\hline $\begin{array}{l}\text { Autorização de Acesso e de Remessa de } \\
\text { Componente do Patrimônio Genético } \\
\text { O Conselho Nacional de Desenvolvimento Científico e } \\
\text { Tecnológico - CNPq, nos termos Deliberação 246/2009, do } \\
\text { Conselho de Gestão do Patrimônio Genético, autoriza a } \\
\text { instituição identificada no verso deste documento a acessar } \\
\text { e remeter componente do Patrimônio Genético com a } \\
\text { finalidade de pesquisa científica. } \\
\text { Brasília, } 19 \text { de Novembro de } 2013 \\
\text { Raquel de Andrade Lima Coelho } \\
\text { Diretor de Ciências Agrárias, Biológicas e da Saúde } \\
\text { PO 161/2010 }\end{array}$ & $\begin{array}{l}\text { Processo: 010476/2013-0 } \\
\text { Validade: 19/11/2013 a 01/08/2018 } \\
\text { Instituição: UNIVERSIDADE DE BRASILIA } \\
\text { CNPJ: 000.381.740/0001-43 } \\
\text { Pesquisador: Márcia Renata Mortari } \\
\text { CPF: 828.885.151-72 } \\
\text { RG: } 1507428 \text { - SSP / DF } \\
\text { Para visualizar a versão digital da Autorização de Acesso e } \\
\text { de Remessa de Componente do Patrimônio Genético, V.Sa. } \\
\text { poderá utilizar a ferramenta disponibilizada pelo CNPq para } \\
\text { esse fim na página } \\
\text { http://servicosweb.cnpq.br/visualizador/</a> e informar o } \\
\text { número do protocolo } 8904338536066393 \text { para recuperá-la } \\
\text { do banco de dados do CNPq }\end{array}$ \\
\hline
\end{tabular}




\subsection{Apêndice A - Preparação da solução PBS}

Para preparar 1L de solução tampão fosfato (PBS), misturar os seguintes reagentes em água destilada.

\begin{tabular}{|c|c|c|}
\hline Reagente & \multicolumn{2}{|c|}{ Molaridade (mM) } \\
\hline $\mathrm{NaCl}$ & 137 & 8,0140 \\
\hline $\mathrm{KCl}$ & 2,7 & 0,2012 \\
\hline $\mathrm{Na}_{2} \mathrm{HPO}_{4} \cdot 2 \mathrm{H}_{2} \mathrm{O}$ & 10 & 1,4176 \\
\hline $\mathrm{KH}_{2} \mathrm{PO}_{4}$ & 2 & 0,2722 \\
\hline
\end{tabular}




\title{
8.5 Apêndice B - Preparação do corante de Nissl
}

\author{
Tampão I (500 mL)
}

- $\quad 497 \mathrm{~mL}$ de água destilada

- $\quad 3 \mathrm{~mL}$ de ácido acético glacial

Tampão II (500 mL)

- $\quad 6,8 \mathrm{~g}$ de acetato de sódio

- $\quad$ Completar para $500 \mathrm{~mL}$ com água destilada

Solução de Cresil Violeta (50 mL)

- $1 \mathrm{~g}$ de Acetato de Cresil Violeta

- $\quad 50 \mathrm{~mL}$ de água destilada

Solução Final

- $\quad 230 \mathrm{~mL}$ do tampão I

- $\quad 20 \mathrm{~mL}$ do tampão II

- $\quad 12,5 \mathrm{~mL}$ da solução de Cresil Violeta 